\title{
Antibacterial and Cytotoxic Phenyltetracenoid Polyketides from Streptomyces morookaense
}

\author{
Xiaoxia Li ${ }^{\dagger, \S}$ Ping Wu, ${ }^{*}{ }^{\dagger}$ Hanxiang $\mathrm{Li},{ }^{\dagger}$ Jinghua Xue,${ }^{\dagger}$ Hanhong Xu, ${ }^{\dagger}$ and Xiaoyi Wei* ${ }^{\dagger}$ \\ ${ }^{\dagger}$ Key Laboratory of Plant Resources Conservation and Sustainable Utilization / Guangdong Provincial Key \\ Laboratory of Applied Botany, South China Botanical Garden, Chinese Academy of Sciences, Xingke Road 723, \\ Tianhe District, Guangzhou 510650, People's Republic of China \\ $\$$ State Key Laboratory for Conservation and Utilization of Subtropical Agro-Bioresources and Key Laboratory \\ of Natural Pesticide and Chemical Biology, Ministry of Education, South China Agricultural University, \\ Guangzhou 510642, People’s Republic of China \\ ${ }^{\S}$ School of Life Sciences, University of Chinese Academy of Sciences, Yuquanlu 19A, Beijing 100049, People’s \\ Republic of China \\ *Corresponding Authors. E-mail: wuping@scbg.ac.cn (P. Wu), wxy@scbg.ac.cn (X. Wei)
}

\section{Contents}

1. Computational Details

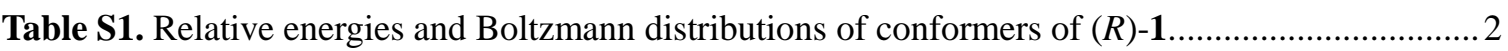

Figure S1. Comparison between ECD spectra calculated for $R \mathbf{- 1}$ and measured for $(+) /(-)-\mathbf{1} / \mathbf{2} \ldots \ldots \ldots . .2$

Figure S2. Reaction coordinate and structures of $\mathrm{HCO}_{2} \mathrm{H}$-mediated TSs ................................. 3

Figure S3. Reaction coordinate and structures of $\mathrm{H}_{2} \mathrm{O}$-mediated TSs. ........................................ 3

Figure S4. IRCs of $\mathrm{HCO}_{2} \mathrm{H}$-mediated TSs for conversion 3 to 1 ......................................... 4

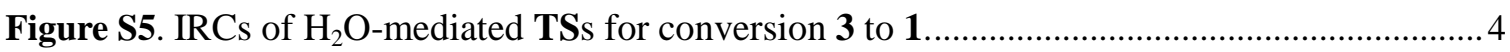

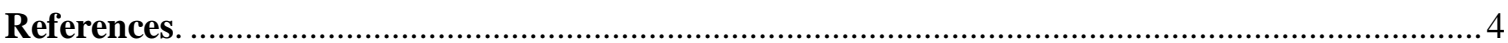

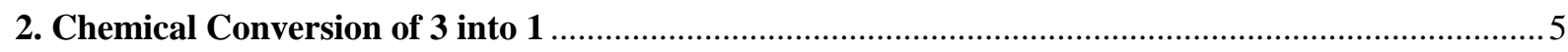

Figure S6. UPLC-ESIMS analysis of reaction products in chemical conversion ................................5

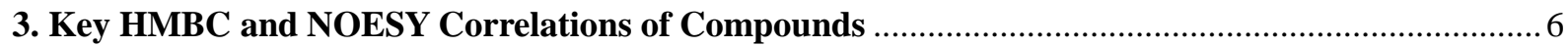

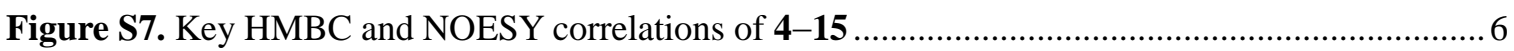

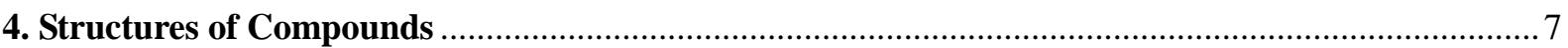

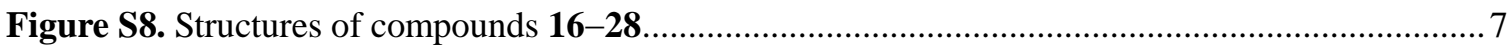

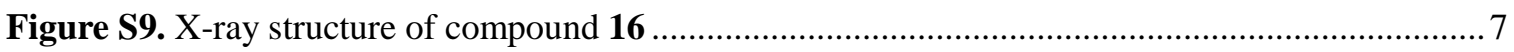

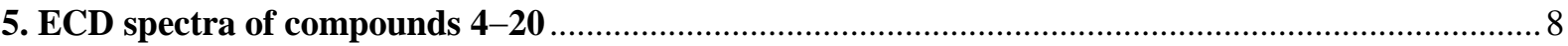

Figure S10. Comparison of ECD spectra of 4-15 and 17-20 with that of 16......................... 8

6. Comparison between Antibacterial and Cytotoxic Potencies of Compounds .................................. 8

Table S2. Molar MIC and $\mathrm{IC}_{50}$ values of antibacterial compounds .............................................. 8

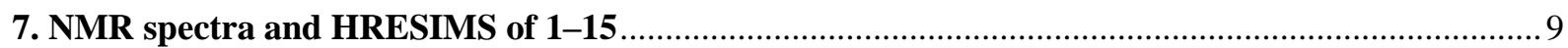

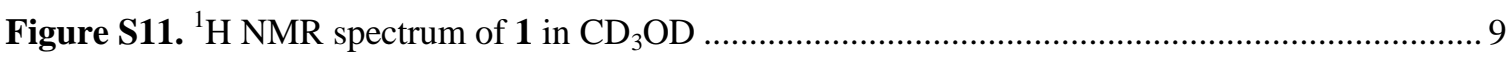

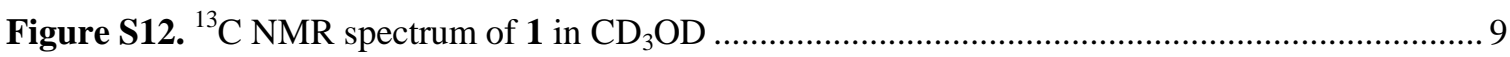

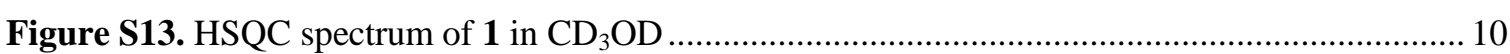




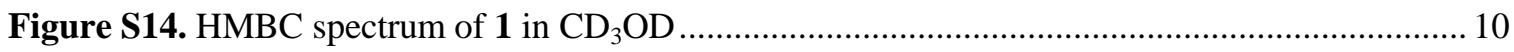

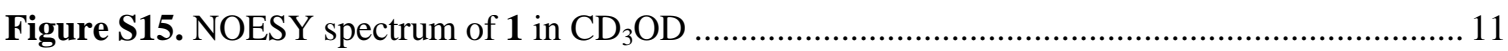

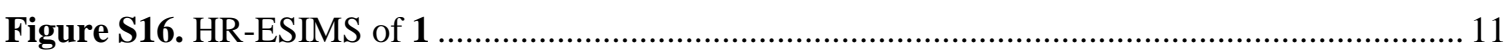

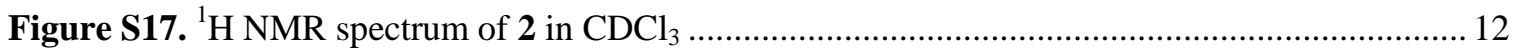

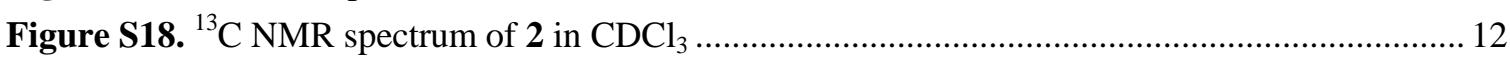

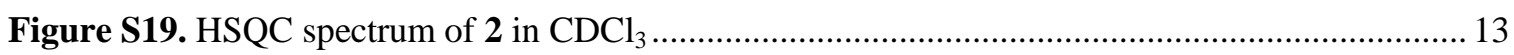

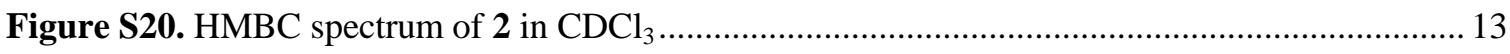

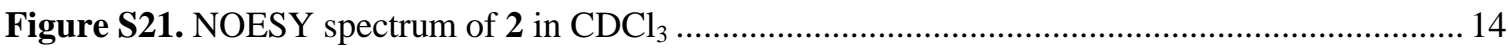

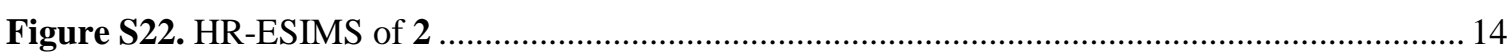

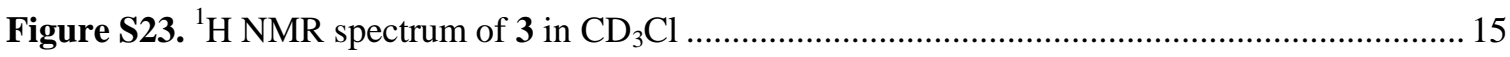

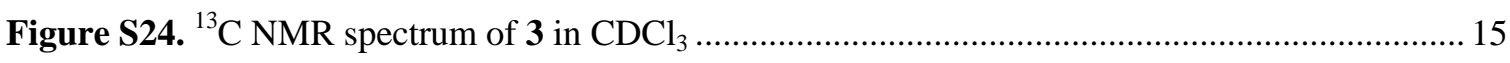

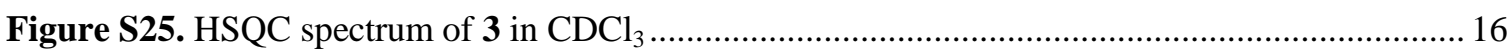

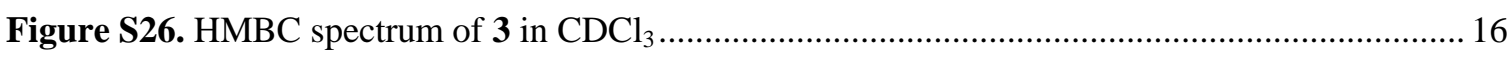

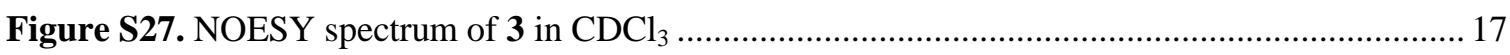

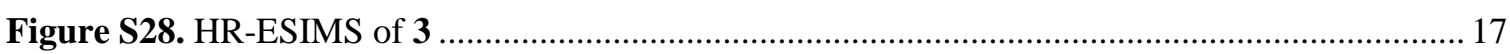

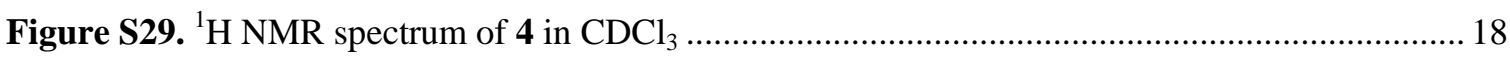

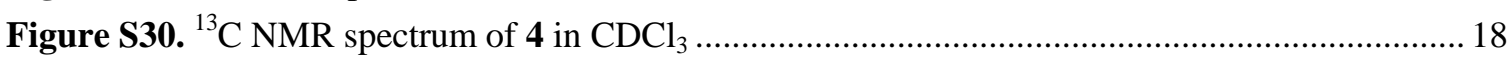

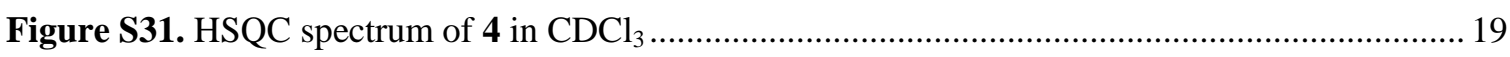

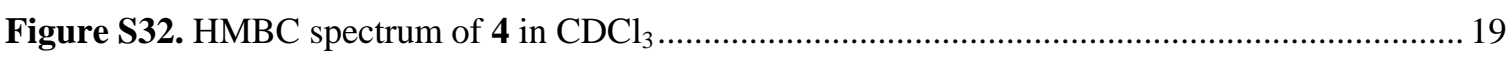

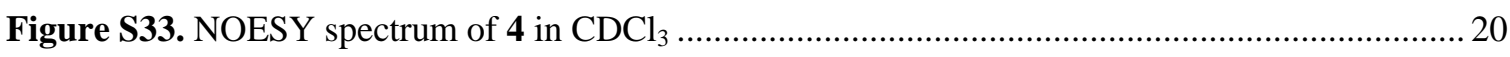

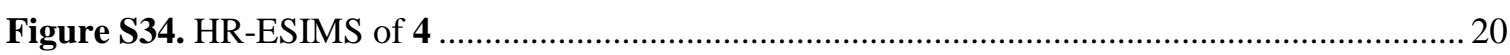

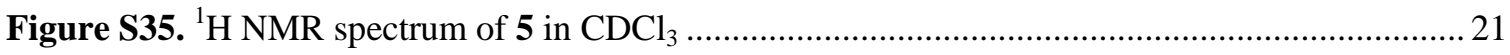

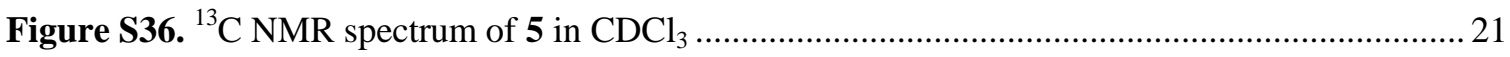

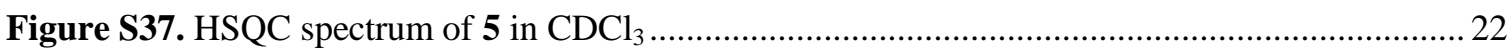

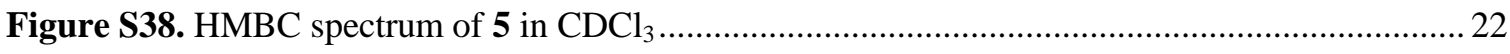

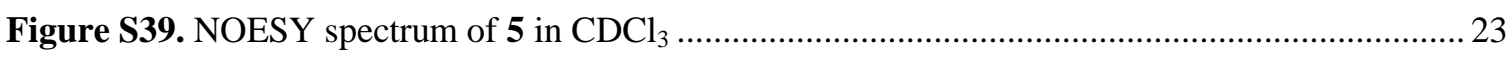

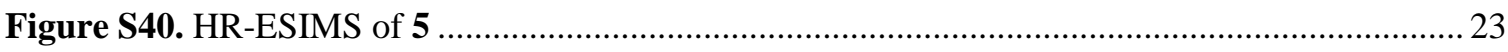

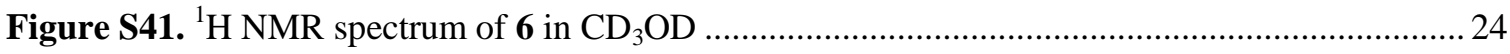

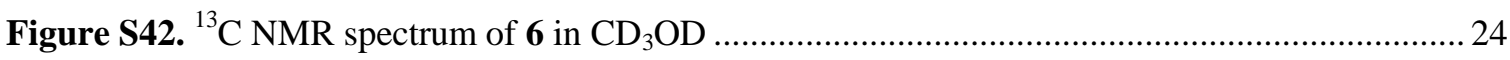

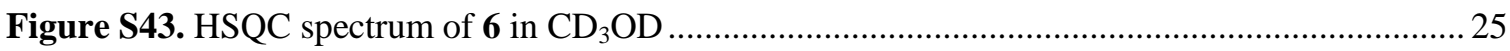

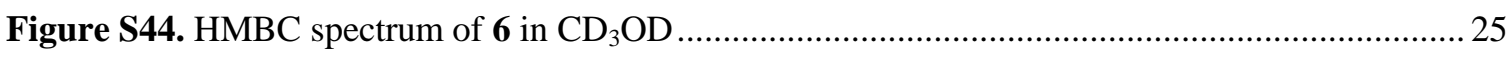

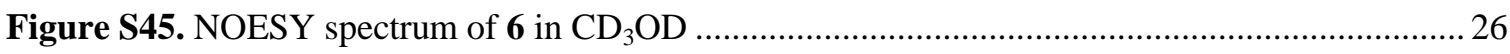

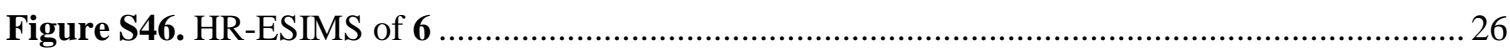

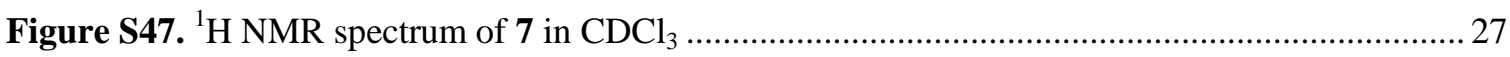

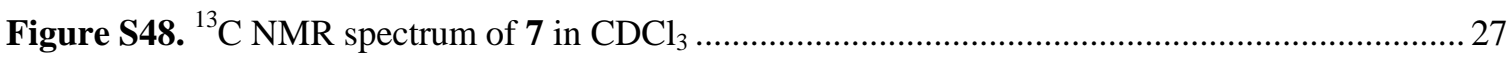

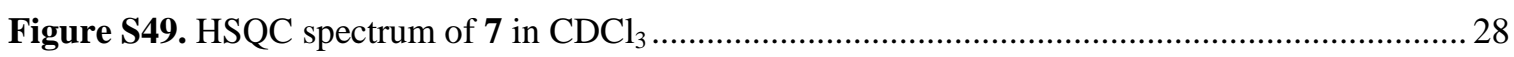

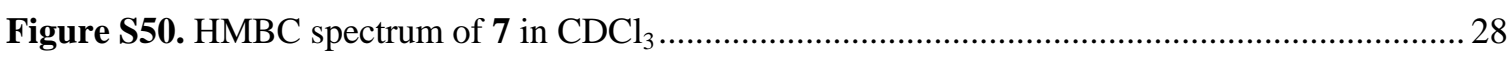

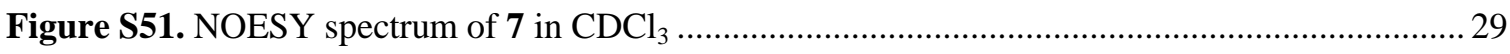

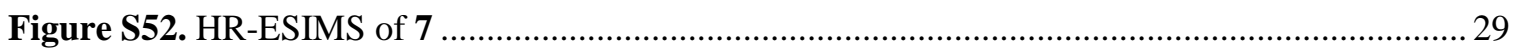

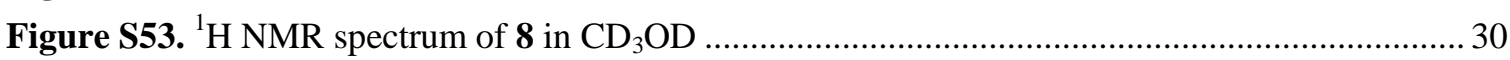

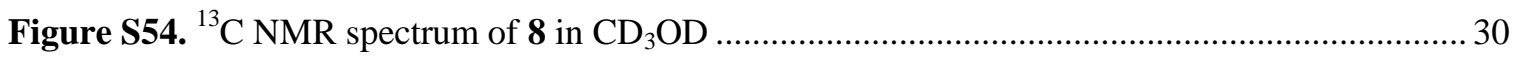

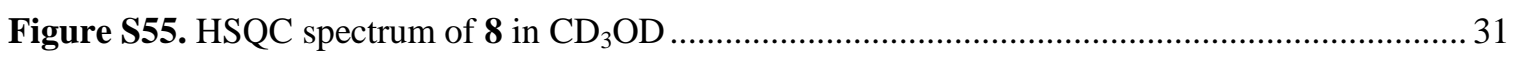

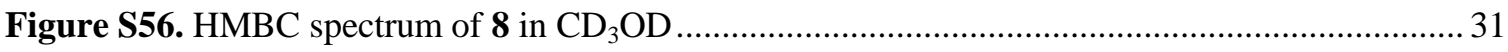

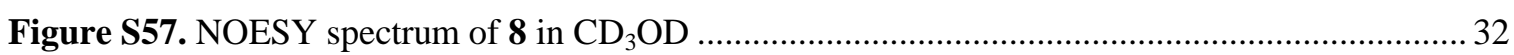




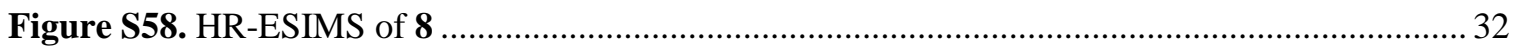

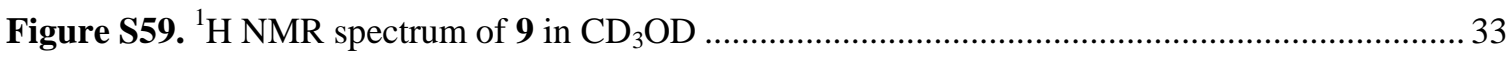

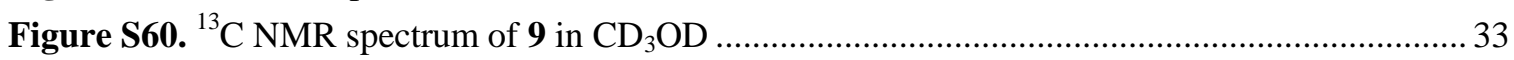

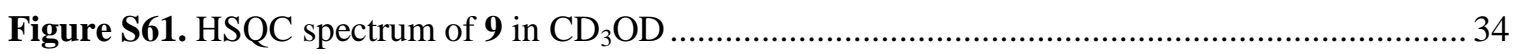

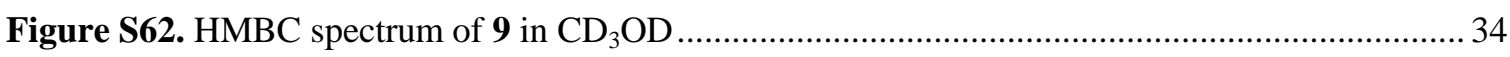

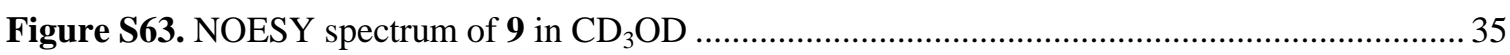

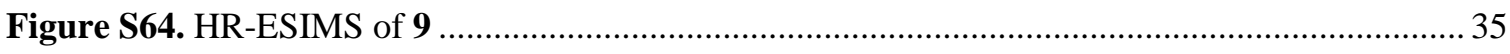

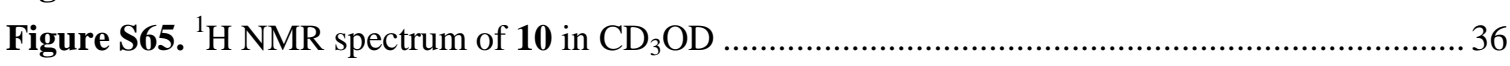

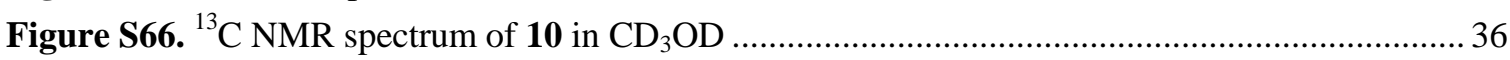

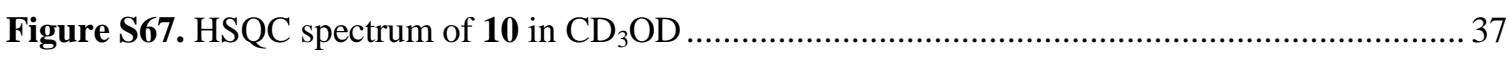

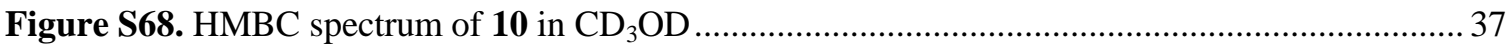

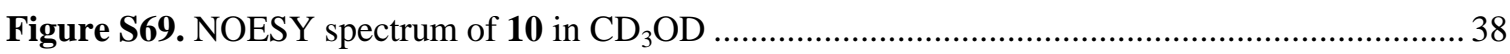

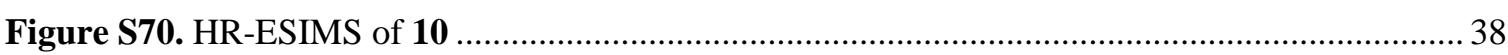

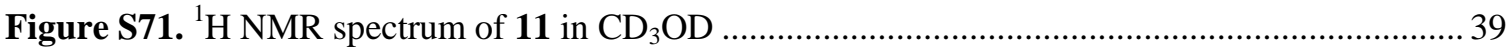

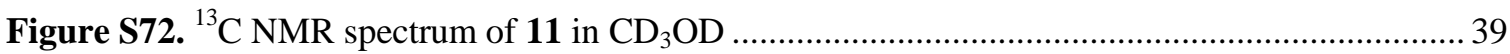

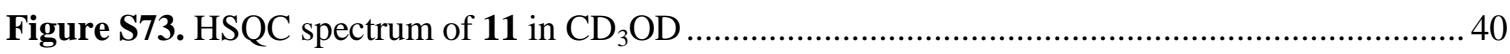

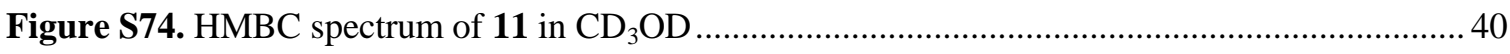

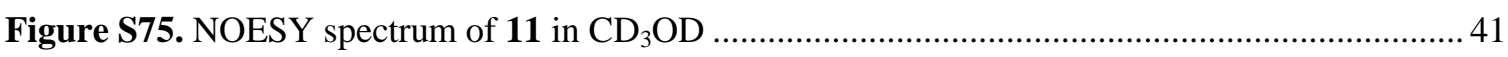

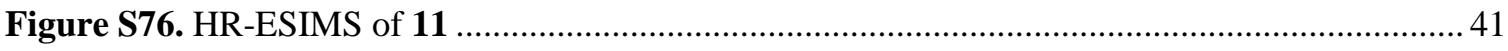

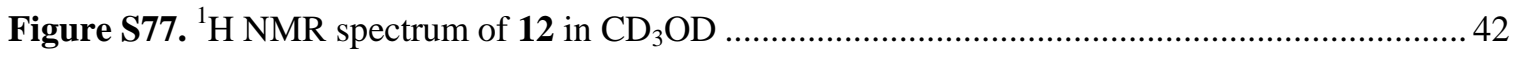

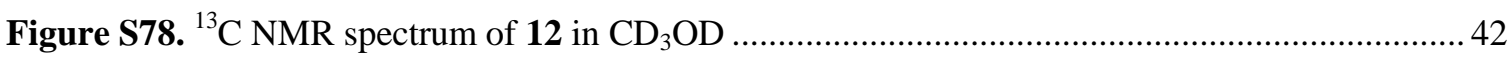

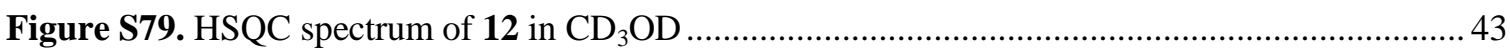

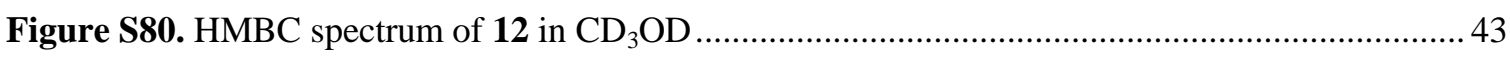

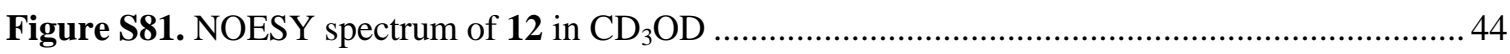

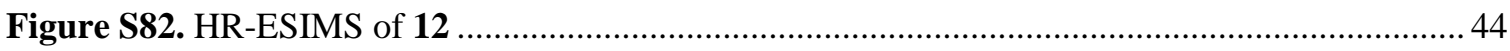

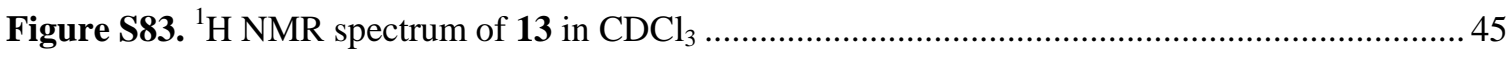

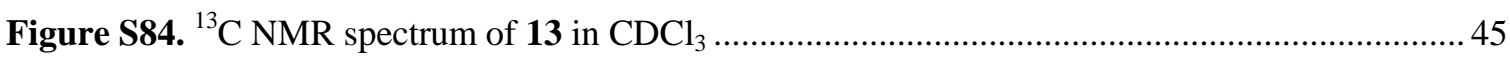

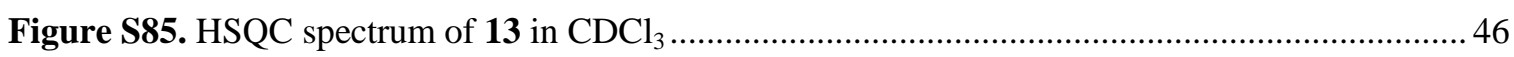

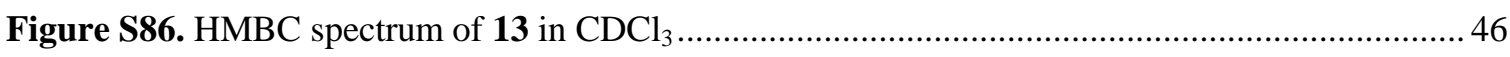

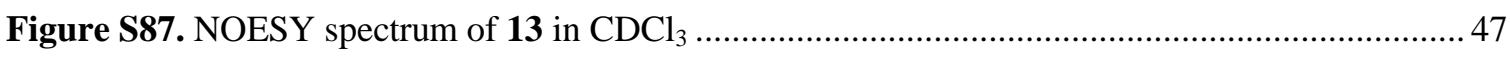

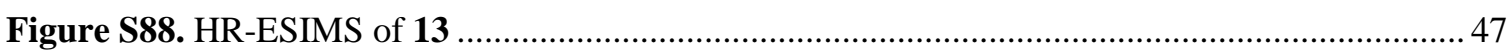

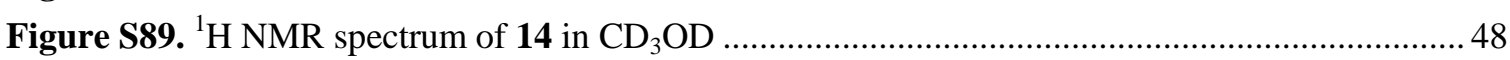

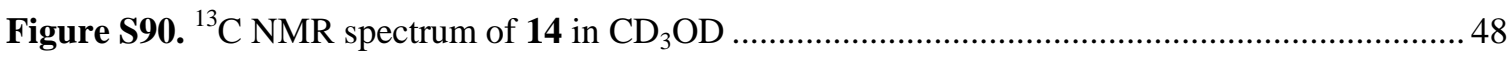

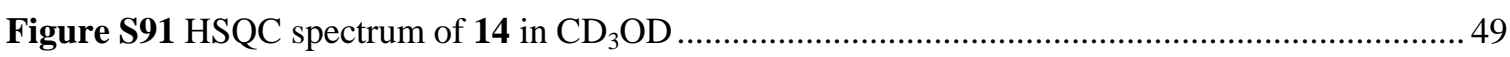

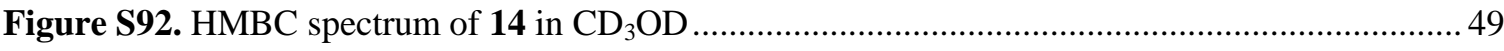

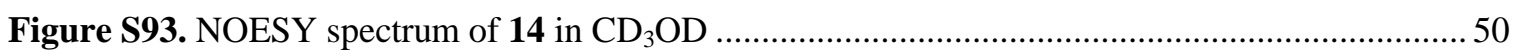

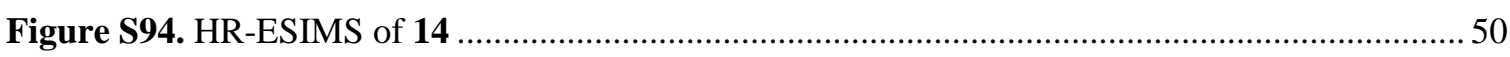

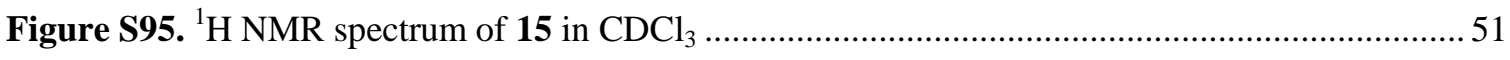

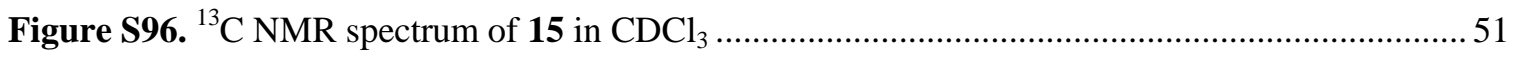

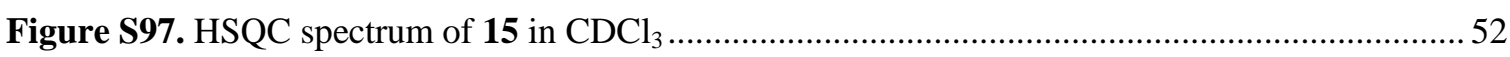

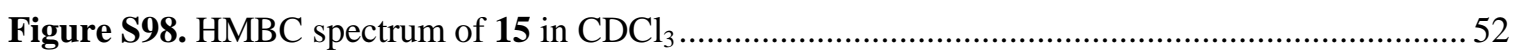

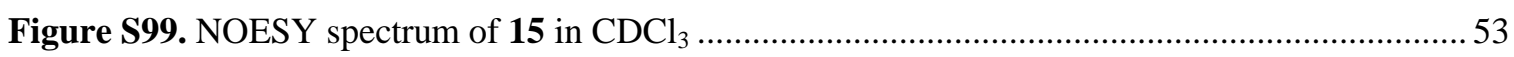

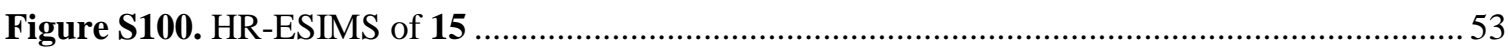




\section{Computational Details}

General Computational Procedure. Conformational searches were done using Molecular Merck force field (MMFF) embedded in Spartan'14 software (Wavefunction Inc., Irvine, CA, USA). Density functional theory (DFT) and time-dependent density functional theory (TDDFT) calculations were performed with Gaussian09 RevD.01. ${ }^{1}$ Double-hybrid (DH) DFT calculations were conducted with ORCA 4.2.1 program package using RIJCOSX approximation, tight SCF criteria, and grid 6 integrity. ${ }^{2}$

ECD Computations. For simulations of ECD spectra of $(+) /(-)-\mathbf{1}$, low-energy conformers of $(R)-\mathbf{1}$ within a $10 \mathrm{kcal} / \mathrm{mol}$ energy window from MMFF conformational search were subjected to geometry optimizations followed by frequency calculations using DFT method at the B3LYP ${ }^{3}-G^{-} 3 B^{4} J^{4,5} /$ Def2-SVP ${ }^{6}$ level of theory with the solvent model PCM for $\mathrm{MeOH}$. To obtain more accurate electronic energies, the optimized low-energy conformers were refined by re-optimizations at the B3LYP-GD3BJ/TZVP 7 /PCM level followed by single point calculations using the DH-DFT method at the PWPB95 ${ }^{8}$-D3BJ/ def2-QZVPP ${ }^{9}$ level with the $\mathrm{SMD}^{10}$ solvent model for $\mathrm{MeOH}$. The TDDFT calculations were carried out on the refined conformers using PBE1PBE (PBE0) ${ }^{11}$ and CAM-B3LYP ${ }^{12}$ functionals in combination with the TZVP basis set and the PCM solvent $(\mathrm{MeOH})$ model. The number of excited states was 90 for all conformers. The results were visualized and exported using the SpecDis program. ${ }^{13}$ The calculated ECD spectrum of $(R)-\mathbf{1}$ was generated as a sum of Gaussian curve with the $\sigma$ value of $0.28 \mathrm{eV}$ using rotatory strengths computed in the dipole-velocity gauge from ECD data of the individual low-energy conformers. Boltzmann distributions of the conformers in equilibrium population were estimated from the relative Gibbs free energies $(\Delta G)$ at $298.15 \mathrm{~K}$.

Simulations of reaction pathway. The reaction pathway of 1,5-dicarbonyl condensation with ammonia for the conversion of compound $\mathbf{3}$ into $\mathbf{1}$ was simulated using the truncated structures, in which the positions C-13-C-16, along with the attached substituents, were removed from the innate structures and 3-OMe and 5-OMe were both replaced with $\mathrm{OH}$ in order to save computational cost. The truncated structures of $\mathbf{3}$ and possible intermediates were subjected to MMFF conformational searches followed by DFT geometry optimizations. With the afforded global minima the combinations of reactant and reaction-mediating $\left(\mathrm{H}_{2} \mathrm{O}\right.$ or formic acid) species were built and subjected to DFT geometry optimizations to obtain conformers suitable as the reactant species for locations of transition states (TSs) of the reactions. These conformers were then subjected to relaxed PES scans along the decreasing distance between two atoms of the new bonds formed or along the increasing distance between atoms of the bonds broken in the reactions. The resultant maxima were subjected to DFT optimizations using the Berny procedure to obtain the TSs for all reactions. The TSs were authenticated by the intrinsic reaction coordinate (IRC) calculations. All the above DFT optimizations were run using the B3LYP-D3BJ/def2-SVP level of theory with the PCM for $\mathrm{H}_{2} \mathrm{O}$. Harmonic vibrational frequency calculations were made at the same level of theory in order to characterize the optimized conformers (minima or TSs) and to estimate their relative thermal $(\Delta E)$ and Gibbs free energies $(\Delta G)$ at $298.15 \mathrm{~K}$. The final electronic energies of stationary points were obtained by re-optimizations using the B3LYP-GD3BJ/TZVP/PCM level of theory followed by single point 
calculations at the PWPB95-D3BJ/def2-QZVPP level of theory with the SMD for $\mathrm{H}_{2} \mathrm{O}$.

Table S1. Electronic energies $\left(\varepsilon_{0}\right)$, relative thermal $(\Delta E)$ and free energies $(\Delta G)$, and Boltzmann distributions $(\mathrm{P})$ of low-energy conformers calculated for $(R)-\mathbf{1}^{a}$

\begin{tabular}{lcccc}
\hline conformer & $\varepsilon_{0}($ Hartree $)$ & $\Delta E(\mathrm{kcal} / \mathrm{mol})$ & $\Delta G(\mathrm{kcal} / \mathrm{mol})$ & $\mathrm{P}(\%)^{b}$ \\
\hline 1a & -1705.74486199183 & 0.0 & 0.0 & 35.4 \\
1b & -1705.74475641998 & 0.066 & 0.03 & 33.6 \\
1c & -1705.74444409599 & 0.262 & 0.113 & 29.2 \\
1d & -1705.74155736598 & 2.74 & 1.770 & 1.8 \\
\hline
\end{tabular}

${ }^{a}$ At the PWPB95-D3BJ/def2-QZVPP/SMD//B3LYP-D3BJ/def2-SVP/PCM level of theory.

${ }^{b}$ From $\Delta G$ values at $298.15 \mathrm{~K}$.

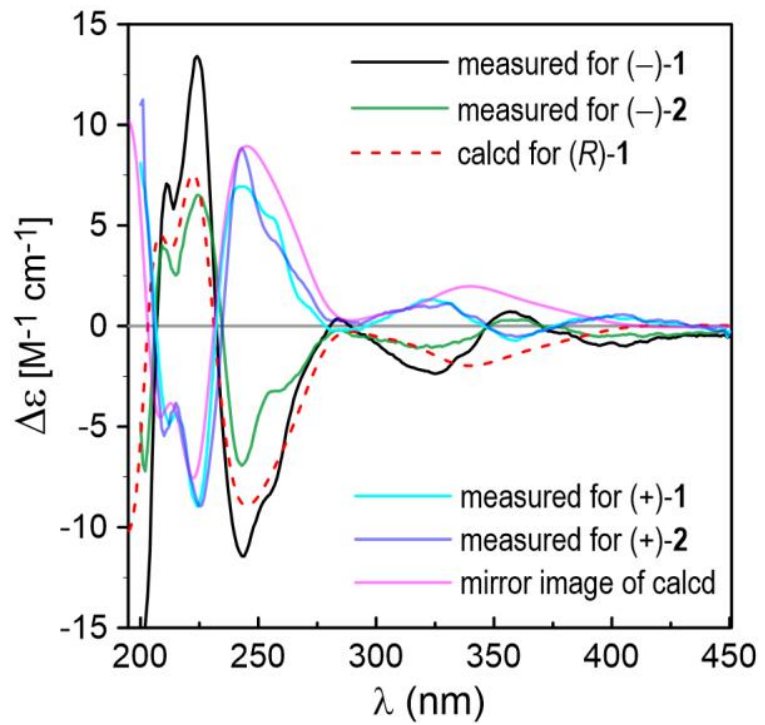

Figure S1. Comparison of the PBE0/TZVP/PCM-calculated ECD spectrum of $(R)-\mathbf{1}$ with the measured spectra of (-)-1/2 and (+)-1/2. 


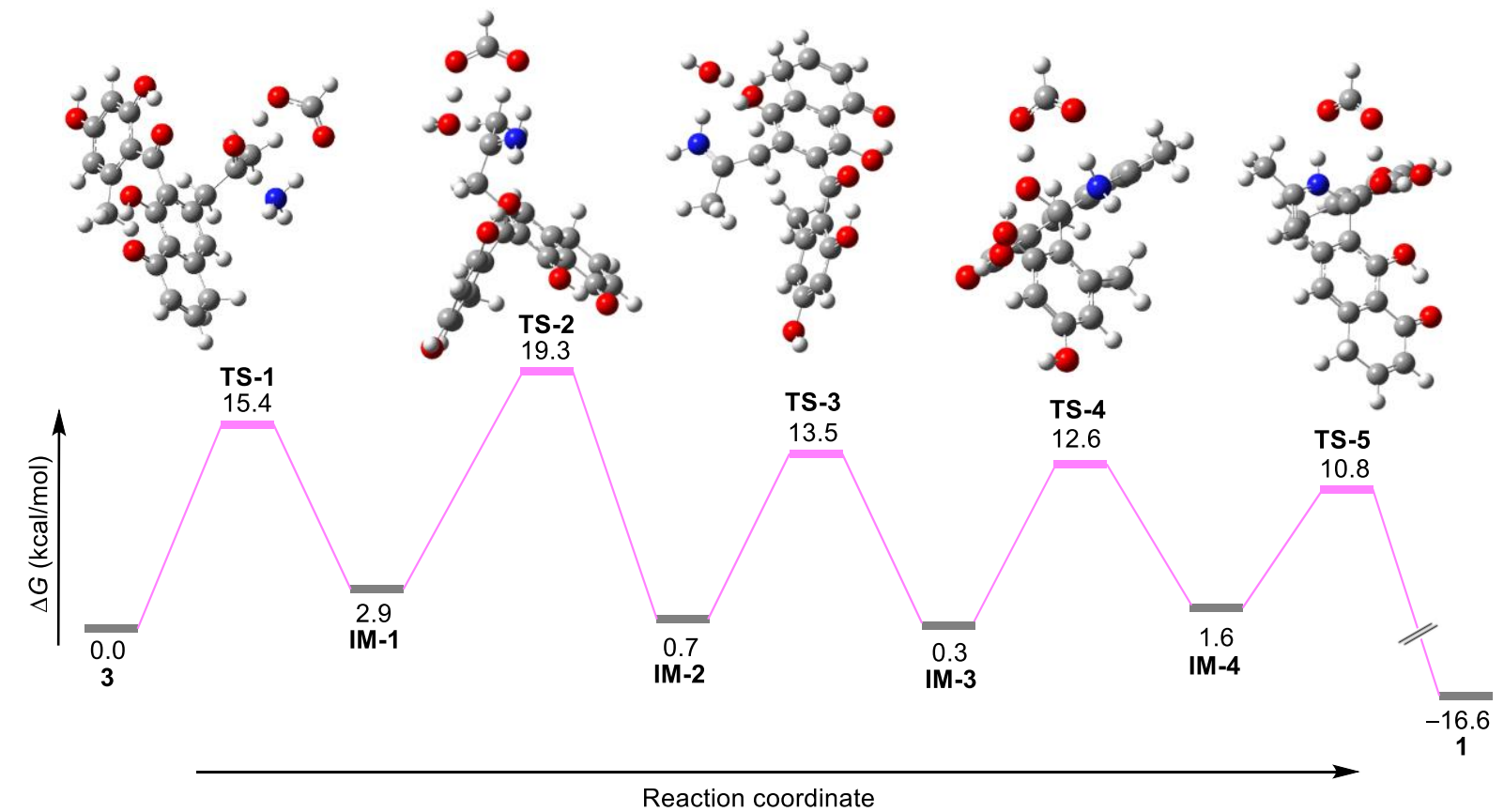

Figure S2. Reaction coordinate and structures of $\mathrm{HCO}_{2} \mathrm{H}$-mediated TSs for conversion of $\mathbf{3}$ to $\mathbf{1}$.

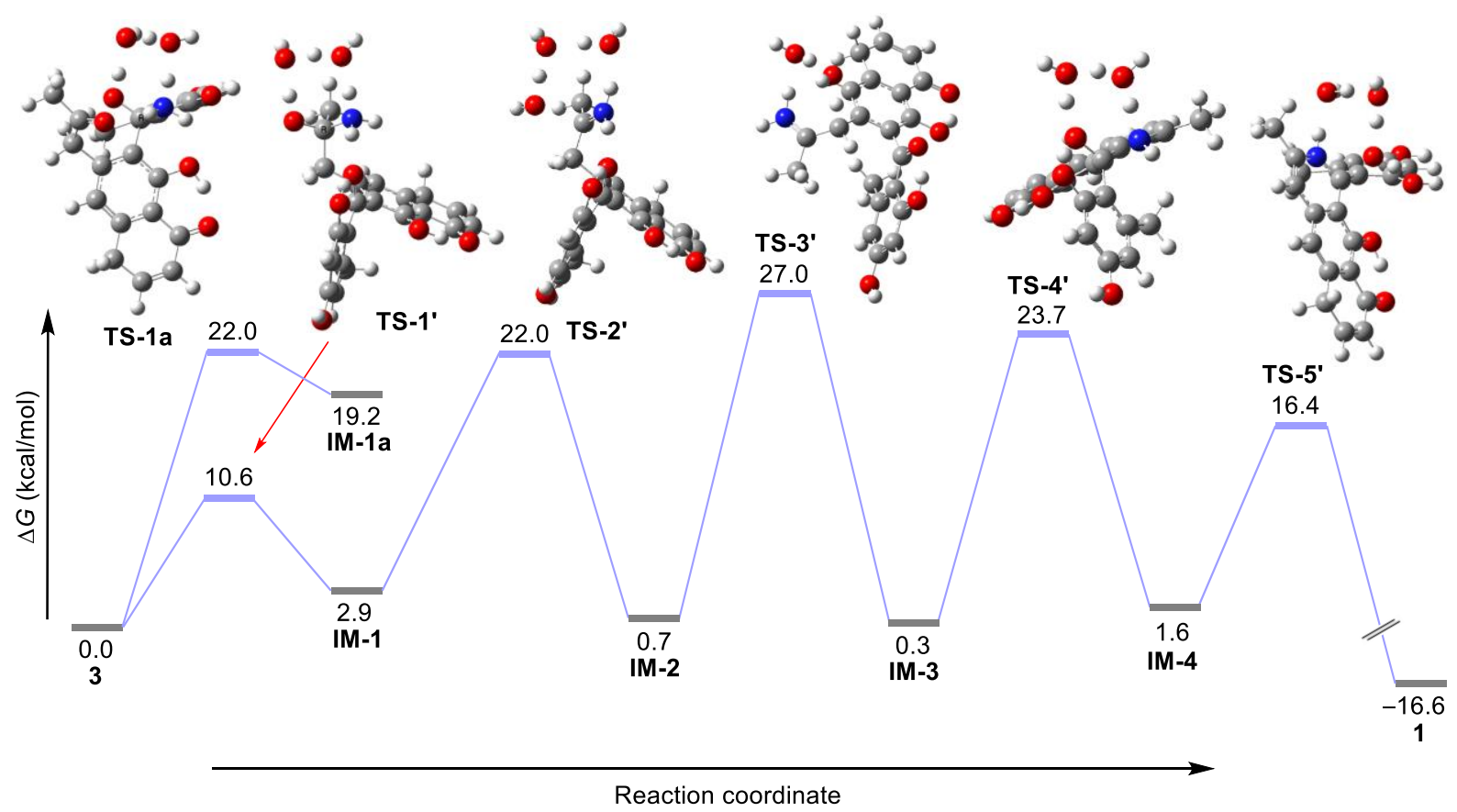

Figure S3. Reaction coordinate and structures of $\mathrm{H}_{2} \mathrm{O}$-mediated TSs for conversion of $\mathbf{3}$ to $\mathbf{1}$. 

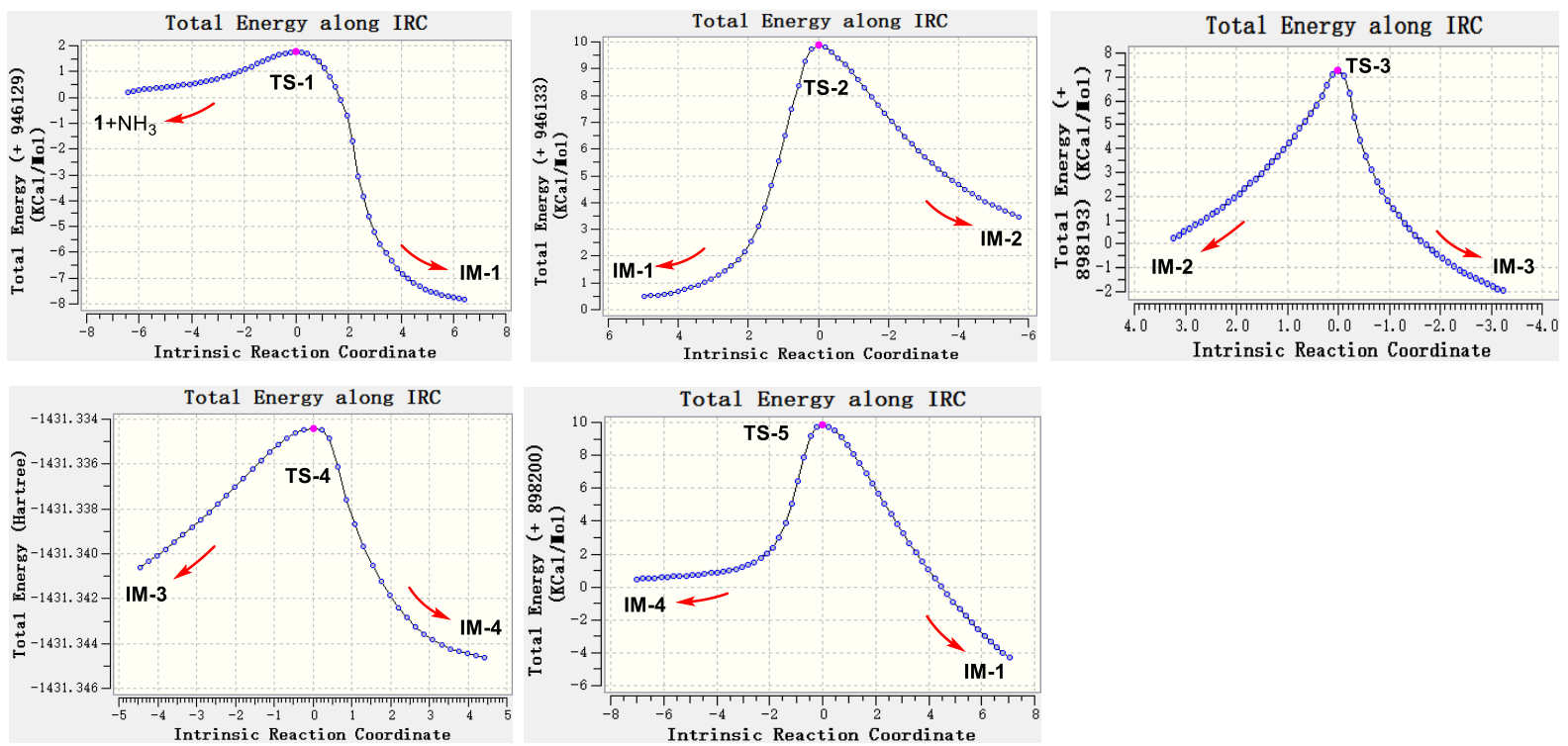

Figure S4. IRCs of $\mathrm{HCO}_{2} \mathrm{H}$-mediated TSs for conversion 3 to $\mathbf{1}$.
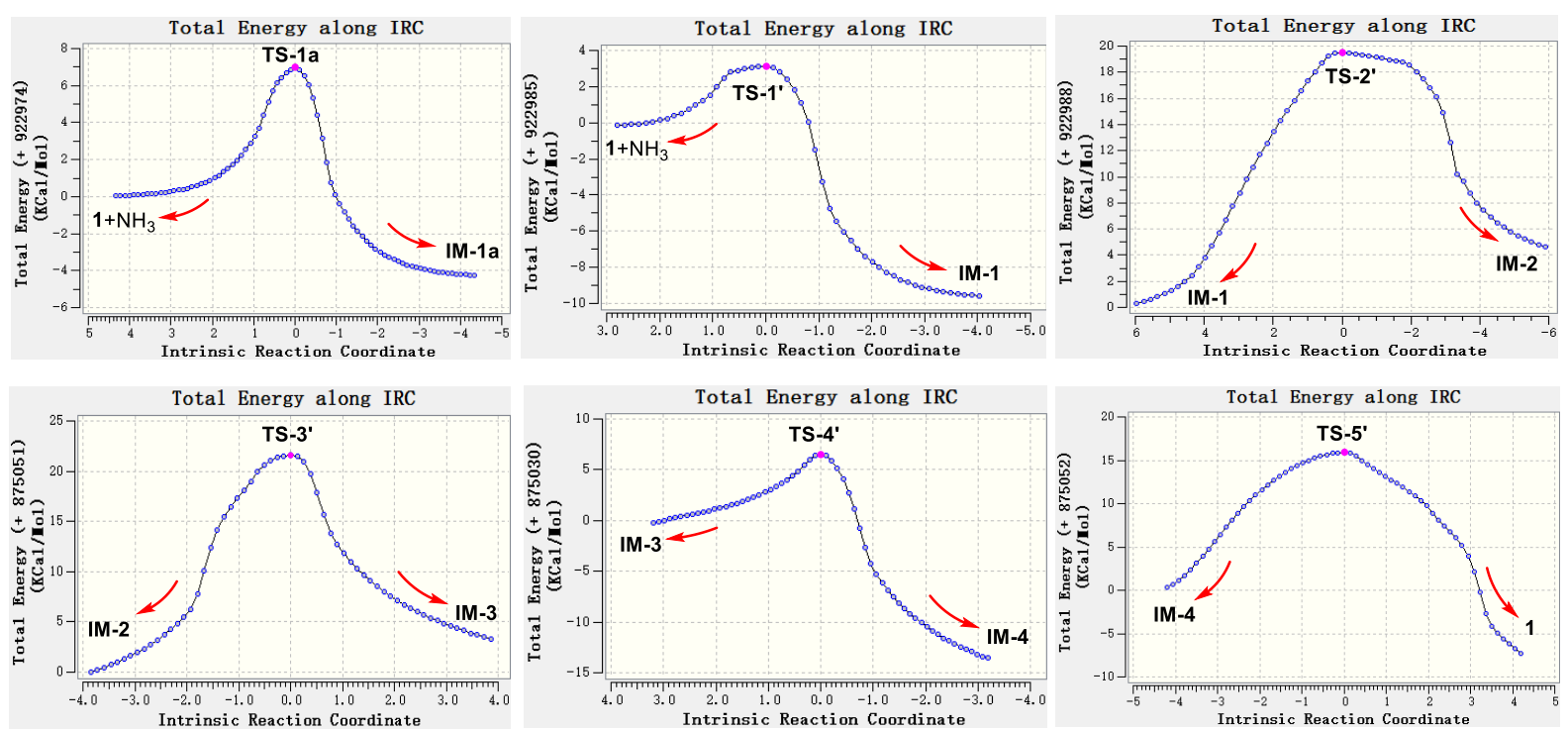

Figure S5. IRCs of $\mathrm{H}_{2} \mathrm{O}$-mediated TSs for conversion 3 to $\mathbf{1}$.

\section{References}

(1) Gaussian 09, revision D.01. Gaussian, Inc.: Wallingford CT, 2013.

(2) Neese, F. WIREs: Comput. Molecul. Sci. 2012, 2(1), 73-78; 2017, 8(1), e1327.

(3) (a) Becke, A. D. J. Chem. Phys. 1993, 98, 5648-5652. (b) Lee, T.; Yang, W. T.; Parr, R. G. Phys. Rev. B: Condens. Matter Mater. Phys. 1988, 37, 785-789.

(4) Grimme, S.; Antony, J.; Ehrlich, S.; Krieg, H. J. Chem. Phys. 2010, 132, 154104.

(5) Grimme,S.; Ehrlich, S.; Goerigk, L. J. Comput. Chem. 2011, 32, 1456-1465.

(6) Weigend, F.; Ahlrichs, R. Phys. Chem. Chem. Phys. 2005, 7, 3297-3305.

(7) Zhao, Y.; Truhlar, D. G. Theor. Chem. Acc. 2008, 120, 215-241. 
(8) Goerigk, L.; Grimme, S. J. Chem. Theory Comput. 2011, 7, 291-309.

(9) Weigend, F.; Ahlrichs, R. Phys. Chem. Chem. Phys. 2005, 7, 3297-3305.

(10) Marenich, A. V.; Cramer, C. J.; Truhlar D. G. J. Phys. Chem. B 2009, 113, 6378-6396.

(11) Adamo, C.; Barone, V. J. Chem. Phys. 1999, 110, 6158-6170.

(12) Yanai, T.; Tew, D. P.; Handy, N. C. Chem. Phys. Lett. 2004, 393, 51-57.

(13) Bruhn, T.; Schaumlöffel, A.; Hemberger, Y.; Bringmann, G. Chirality 2013, 25, 243-249.

(14) Yang, L.; Li, X.; Wu, P.; Xue, J.; Xu, L.; Li, H.; Wei, X. J. Antibiot. 2020, 73, $283-289$.

\section{Chemical Conversion of 3 into 1}
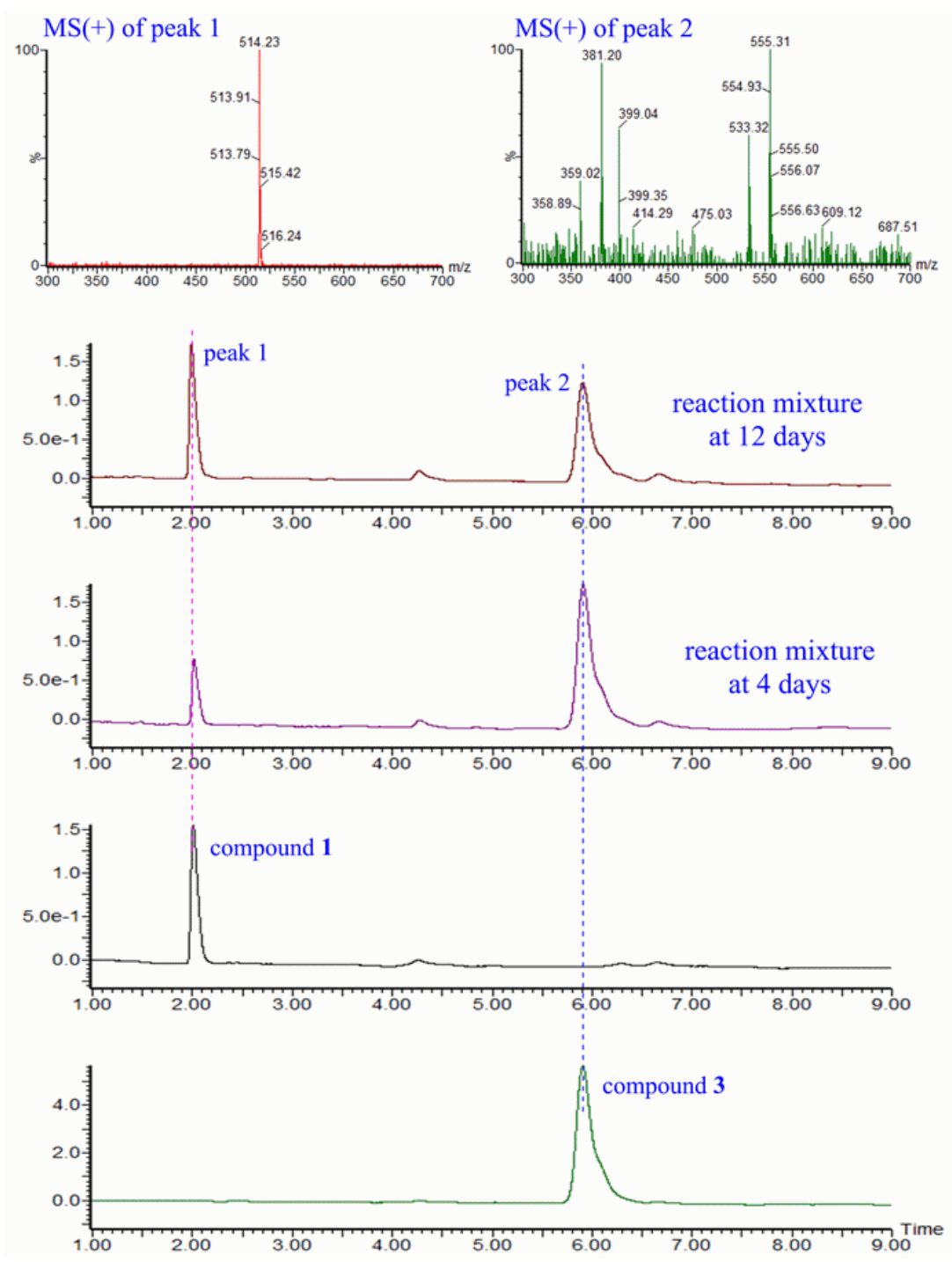

Figure S6. UPLC-PDA-ESIMS analysis of the reaction mixture for conversion $\mathbf{3}$ to $\mathbf{1}$ (column: ACQUITY UPLC BEH C18 $(2.1 \times 100 \mathrm{~mm}, 1.7 \mu \mathrm{m}) ; 55 \% \mathrm{MeCN}$; flow rate: $0.3 \mathrm{~mL} / \mathrm{min}$; volume of injection: $1 \mu \mathrm{L}$; column temperature: $40^{\circ} \mathrm{C}$ ) 


\section{Key HMBC and NOESY Correlations of Compounds 4-15}
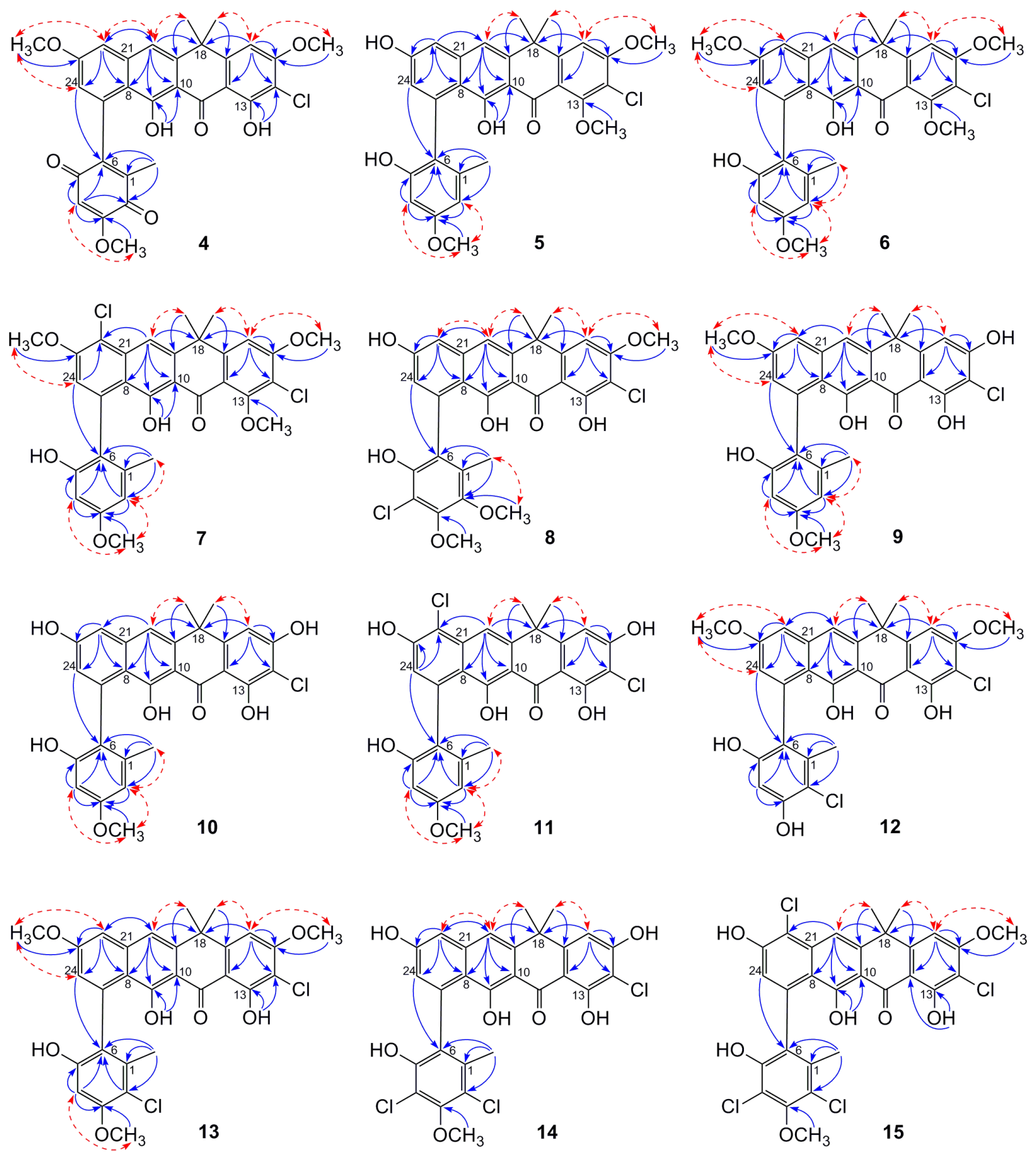

Figure S7. Key HMBC and NOESY correlations of 4-15 

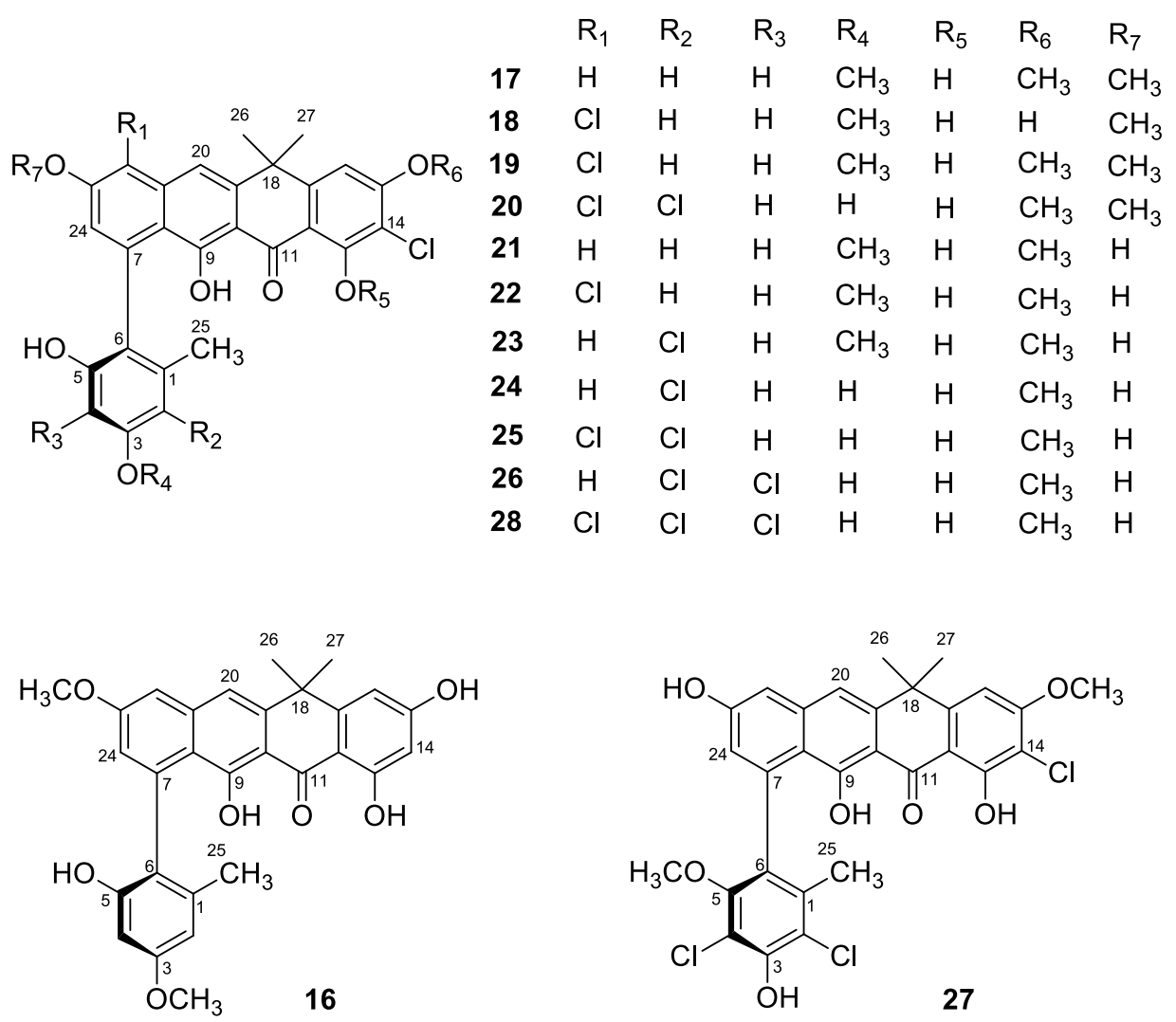

Figure S8. Structures of compounds 16-28

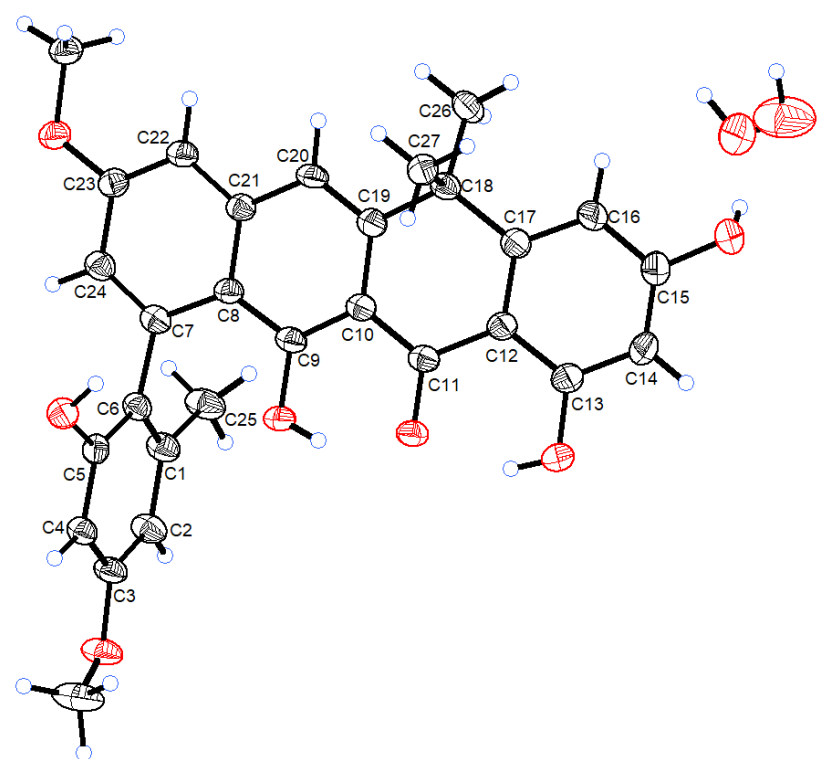

Figure S9. X-ray structure of compound $\mathbf{1 6}$ 


\section{ECD spectra of compounds 4-20}

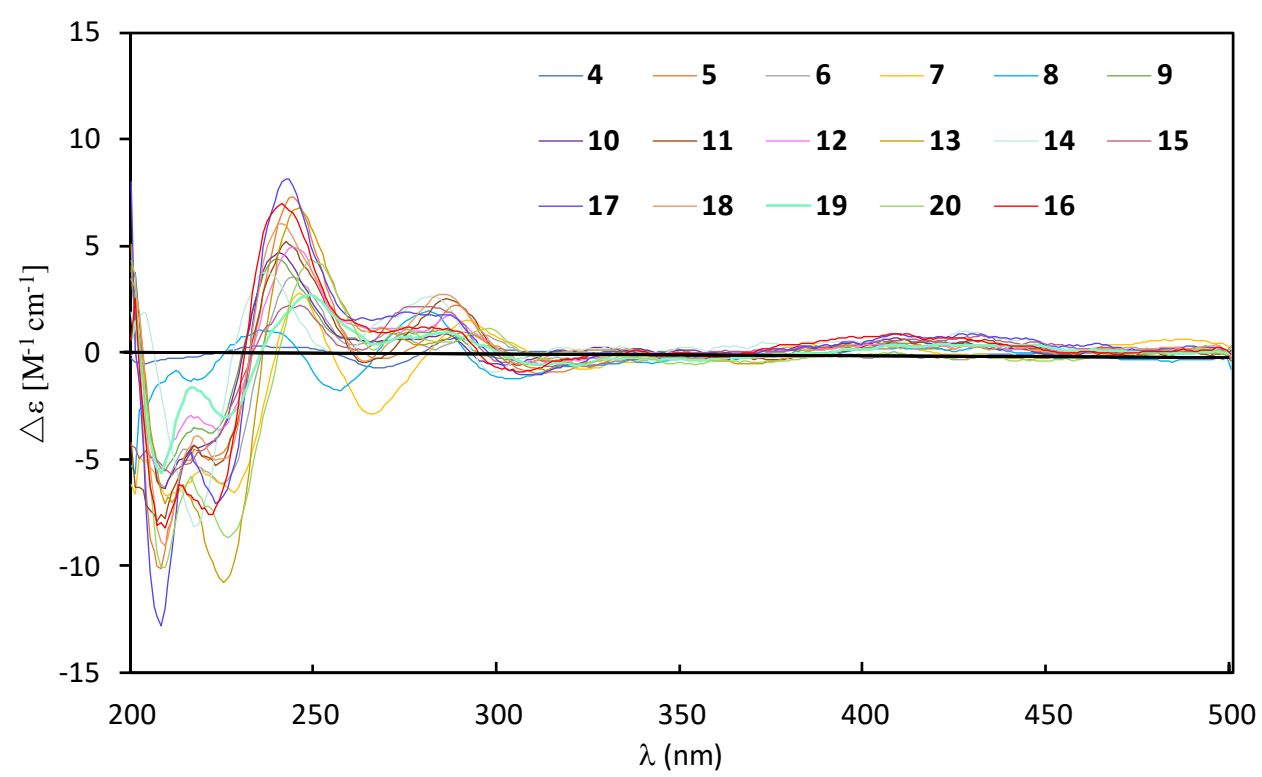

Figure S10. Comparison of ECD spectra of 4-15 and 17-20 with that of 16

\section{Comparison between Antibacterial and Cytotoxic Potencies of Compounds}

Table S2. Molar MIC and $\mathrm{IC}_{50}$ values of antibacterial compounds for comparison between their potencies against the bacteria and Vero cells

\begin{tabular}{l|cccc|c}
\hline & \multicolumn{4}{|c|}{${\mathrm{MIC} / \mathrm{MIC}_{50}(\mu \mathrm{M})^{a}}^{a}$} & $\mathrm{IC}_{50}(\mu \mathrm{M})$ \\
compound & MRSA & MSSA & VRE & VSE & Vero \\
\hline $\mathbf{5}$ & $4.7 / 2.5$ & $4.7 / 3.0$ & $4.7 / 2.0$ & $4.7 / 1.8$ & 3.0 \\
$\mathbf{8}$ & 2.1 & 2.1 & 8.6 & 4.3 & 14.5 \\
$\mathbf{9}$ & 4.8 & 4.8 & 9.6 & 4.8 & 18.9 \\
$\mathbf{1 0}$ & 9.9 & 9.9 & 19.8 & 4.9 & 33.0 \\
$\mathbf{1 1}$ & 2.3 & 2.3 & 9.3 & 4.6 & 47.0 \\
$\mathbf{1 2}$ & 2.3 & 4.5 & 9.0 & 2.3 & 13.7 \\
$\mathbf{1 4}$ & $2.2 / 1.0$ & $2.2 / 1.5$ & $2.2 / 0.9$ & $2.2 / 0.5$ & 12.4 \\
$\mathbf{1 5}$ & 4.0 & 4.0 & 8.0 & 4.0 & 12.0 \\
$\mathbf{1 6}$ & 2.6 & 2.6 & 2.6 & 2.6 & 6.4 \\
$\mathbf{1 8}$ & 2.3 & 2.3 & 4.5 & 4.5 & 4.8 \\
$\mathbf{2 0}$ & $4.3 / 0.8$ & $4.3 / 2.6$ & $8.5 / 4.2$ & $2.1 / 0.8$ & 7.9 \\
$\mathbf{2 1}$ & $4.8 / 1.0$ & $4.8 / 1.6$ & $4.8 / 1.0$ & $4.8 / 0.8$ & 3.3 \\
$\mathbf{2 2}$ & 4.5 & 4.5 & 4.5 & 4.5 & 9.0 \\
$\mathbf{2 3}$ & $4.5 / 0.8$ & $4.5 / 1.4$ & $4.5 / 2.3$ & $4.5 / 0.8$ & 3.5 \\
$\mathbf{2 4}$ & 2.3 & 2.3 & 2.3 & 2.3 & 14.6 \\
$\mathbf{2 5}$ & 4.4 & 4.4 & 4.4 & 4.4 & 14.6 \\
$\mathbf{2 6}$ & 4.4 & 4.4 & 4.4 & 4.4 & 12.5 \\
$\mathbf{2 7}$ & 1.1 & 1.1 & 2.1 & 2.1 & 11.1 \\
$\mathbf{2 8}$ & 8.2 & 8.2 & 8.2 & 8.2 & 27.3 \\
\hline
\end{tabular}

${ }^{a}$ MIC values of compounds 21-28 from our previous work (Yang et al. J. Antibiot. 2020, 73, 283). 
7. NMR spectra and HRESIMS of 1-15

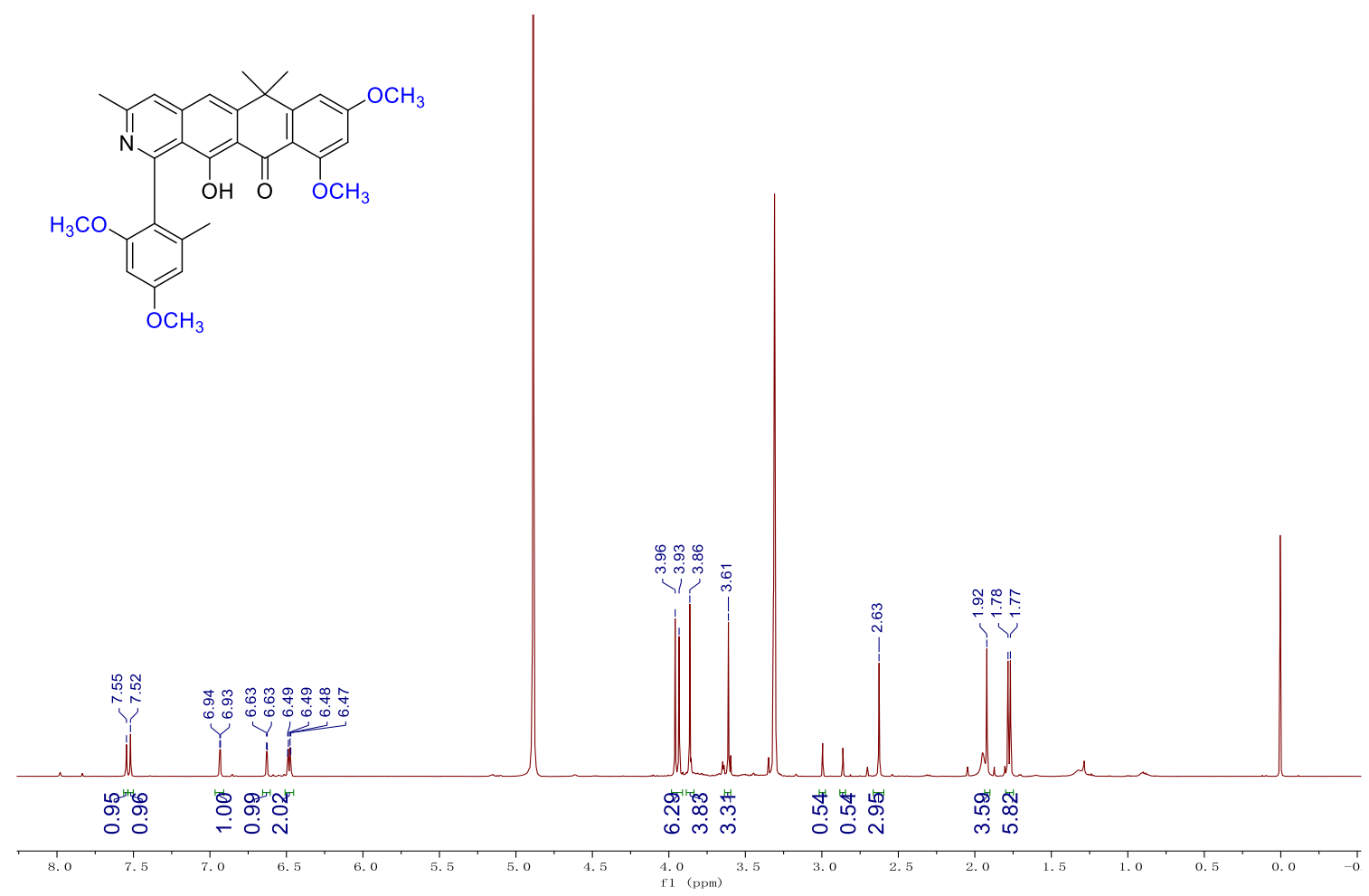

Figure S11. ${ }^{1} \mathrm{H}$ NMR $(500 \mathrm{MHz})$ spectrum of 1 in $\mathrm{CD}_{3} \mathrm{OD}$
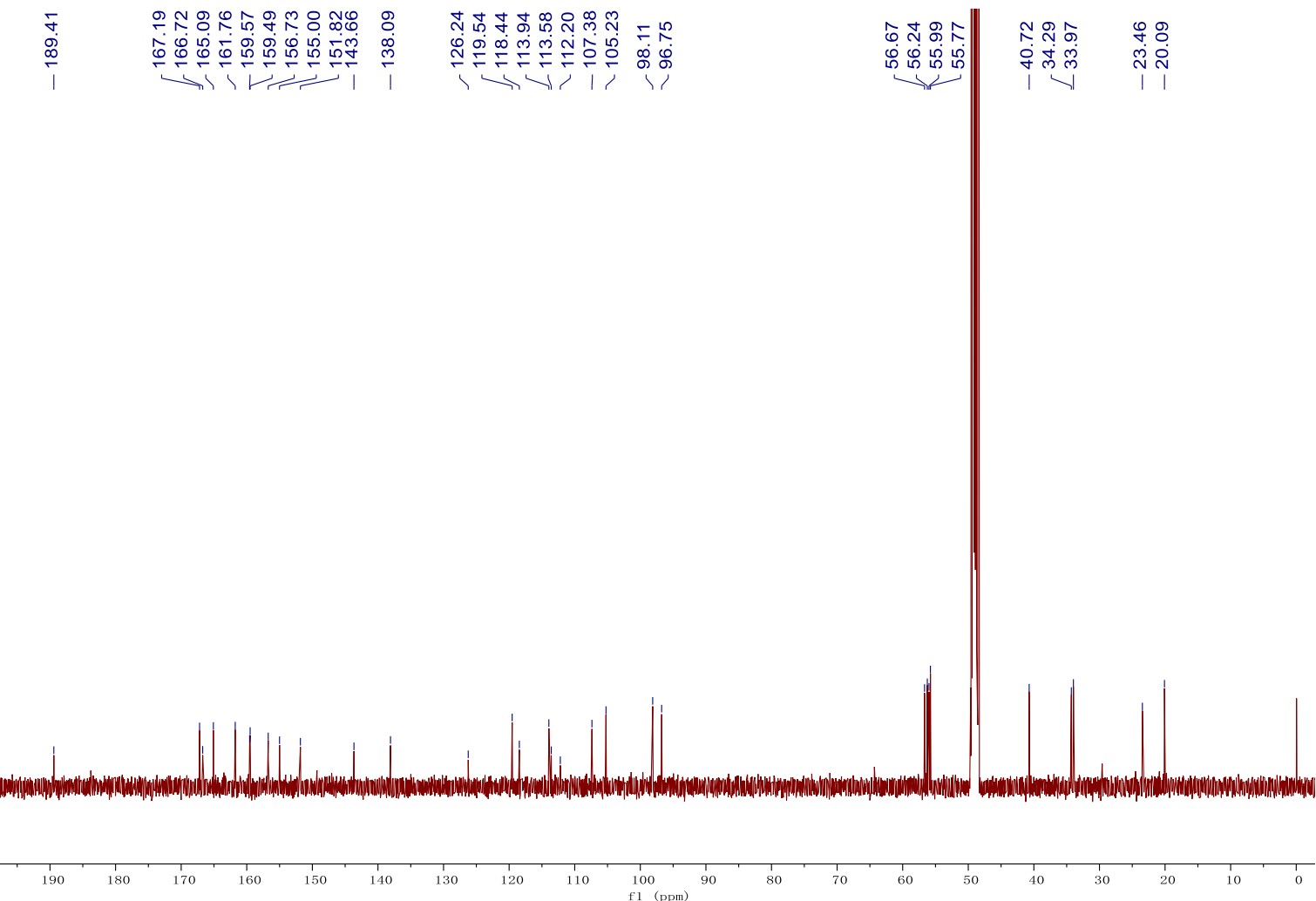

Figure S12. ${ }^{13} \mathrm{C}$ NMR $(125 \mathrm{MHz})$ spectrum of $\mathbf{1}$ in $\mathrm{CD}_{3} \mathrm{OD}$ 


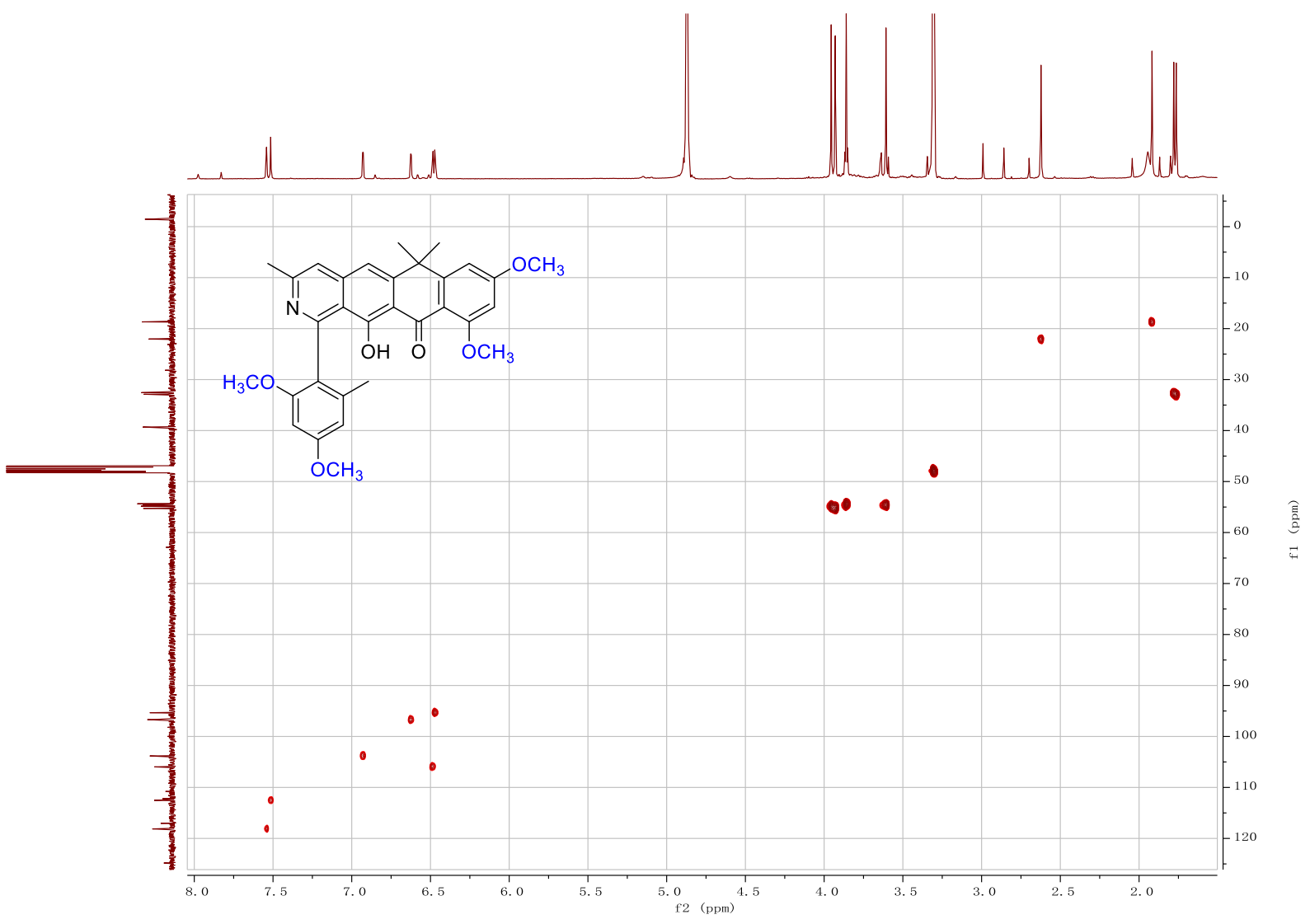

Figure S13. HSQC spectrum of 1 in $\mathrm{CD}_{3} \mathrm{OD}$

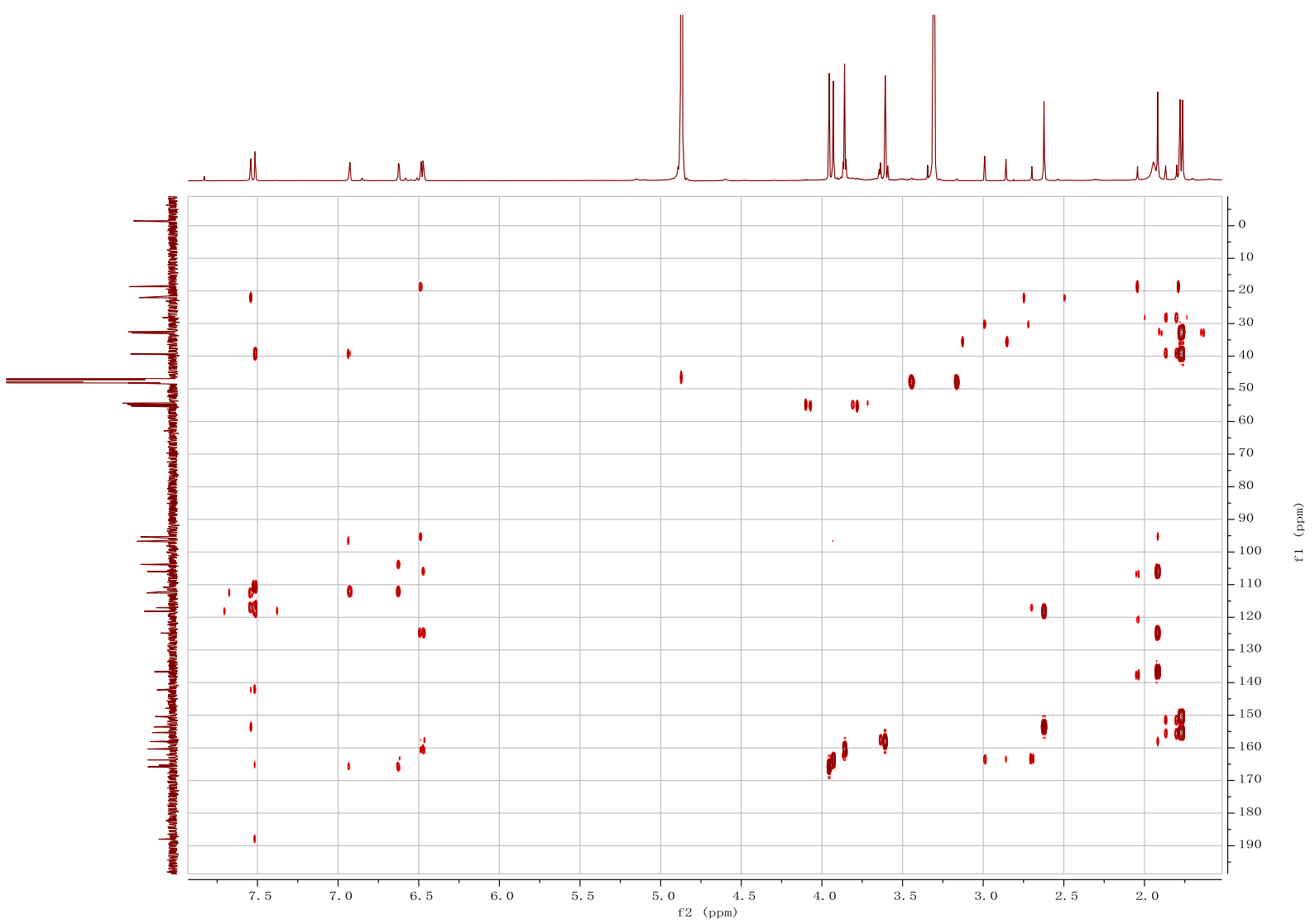

Figure S14. $\mathrm{HMBC}$ spectrum of $\mathbf{1}$ in $\mathrm{CD}_{3} \mathrm{OD}$

10 


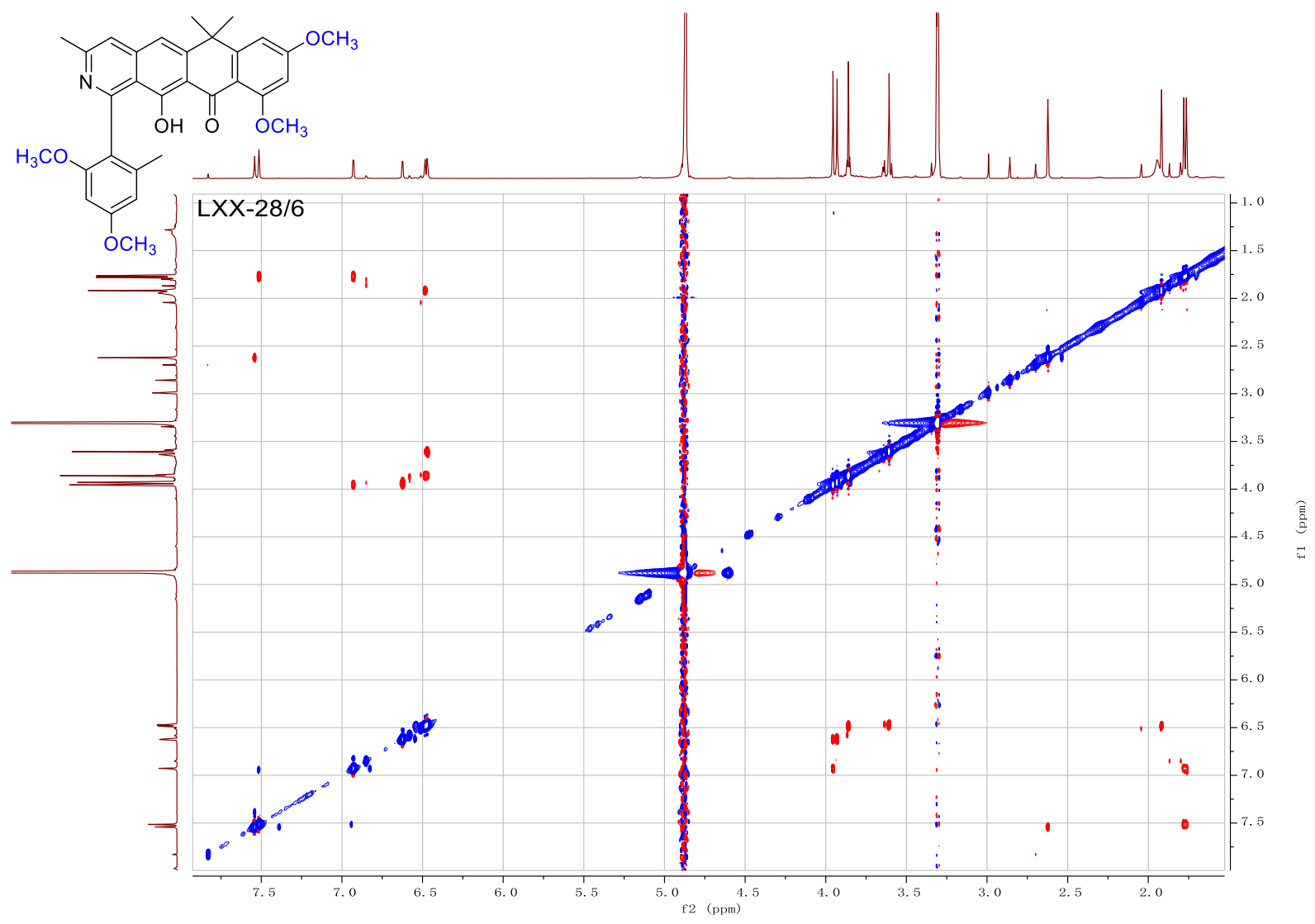

Figure S15. NOESY spectrum of $\mathbf{1}$ in $\mathrm{CD}_{3} \mathrm{OD}$

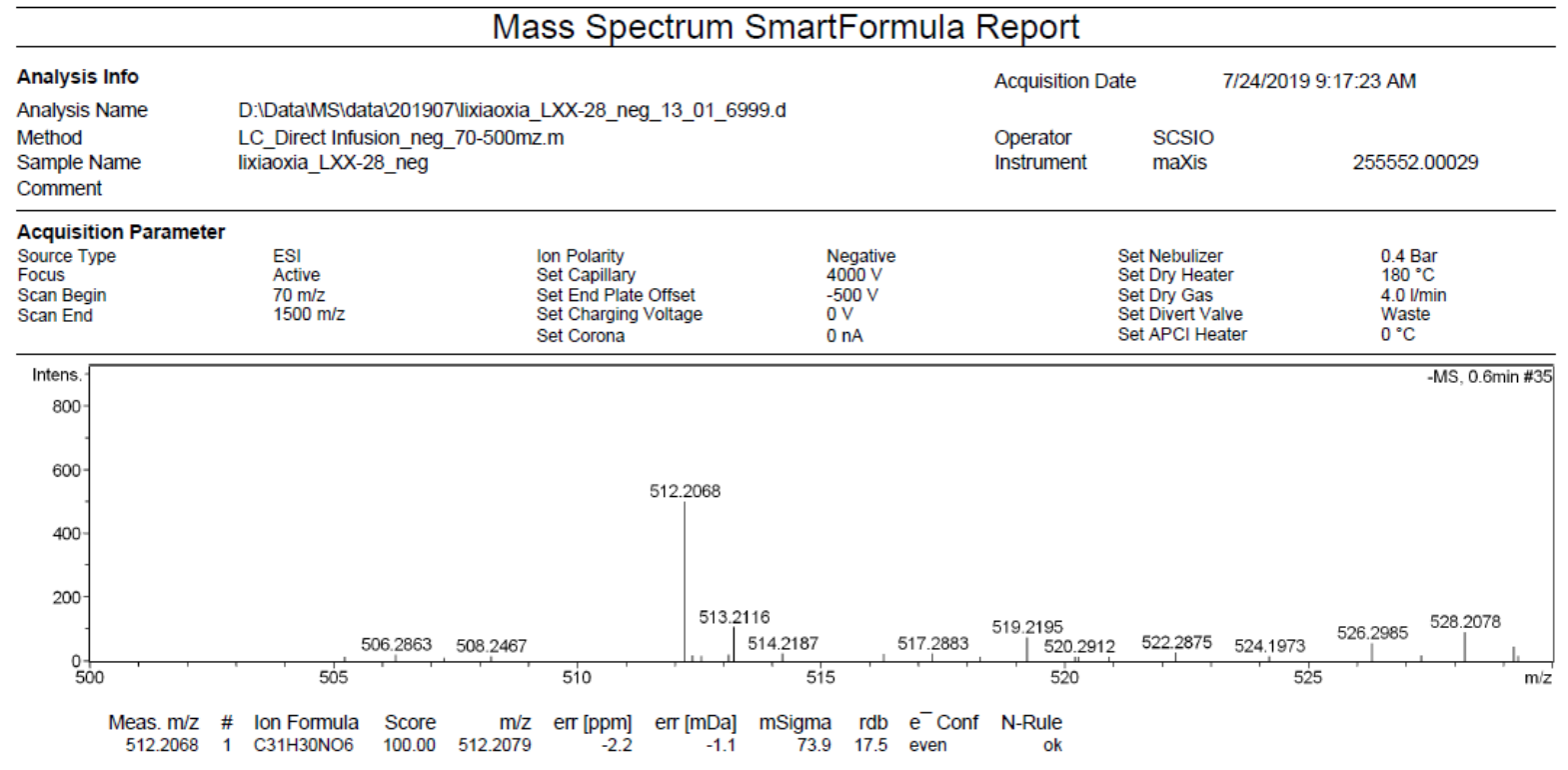

Figure S16. HR-ESI (-) MS of 1

11 

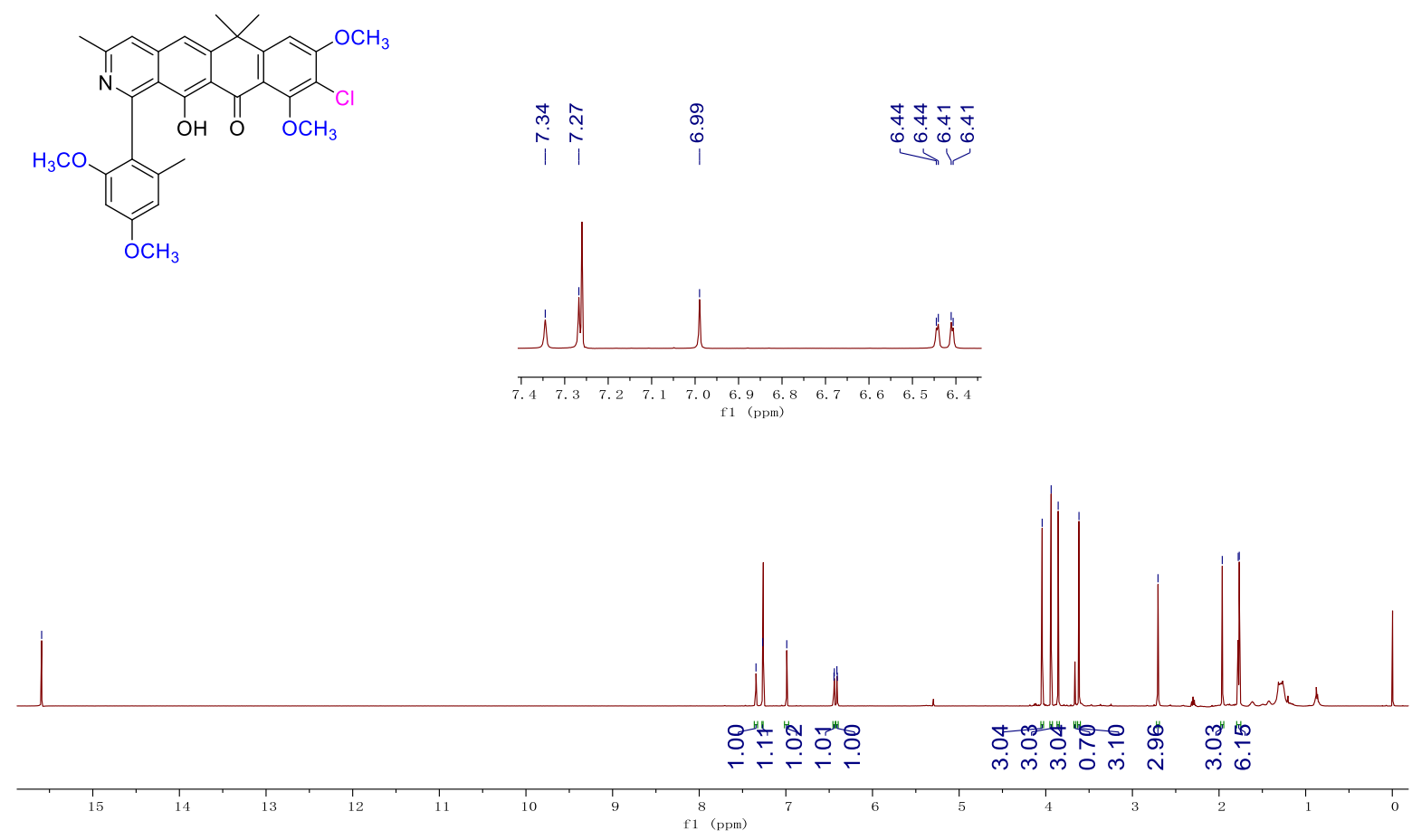

Figure S17. ${ }^{1} \mathrm{H}$ NMR $(500 \mathrm{MHz})$ spectrum of 2 in $\mathrm{CDCl}_{3}$
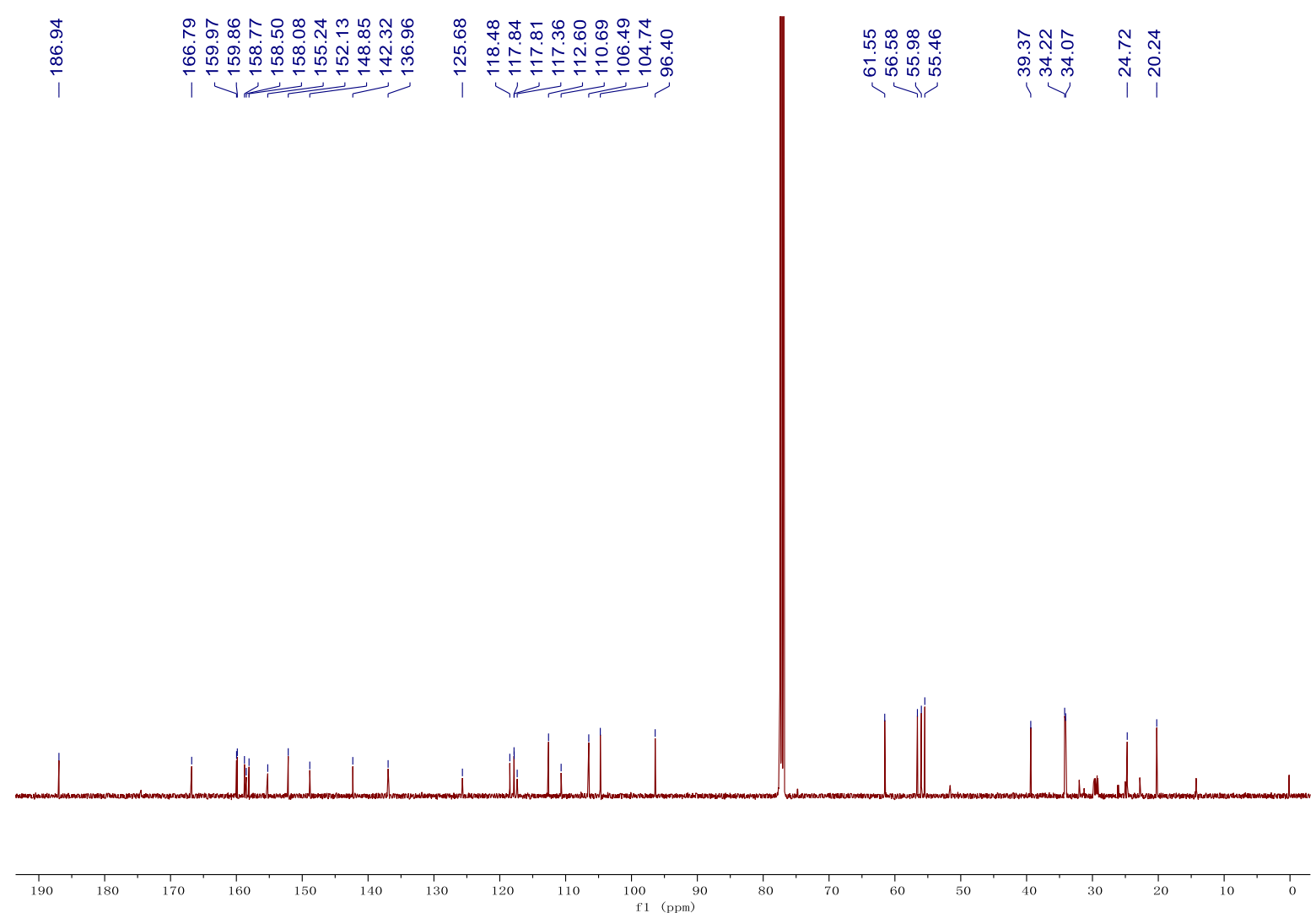

Figure S18. ${ }^{13} \mathrm{C}$ NMR (125 MHz) spectrum of 2 in $\mathrm{CDCl}_{3}$ 


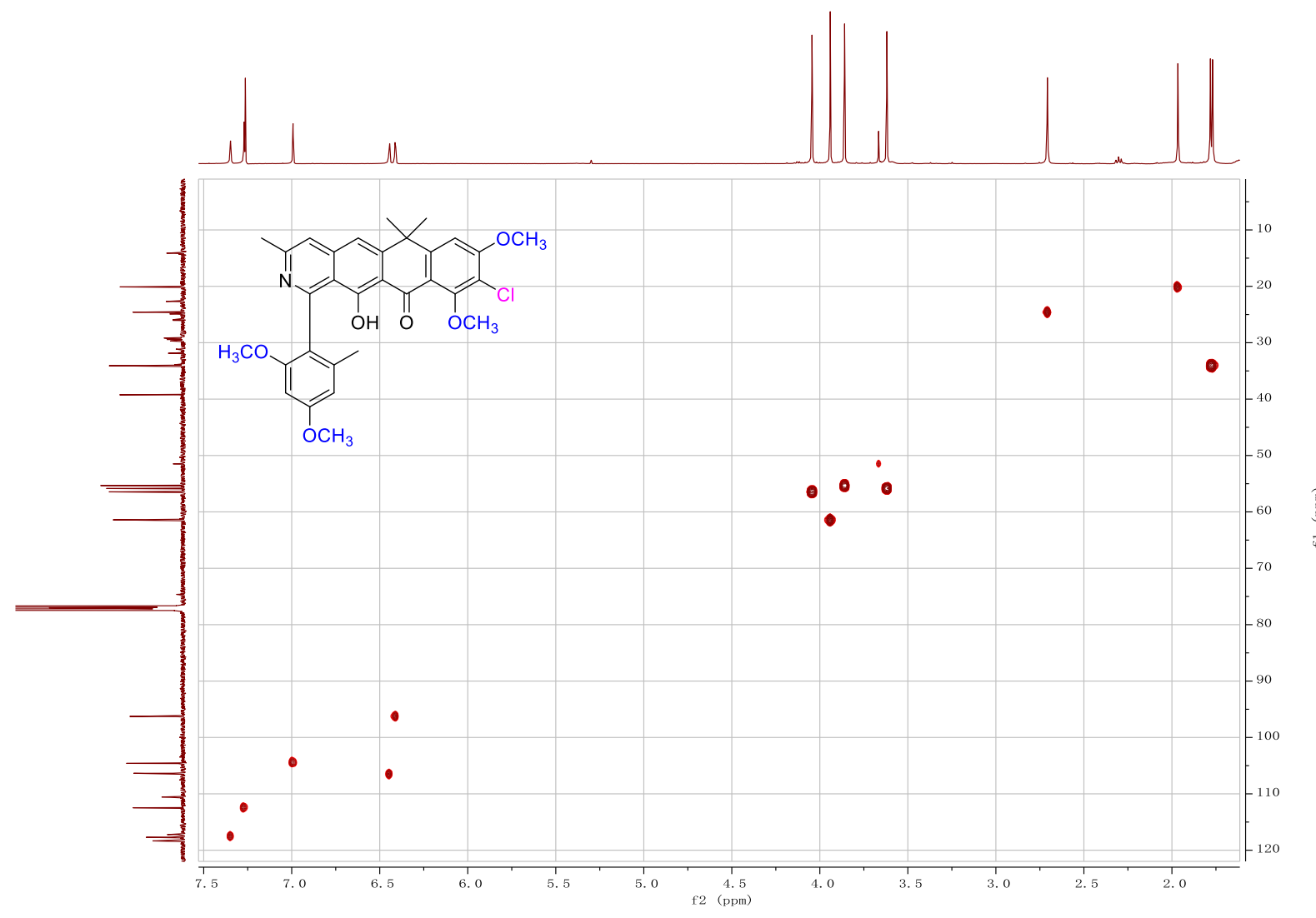

Figure S19. HSQC spectrum of 2 in $\mathrm{CDCl}_{3}$

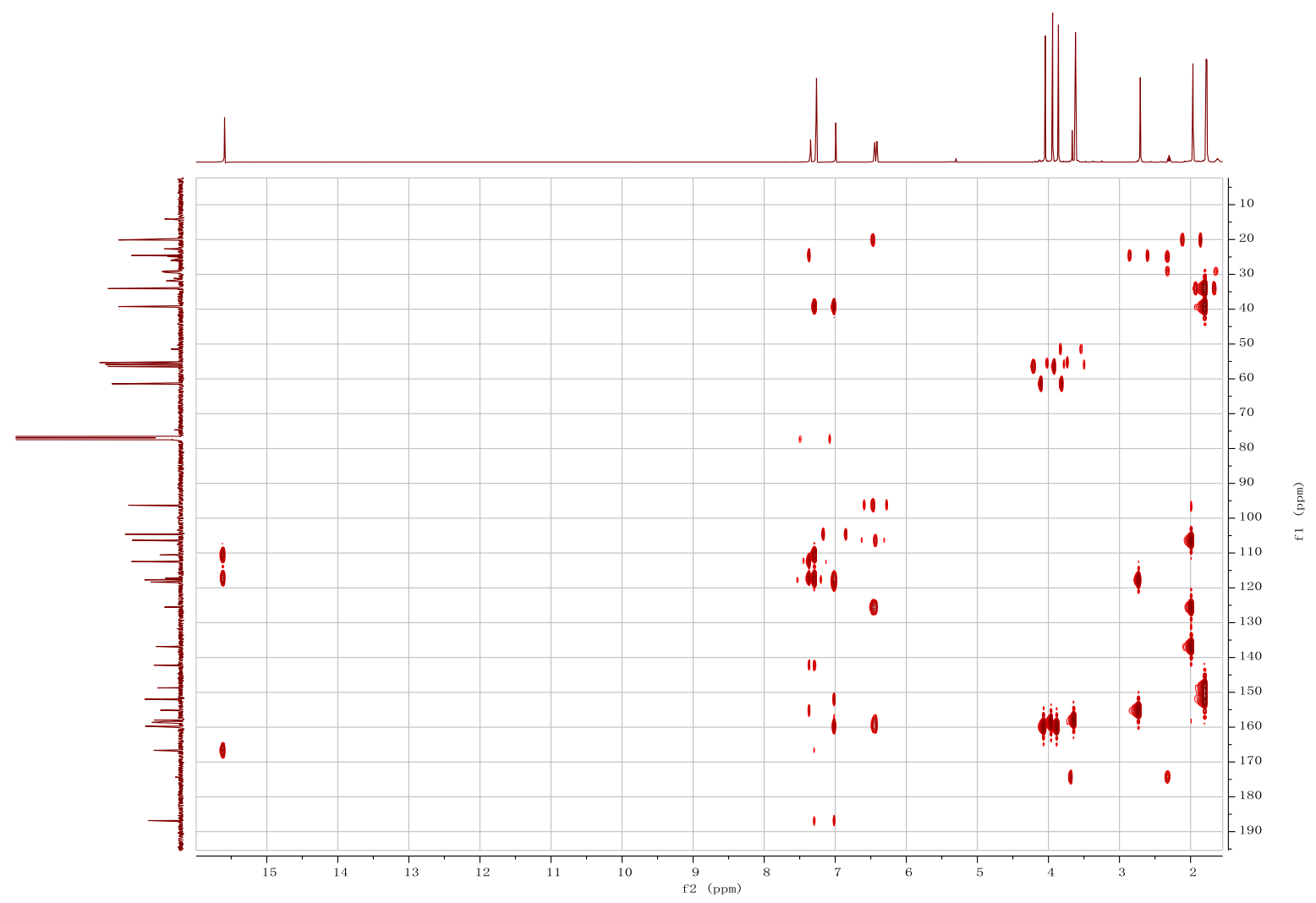

Figure S20. $\mathrm{HMBC}$ spectrum of $\mathbf{2}$ in $\mathrm{CDCl}_{3}$ 


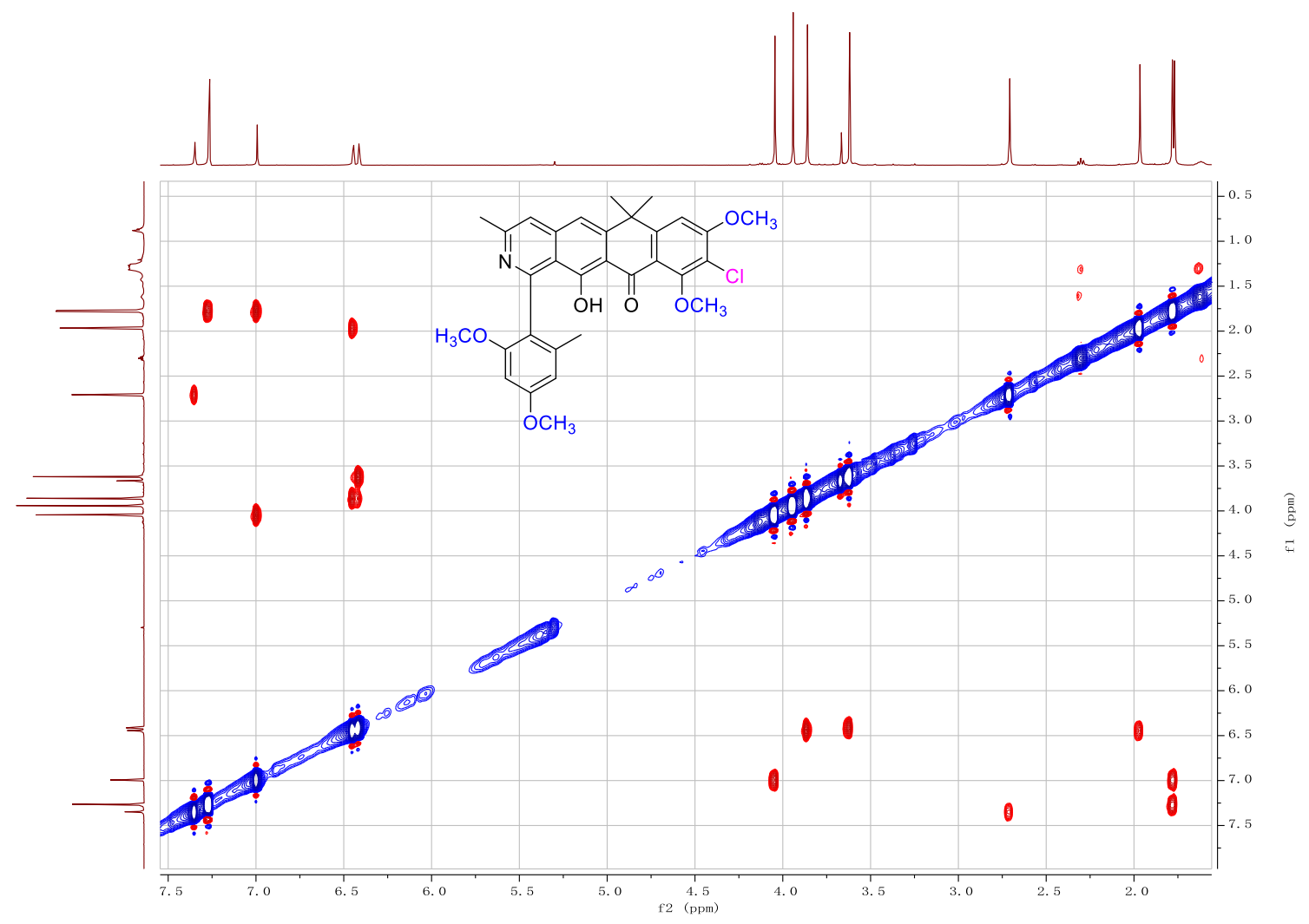

Figure S21. NOESY spectrum of 2 in $\mathrm{CDCl}_{3}$

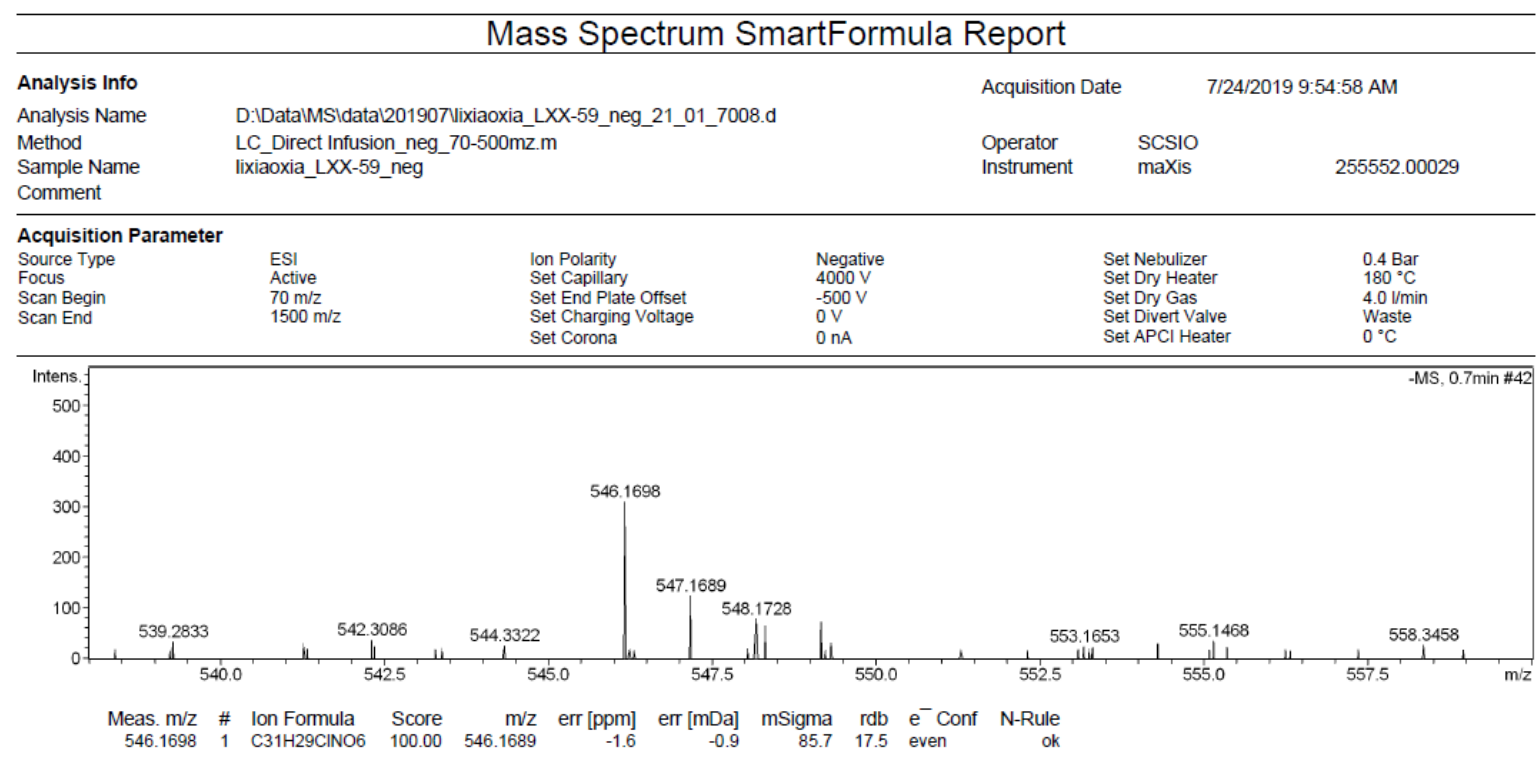

Figure S22. HR-ESI(-)MS of 2 

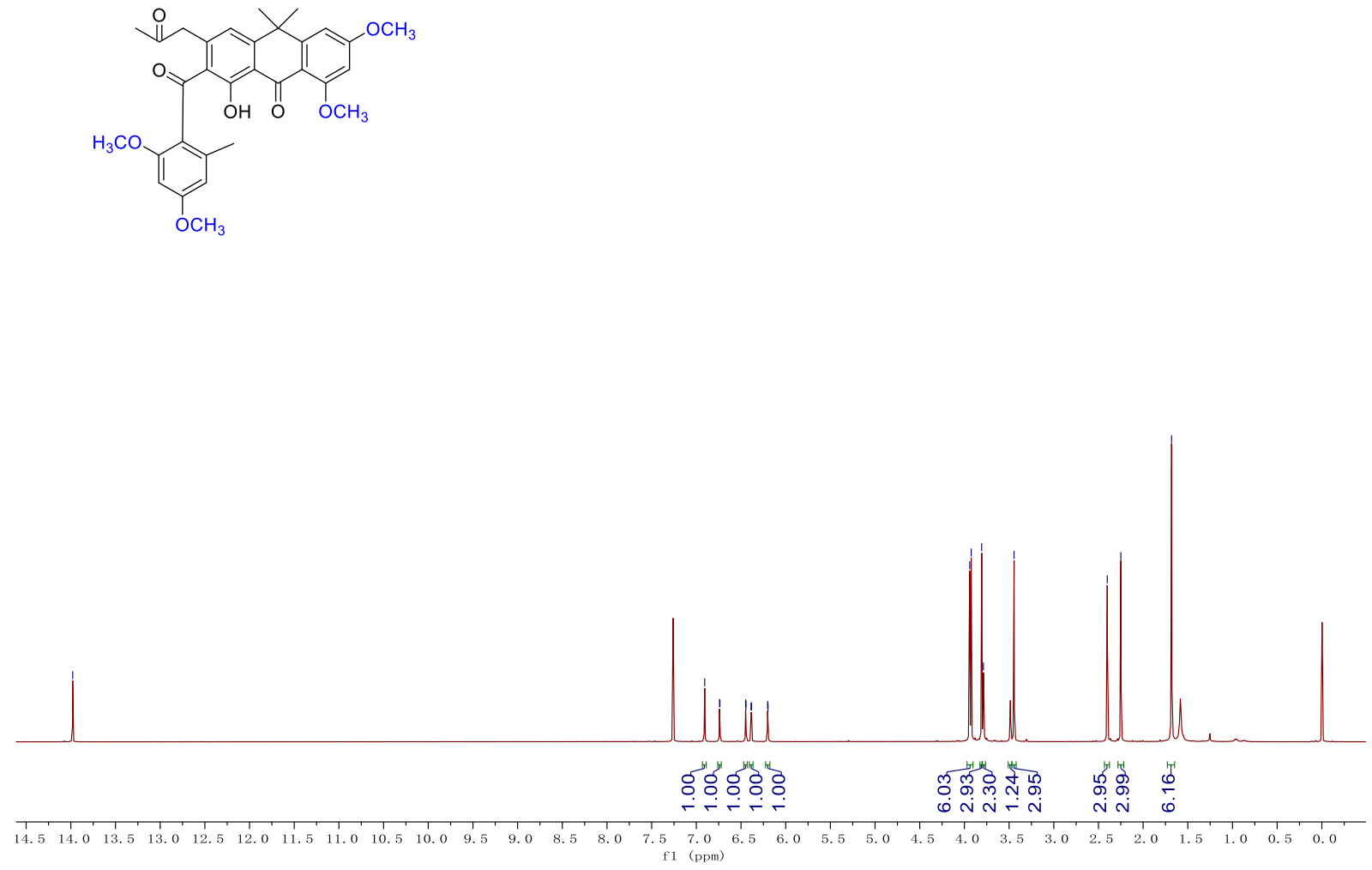

Figure S23. ${ }^{1} \mathrm{H}$ NMR $(500 \mathrm{MHz})$ spectrum of 3 in $\mathrm{CDCl}_{3}$

至

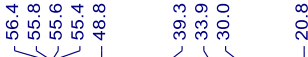
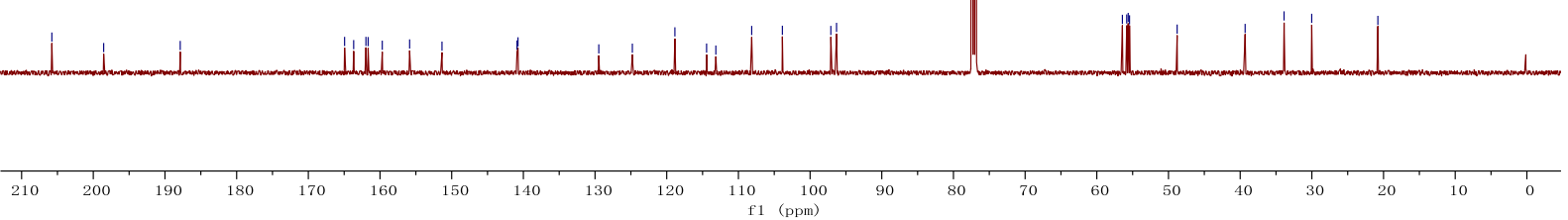

Figure S24. ${ }^{13} \mathrm{C}$ NMR (125 MHz) spectrum of 3 in $\mathrm{CDCl}_{3}$ 


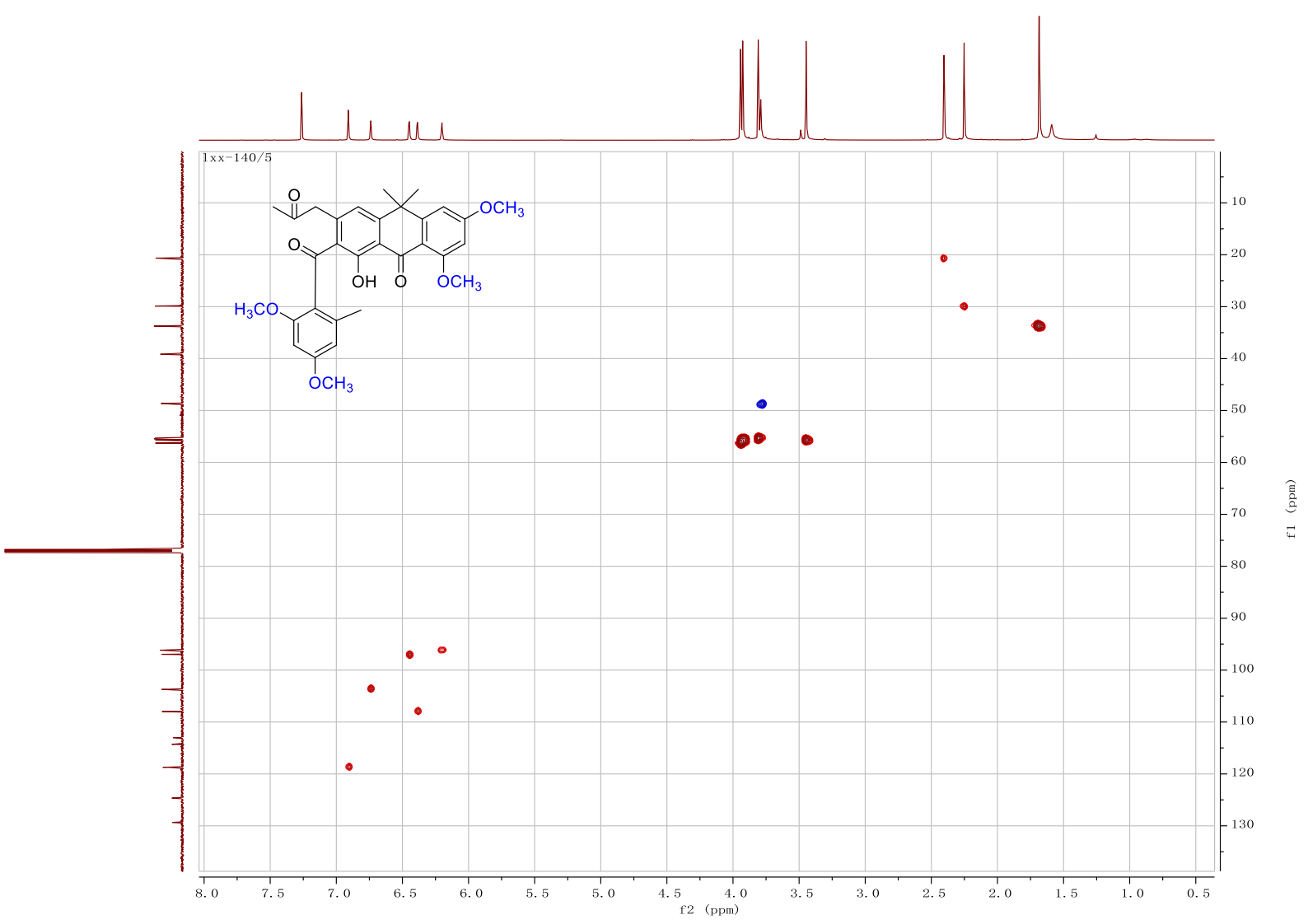

Figure S25. HSQC spectrum of $\mathbf{3}$ in $\mathrm{CDCl}_{3}$

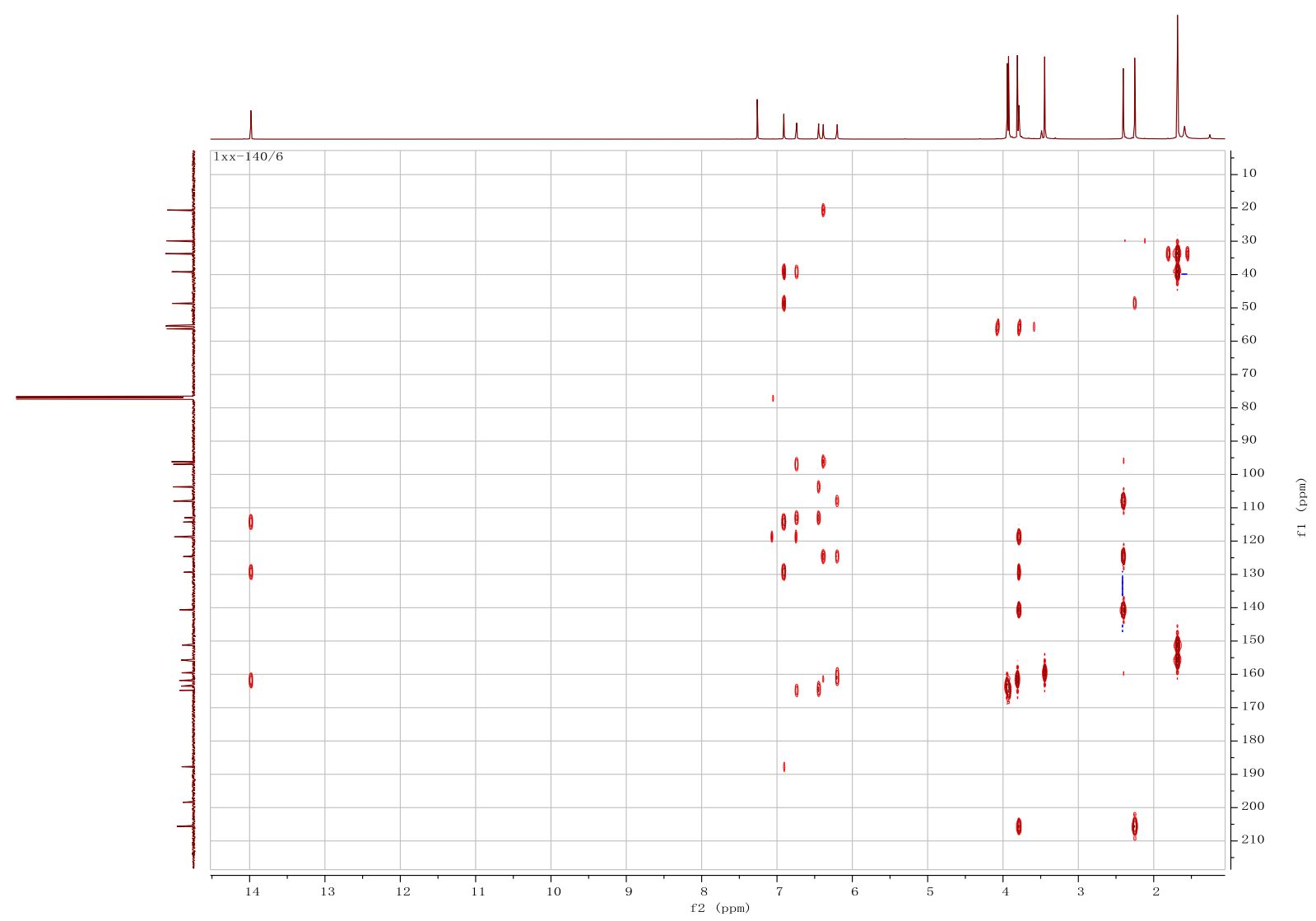

Figure S26. $\mathrm{HMBC}$ spectrum of $\mathbf{3}$ in $\mathrm{CDCl}_{3}$ 


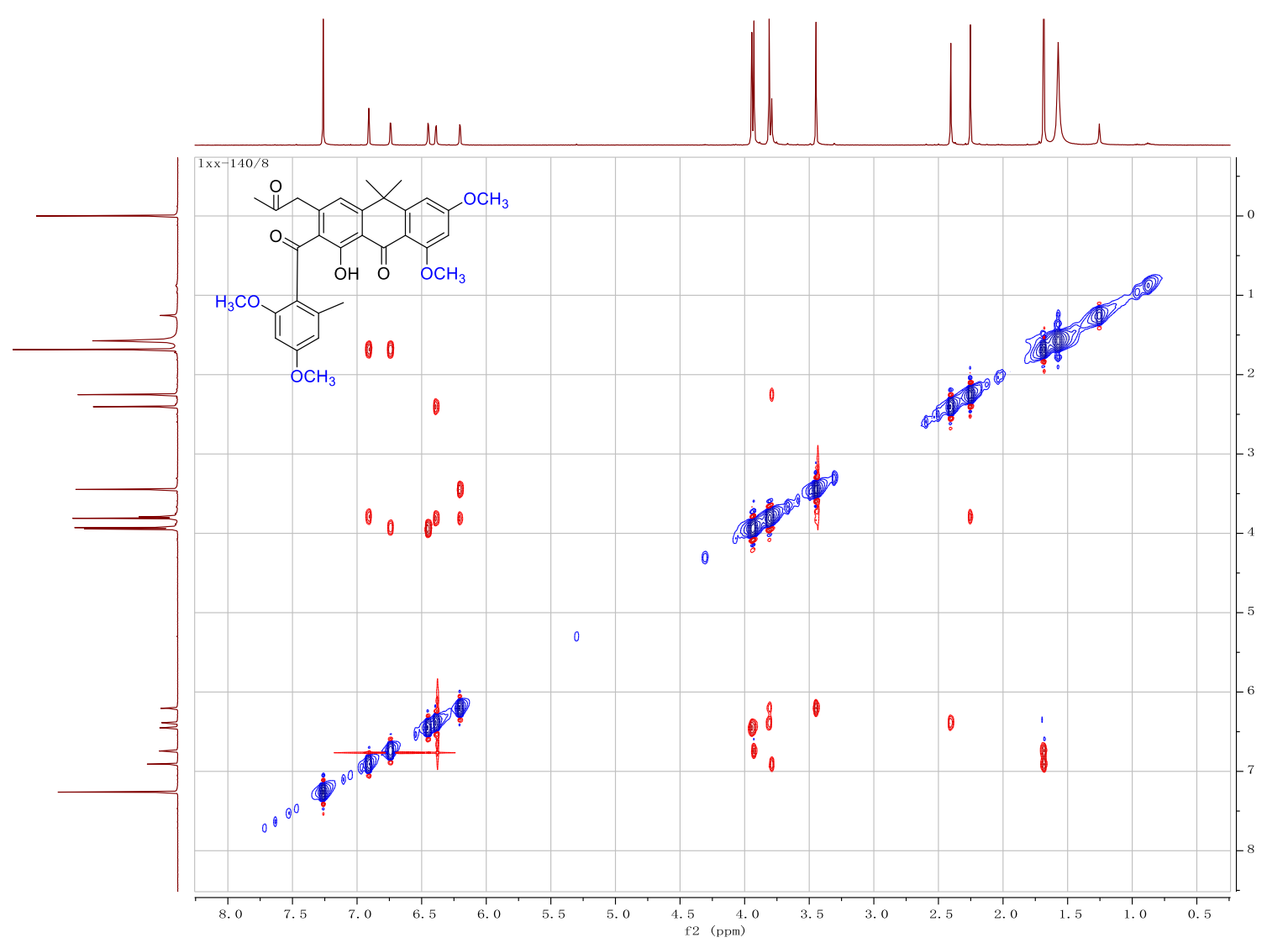

Figure S27. NOESY spectrum of $\mathbf{3}$ in $\mathrm{CDCl}_{3}$

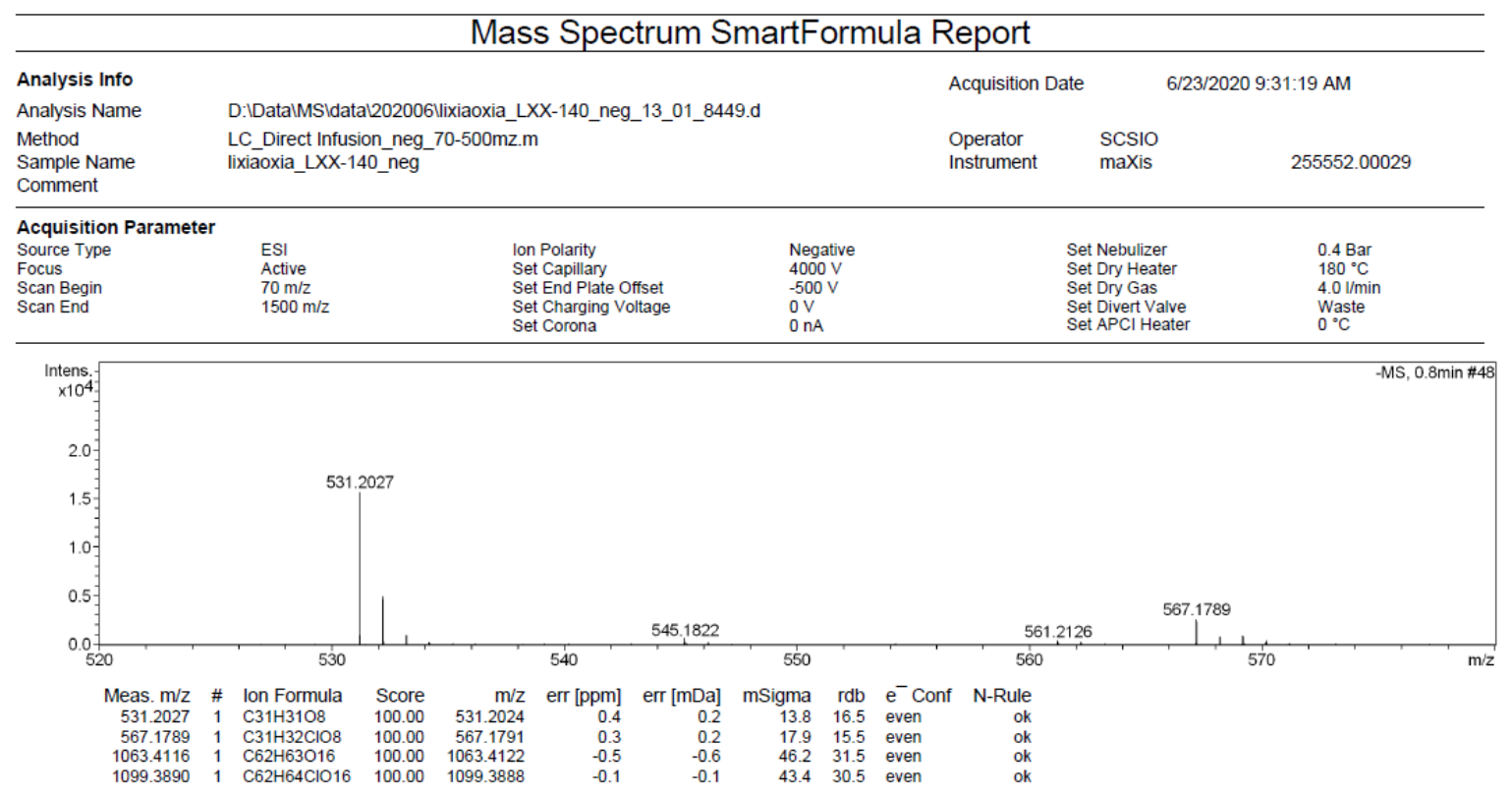

Figure S28. HR-ESI(-)MS of 3 


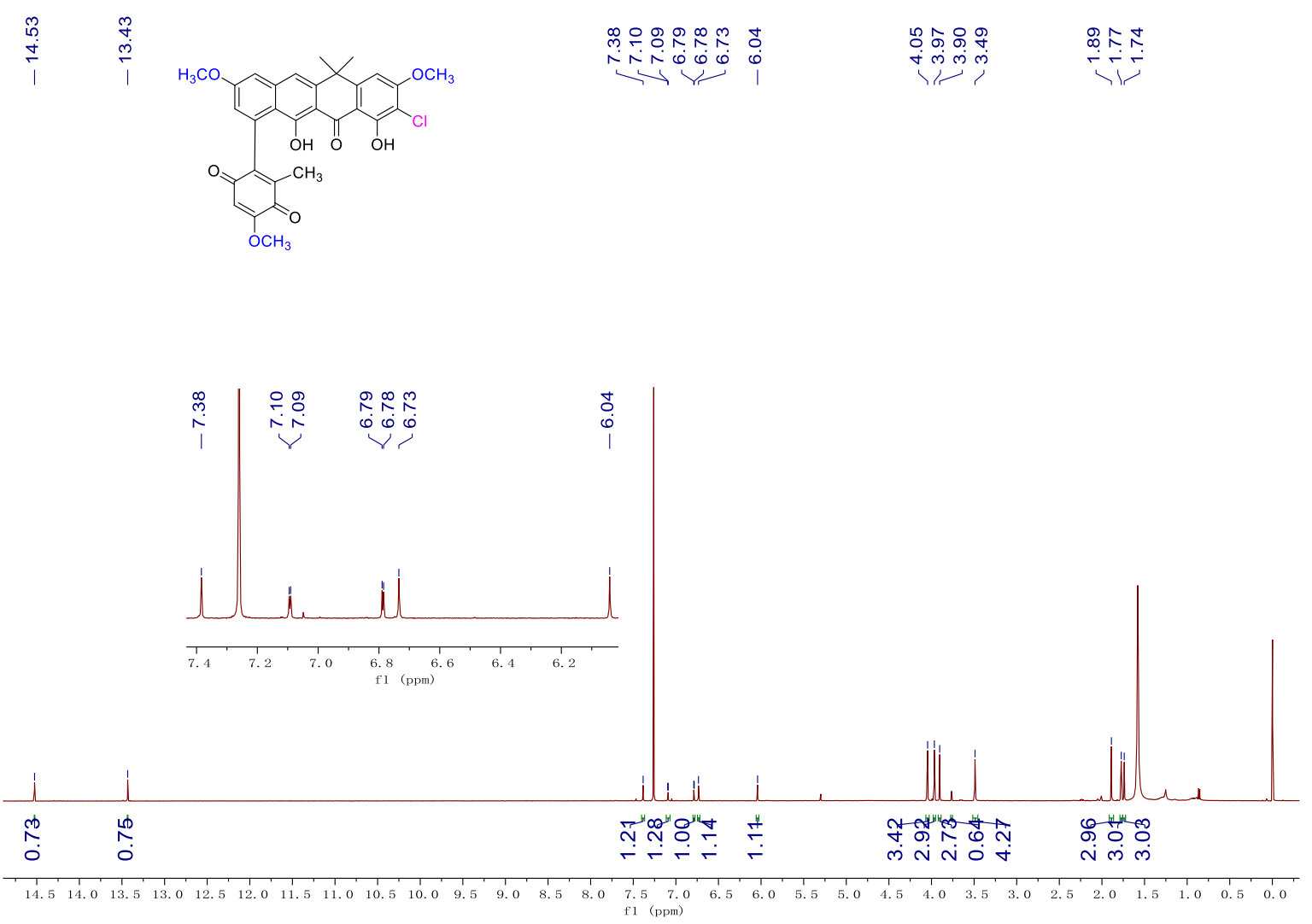

Figure S29. ${ }^{1} \mathrm{H}$ NMR $(500 \mathrm{MHz})$ spectrum of 4 in $\mathrm{CDCl}_{3}$
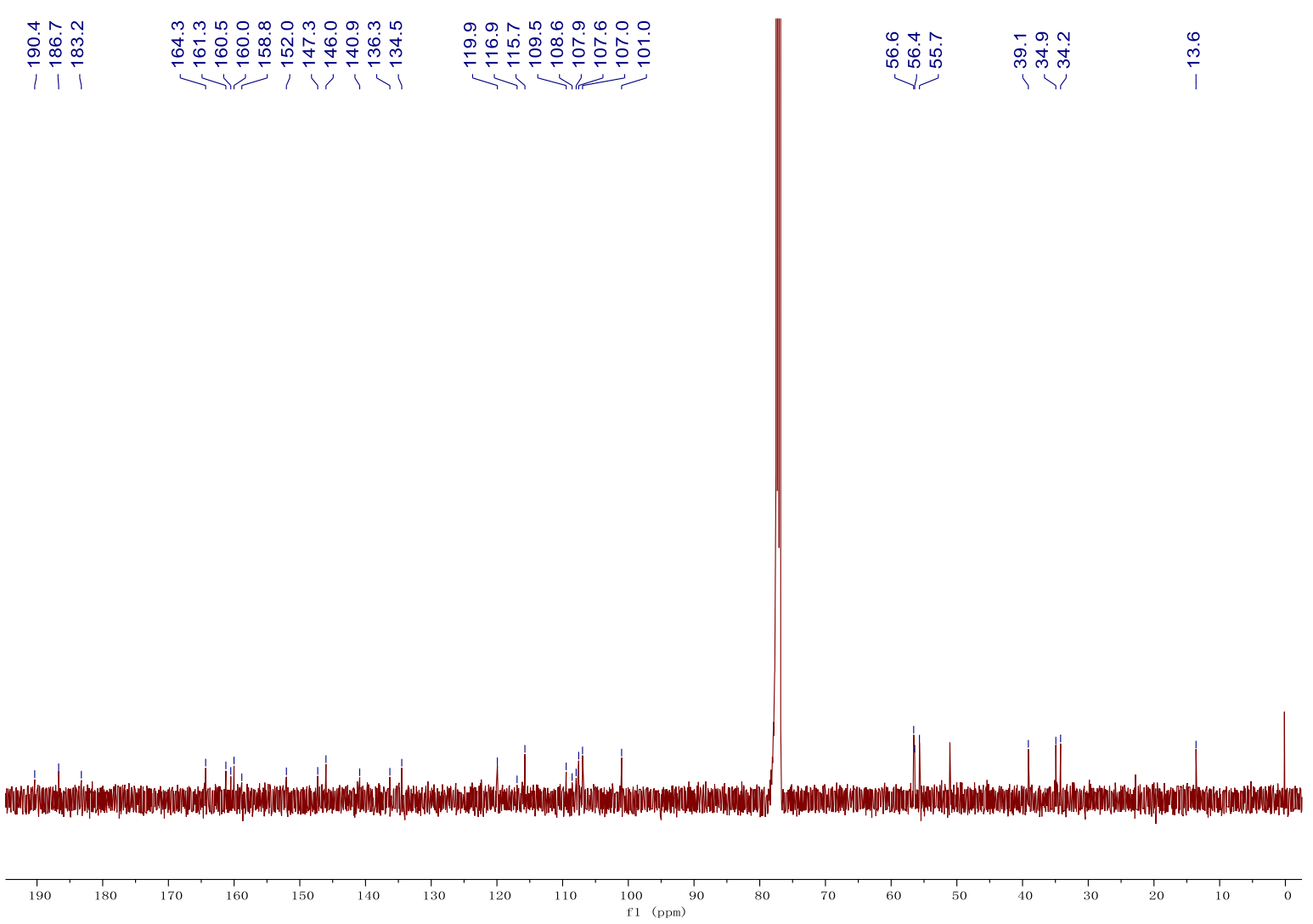

Figure S30. ${ }^{13} \mathrm{C}$ NMR (125 MHz) spectrum of 4 in $\mathrm{CDCl}_{3}$ 


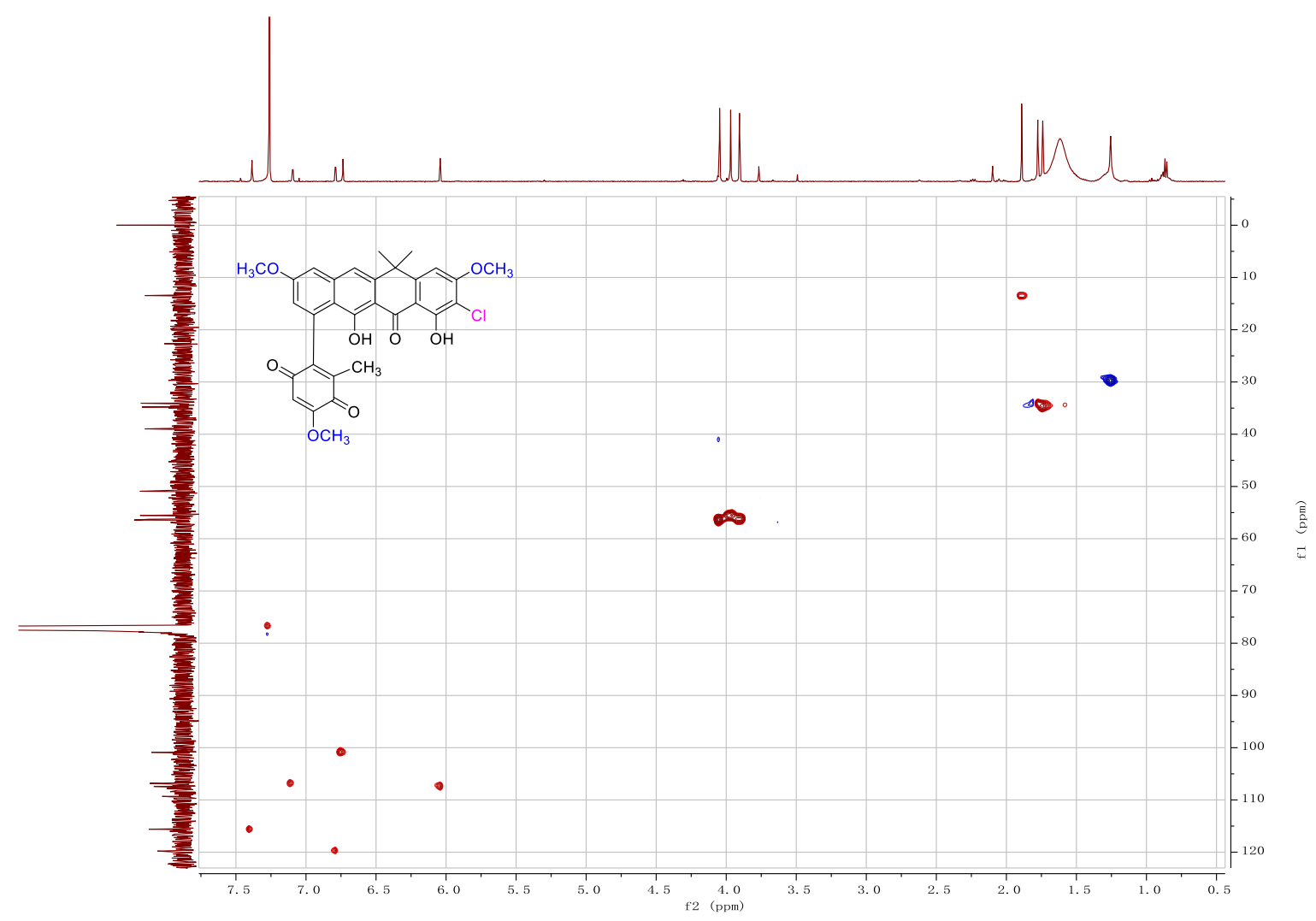

Figure S31. HSQC spectrum of $\mathbf{4}$ in $\mathrm{CDCl}_{3}$

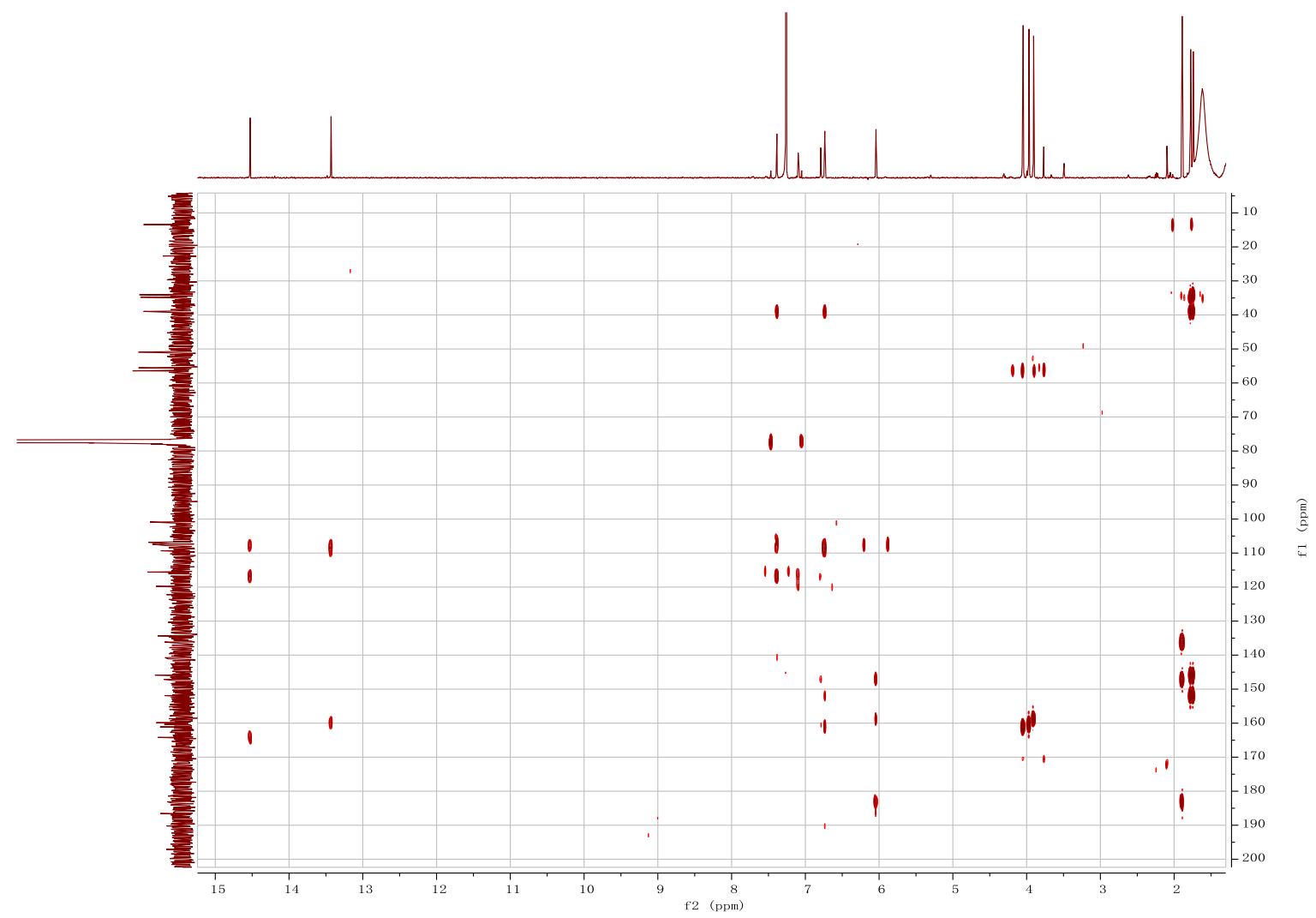

Figure S32. $\mathrm{HMBC}$ spectrum of $\mathbf{4}$ in $\mathrm{CDCl}_{3}$ 


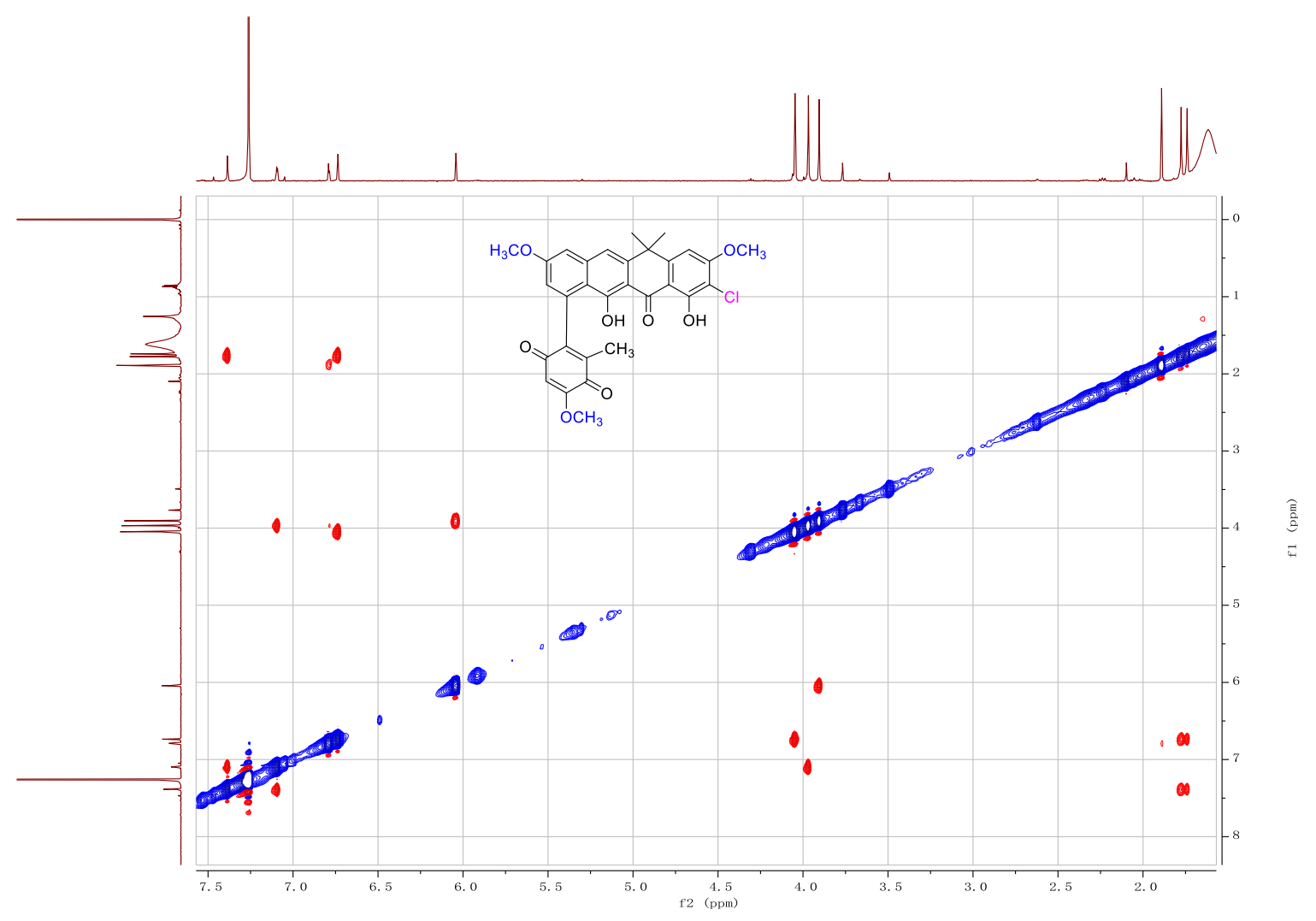

Figure S33. NOESY spectrum of 4 in $\mathrm{CDCl}_{3}$

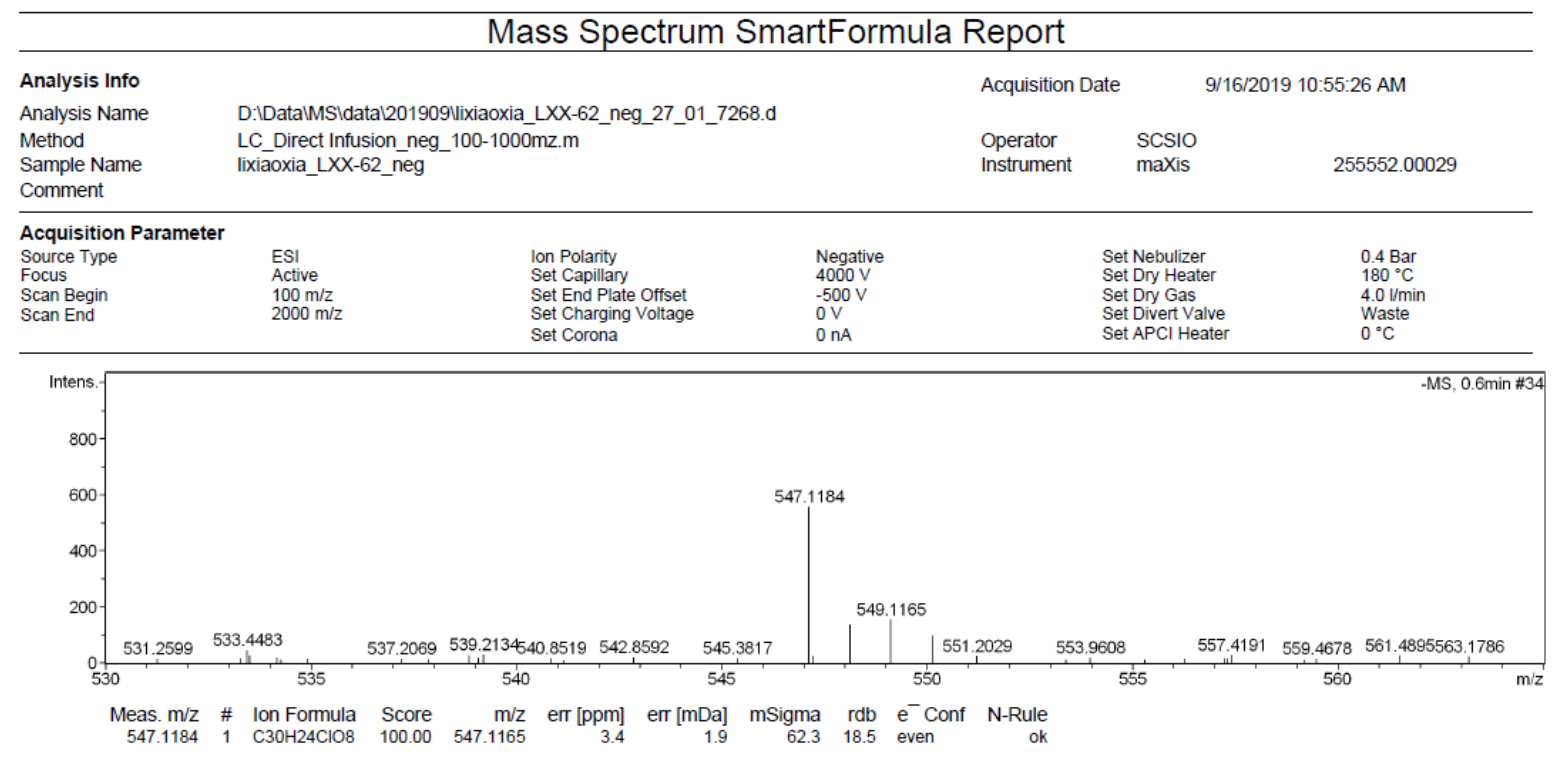

Figure S34. HR-ESI(-)MS of 4 


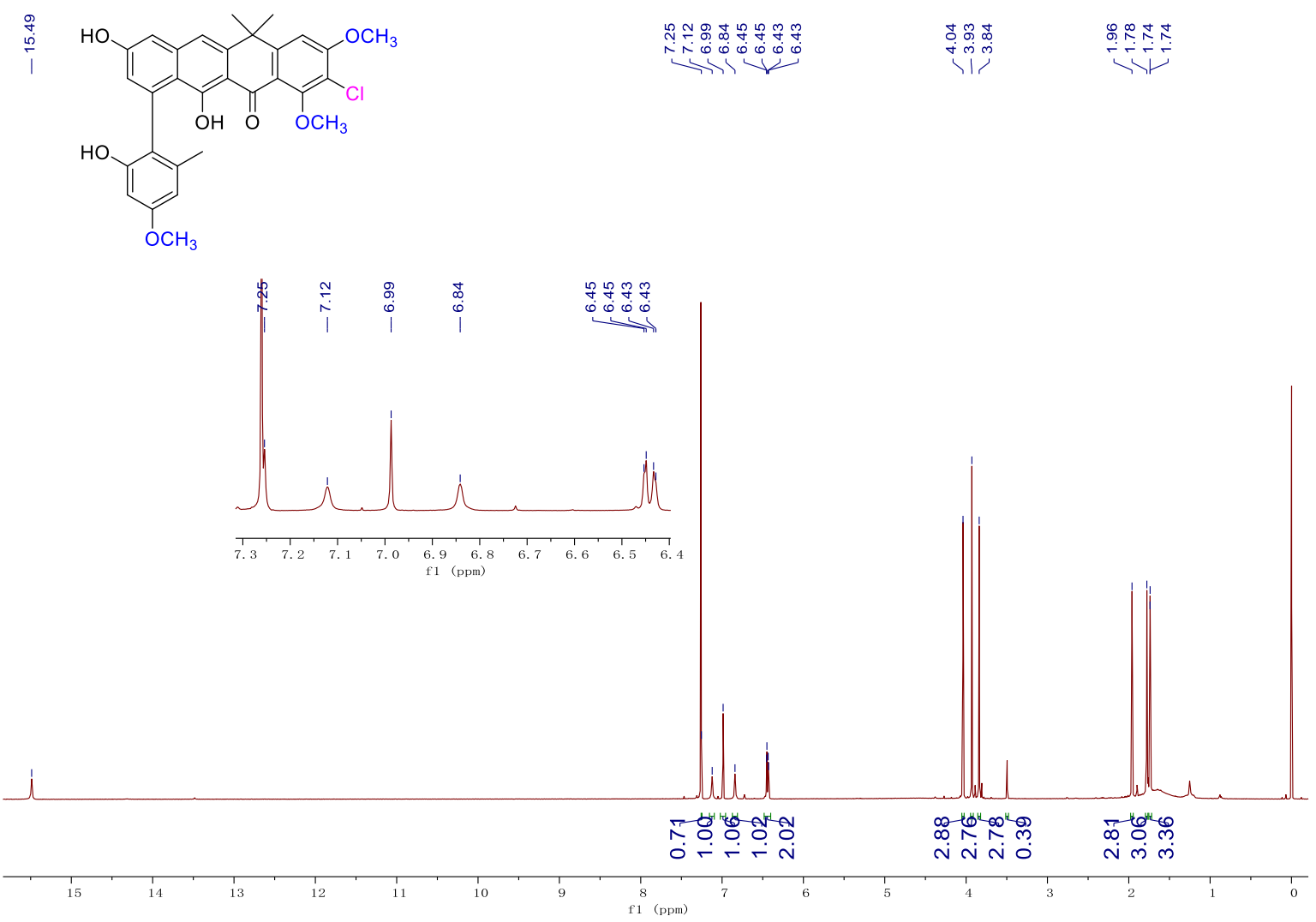

Figure S35. ${ }^{1} \mathrm{H}$ NMR (500 MHz) spectrum of 5 in $\mathrm{CDCl}_{3}$

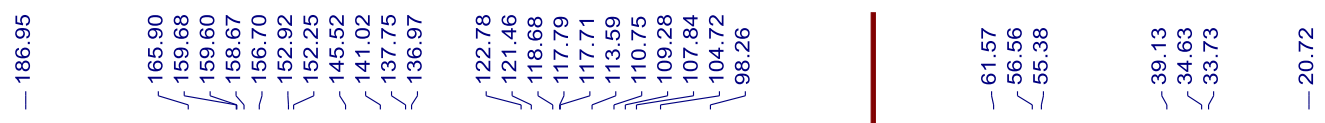
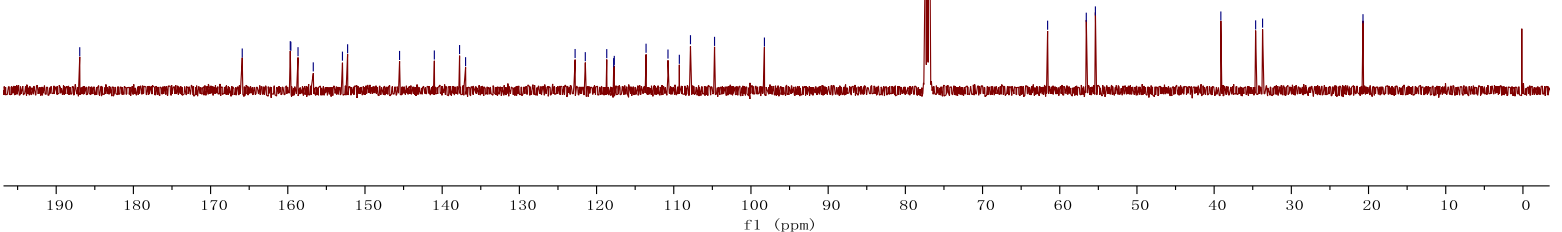

Figure S36. ${ }^{13} \mathrm{C}$ NMR (125 MHz) spectrum of 5 in $\mathrm{CDCl}_{3}$ 


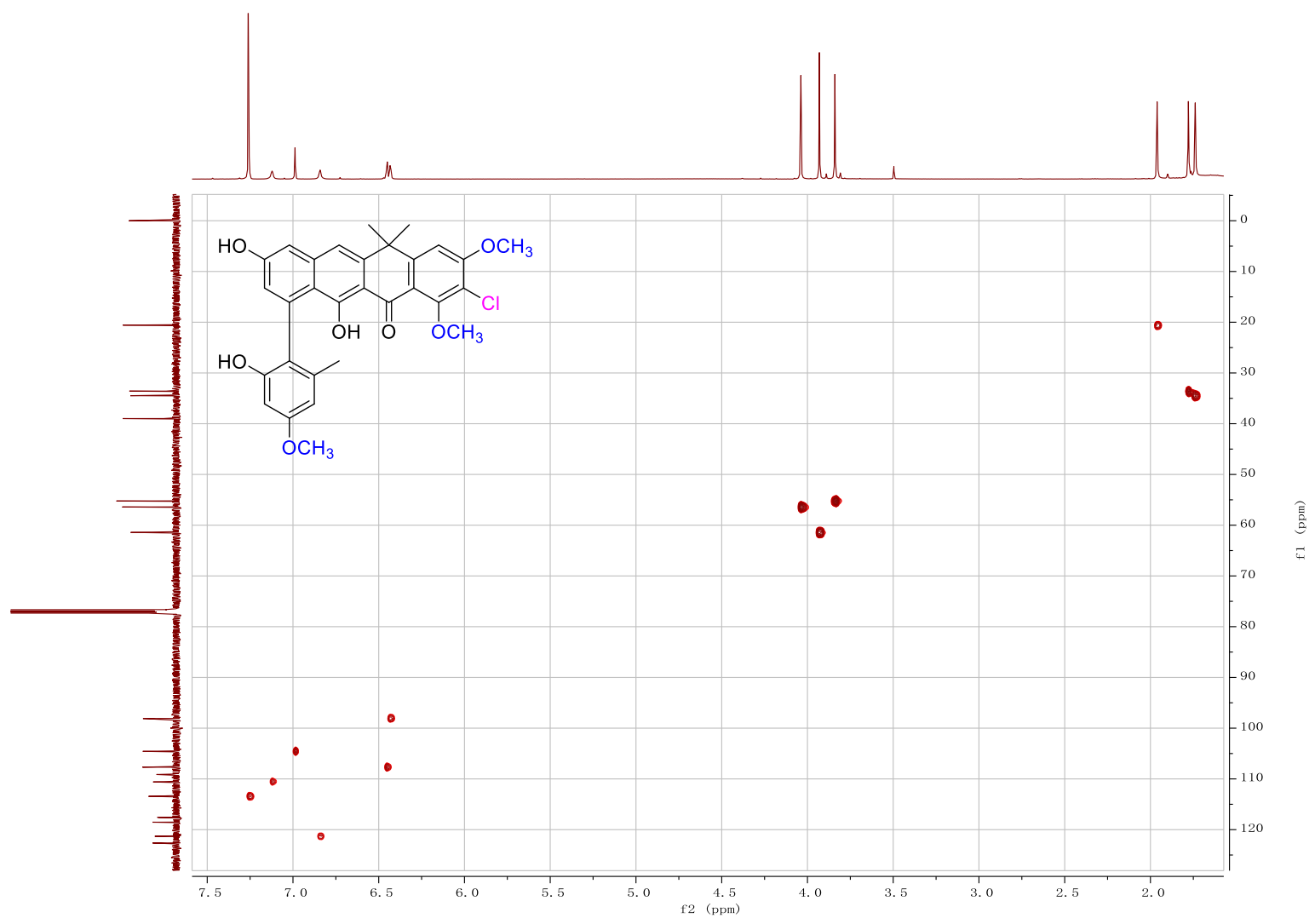

Figure S37. HSQC spectrum of 5 in $\mathrm{CDCl}_{3}$

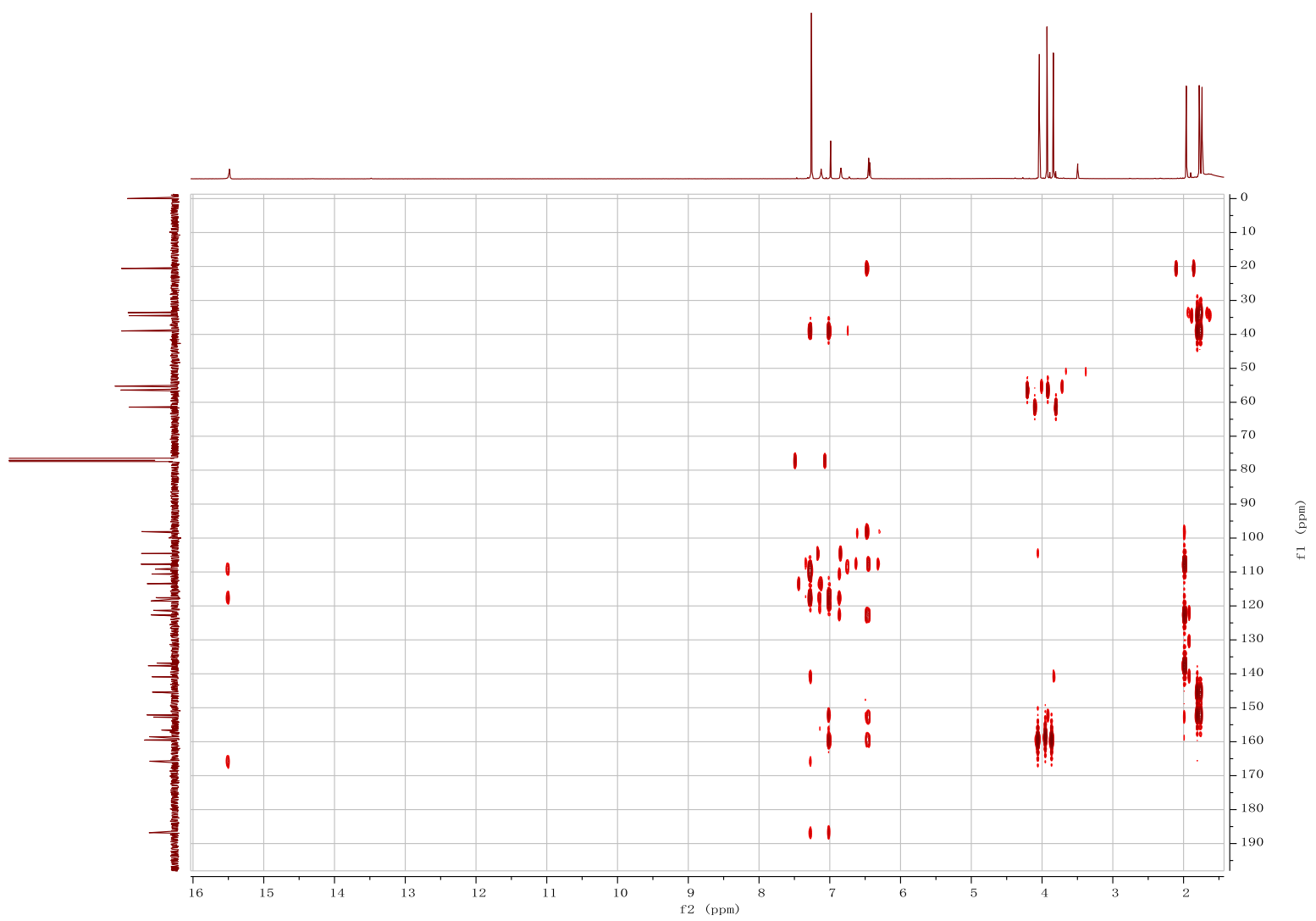

Figure S38. $\mathrm{HMBC}$ spectrum of 5 in $\mathrm{CDCl}_{3}$

22 


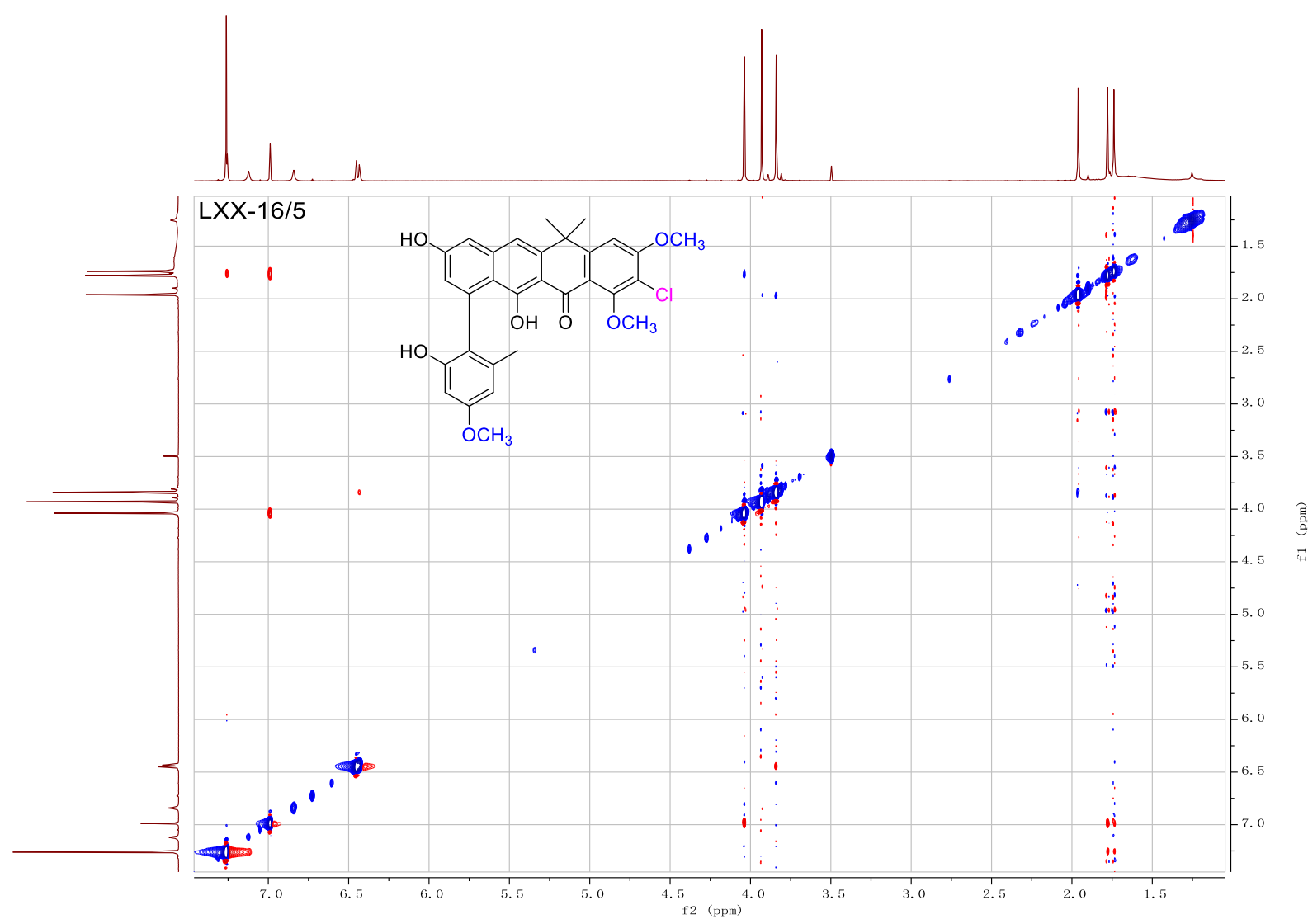

Figure S39. NOESY spectrum of 5 in $\mathrm{CDCl}_{3}$

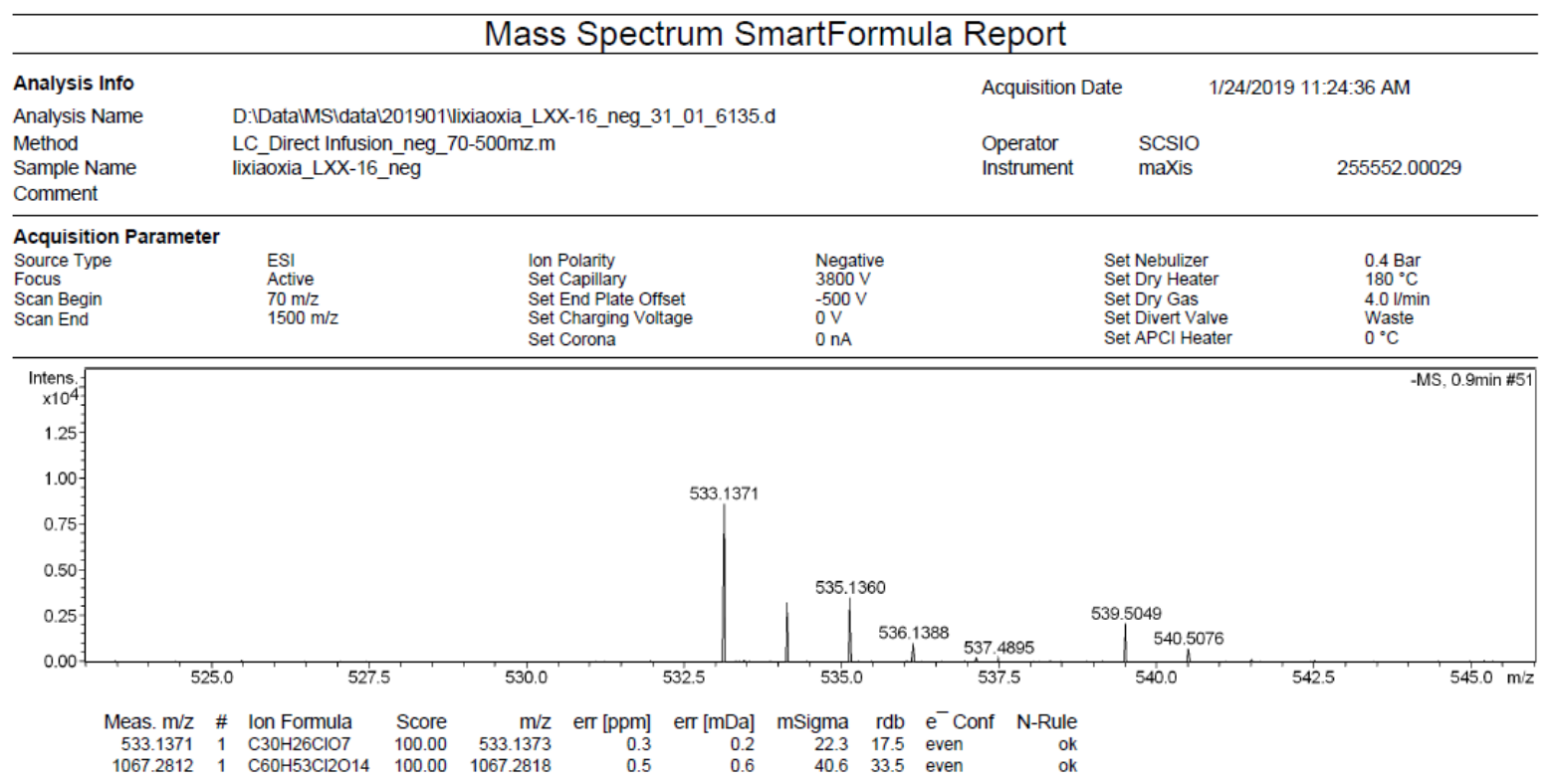

Figure S40. HR-ESI(-)MS of 5 

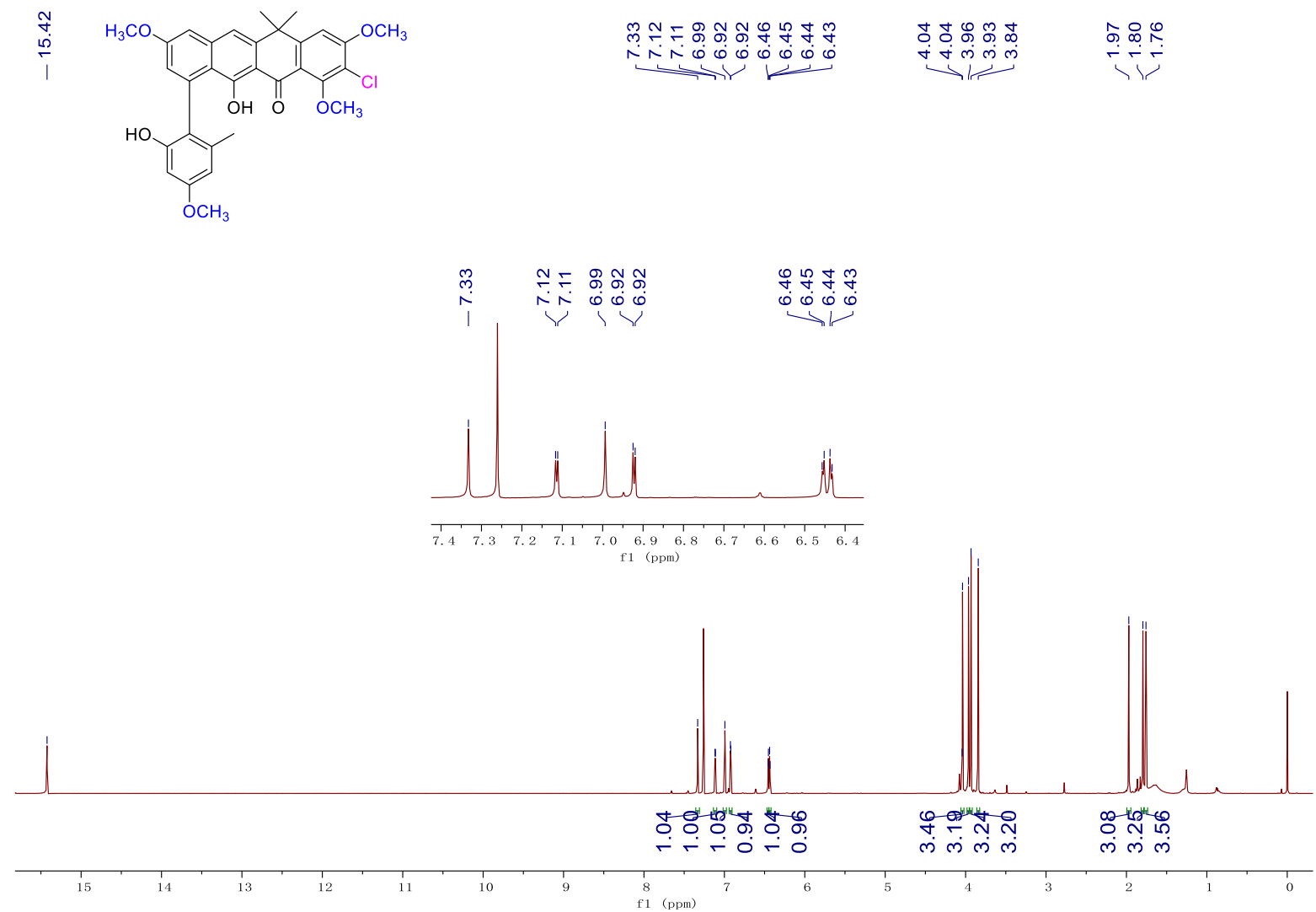

Figure S41. ${ }^{1} \mathrm{H}$ NMR $(500 \mathrm{MHz})$ spectrum of 6 in $\mathrm{CDCl}_{3}$

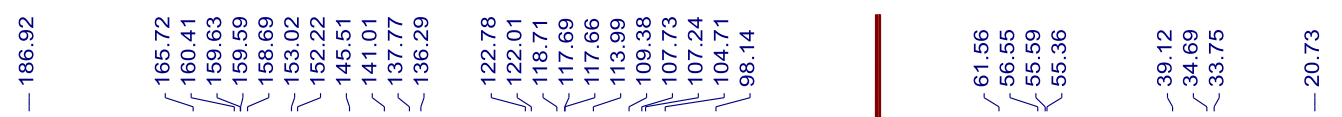

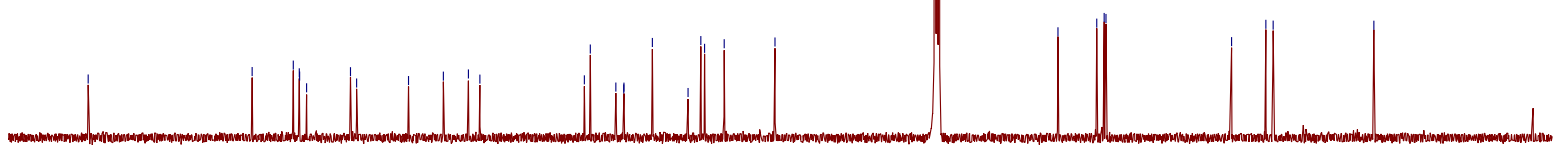

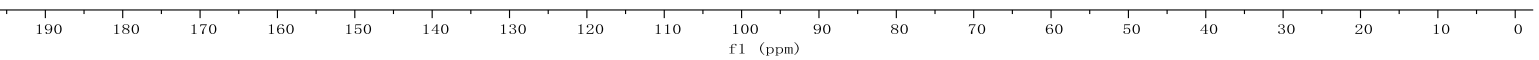

Figure S42. ${ }^{13} \mathrm{C}$ NMR $(125 \mathrm{MHz})$ spectrum of 6 in $\mathrm{CDCl}_{3}$ 


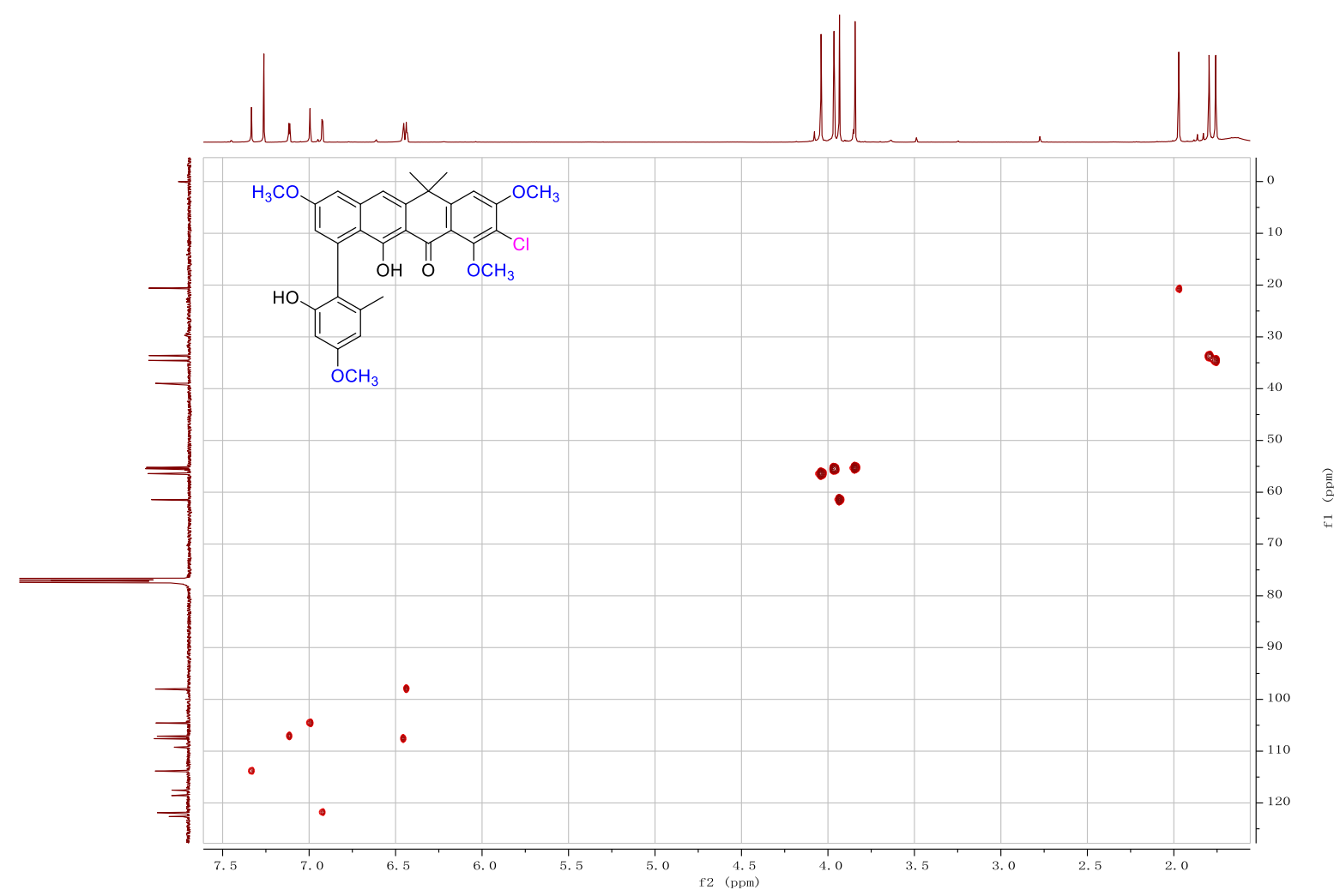

Figure S43. HSQC spectrum of 6 in $\mathrm{CDCl}_{3}$

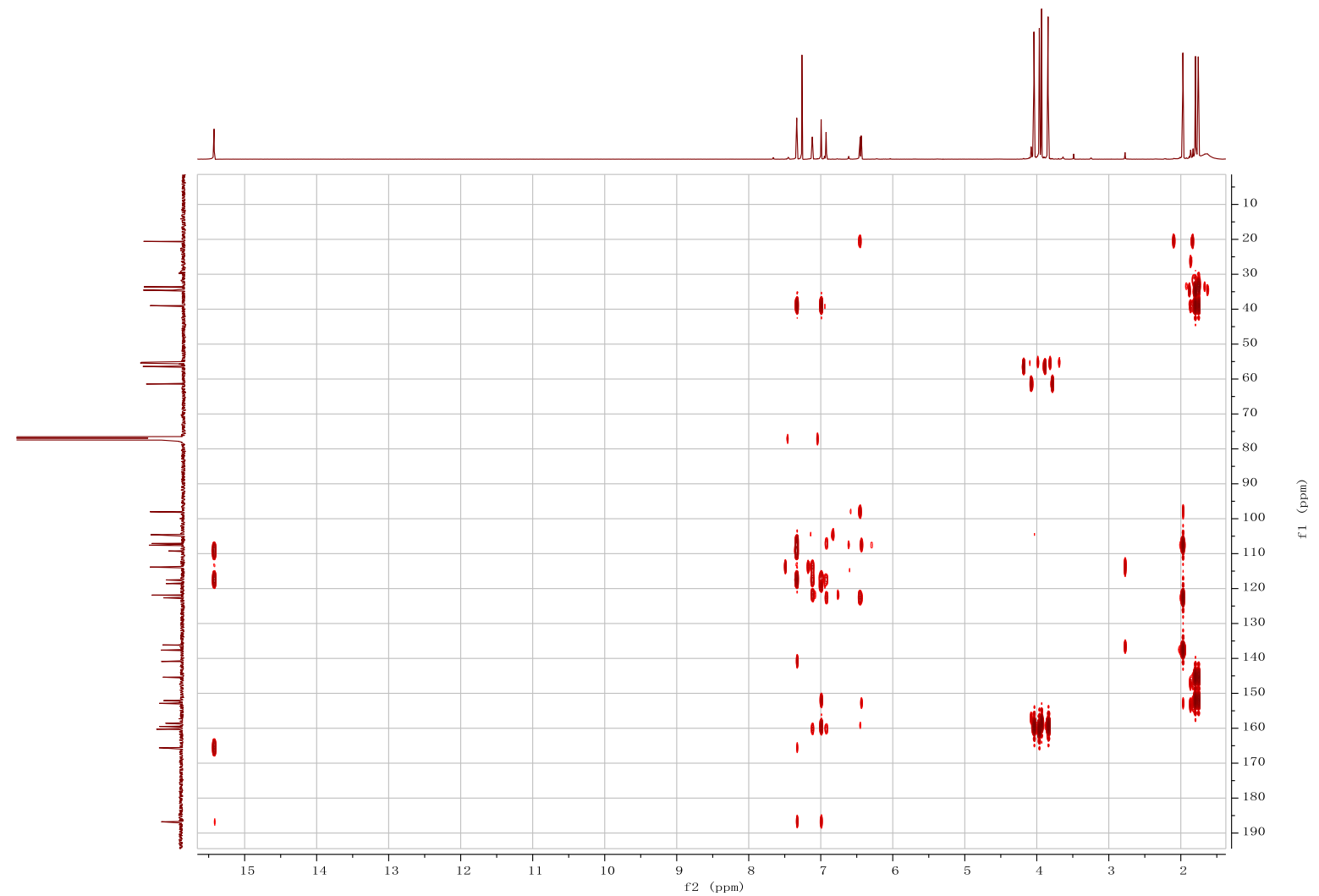

Figure S44. $\mathrm{HMBC}$ spectrum of 6 in $\mathrm{CDCl}_{3}$ 


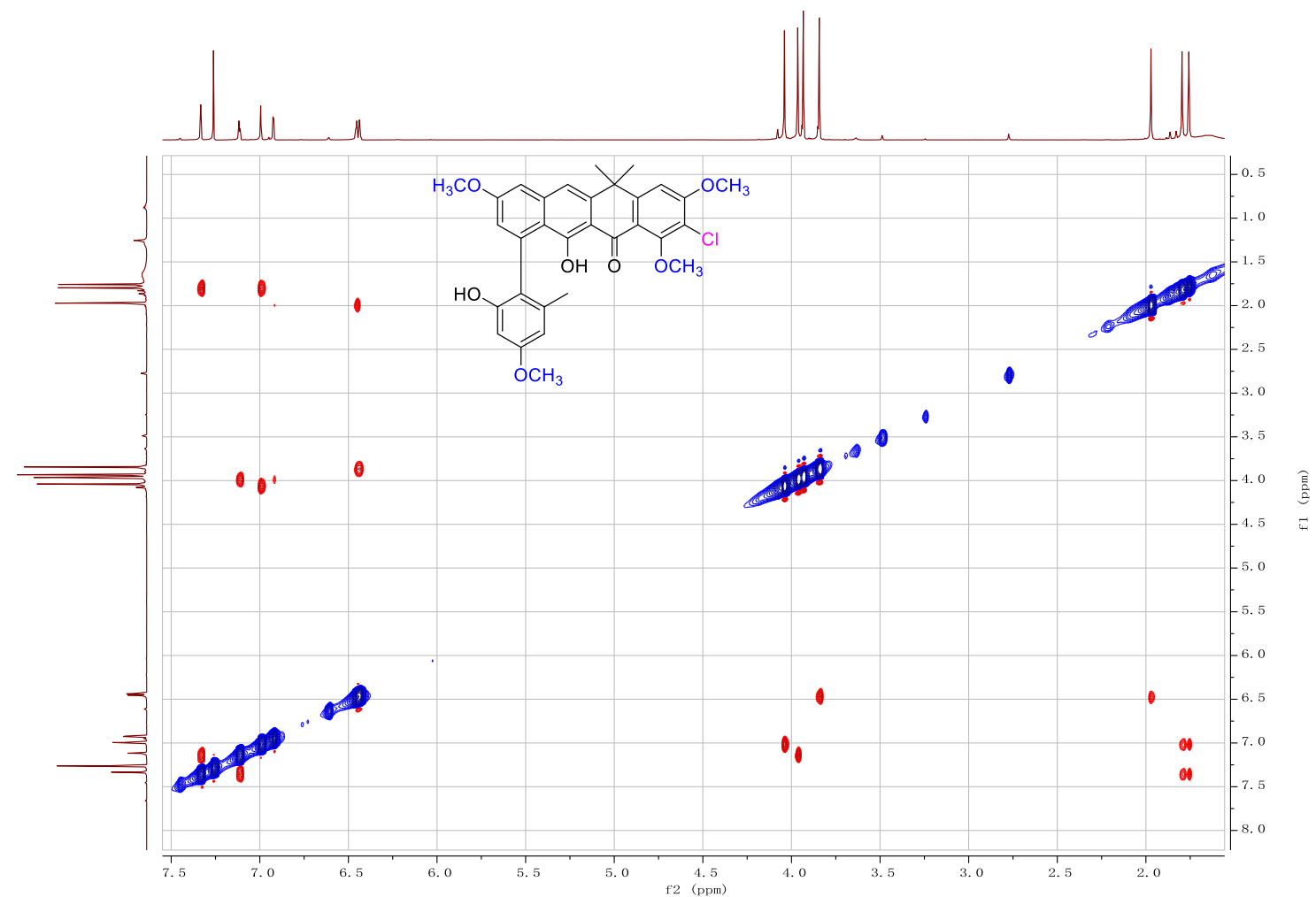

Figure S45. NOESY spectrum of 6 in $\mathrm{CDCl}_{3}$

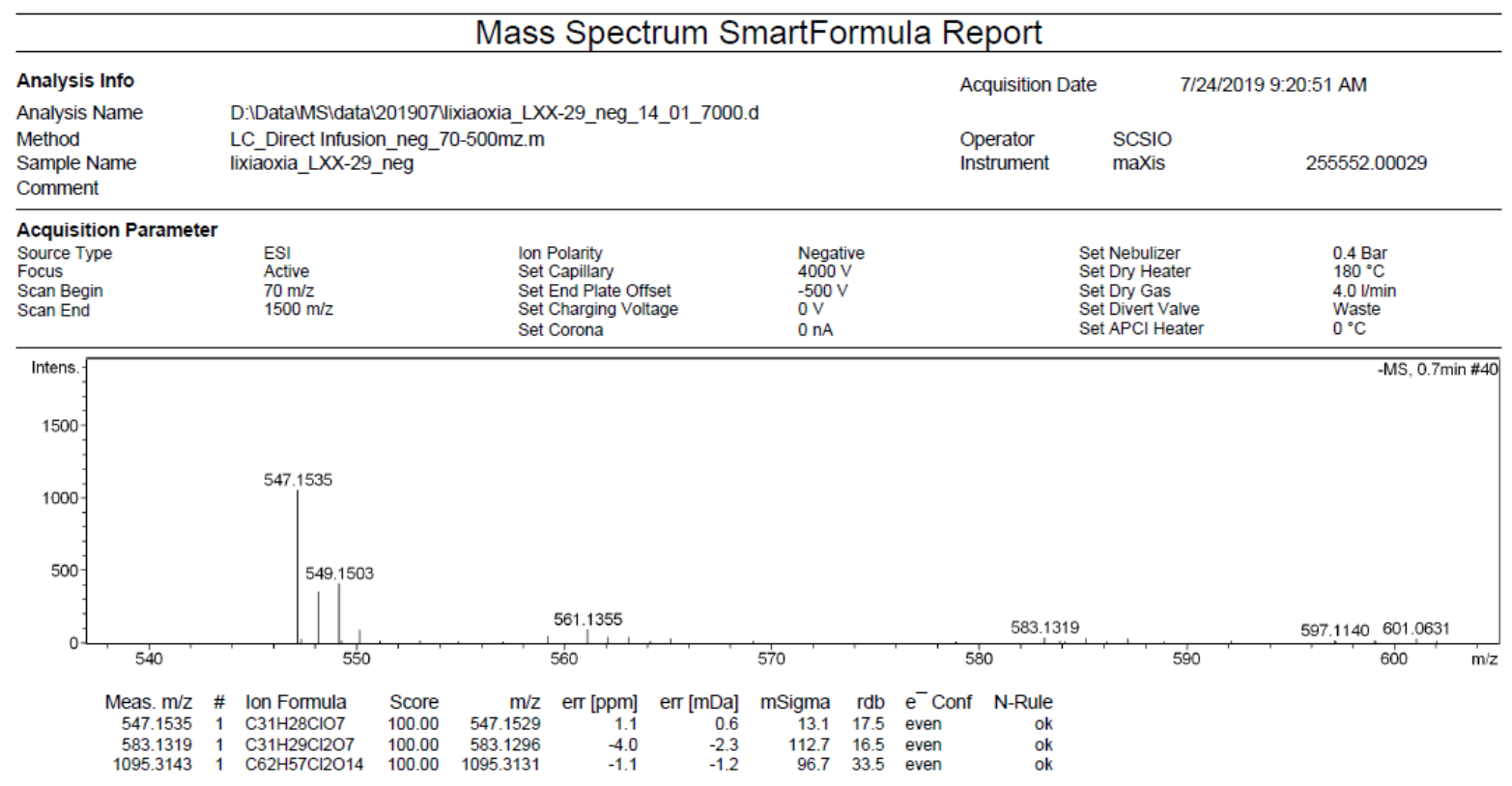

Figure S46. HR-ESI(-)MS of 6 


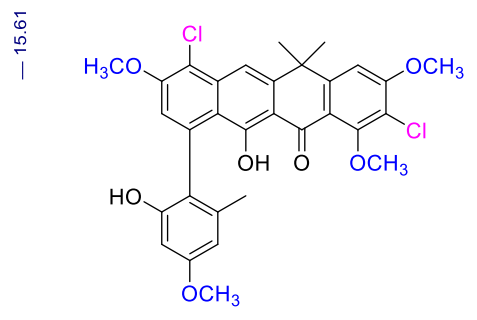

至
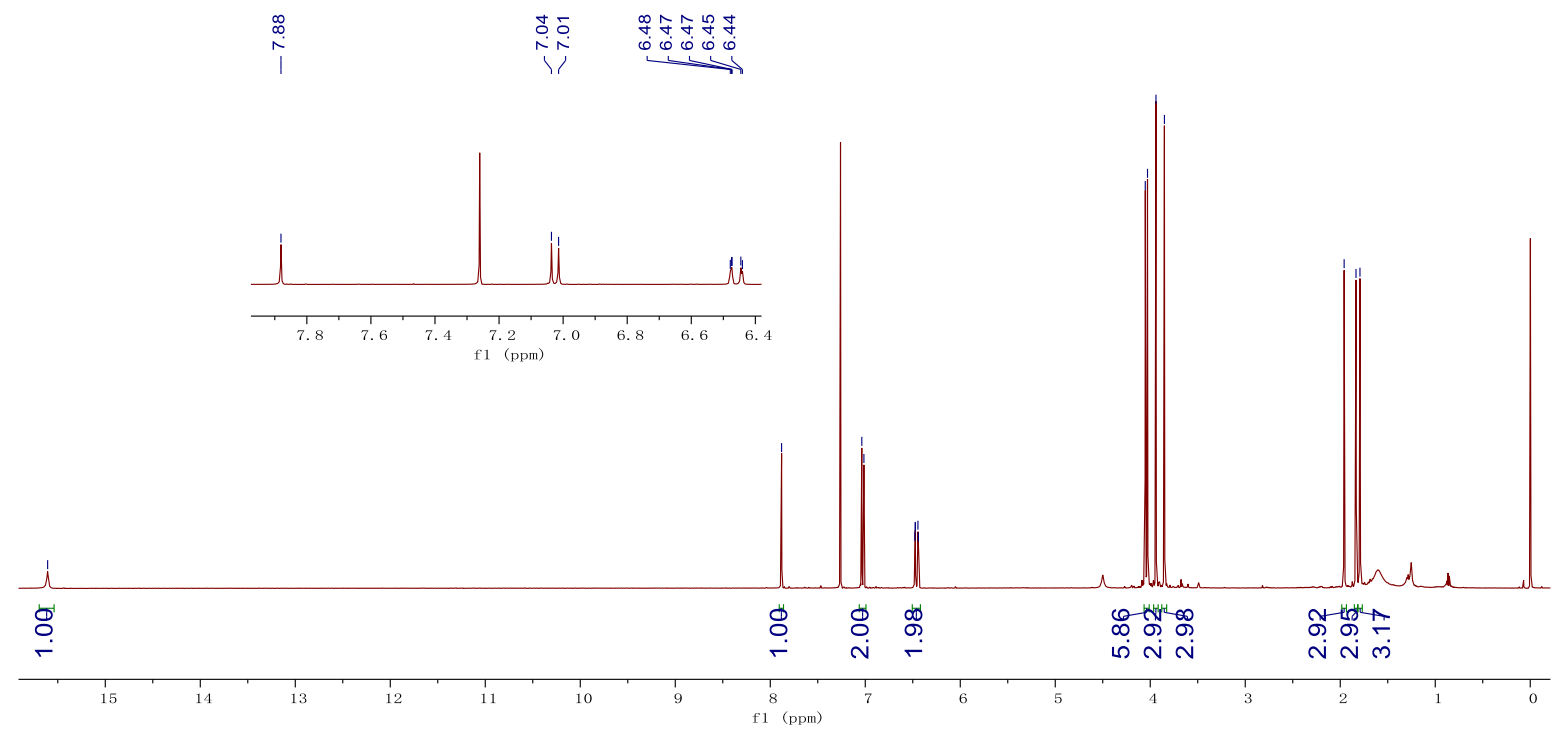

Figure S47. ${ }^{1} \mathrm{H}$ NMR $(500 \mathrm{MHz})$ spectrum of 7 in $\mathrm{CDCl}_{3}$

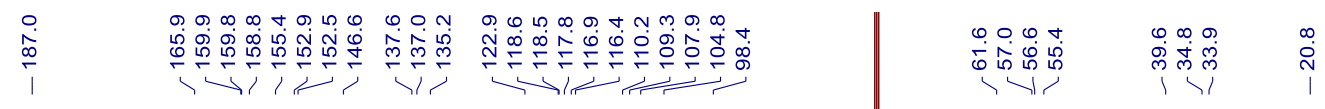

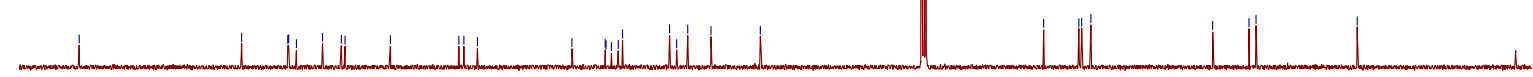

Figure S48. ${ }^{13} \mathrm{C}$ NMR (125 MHz) spectrum of 7 in $\mathrm{CDCl}_{3}$ 


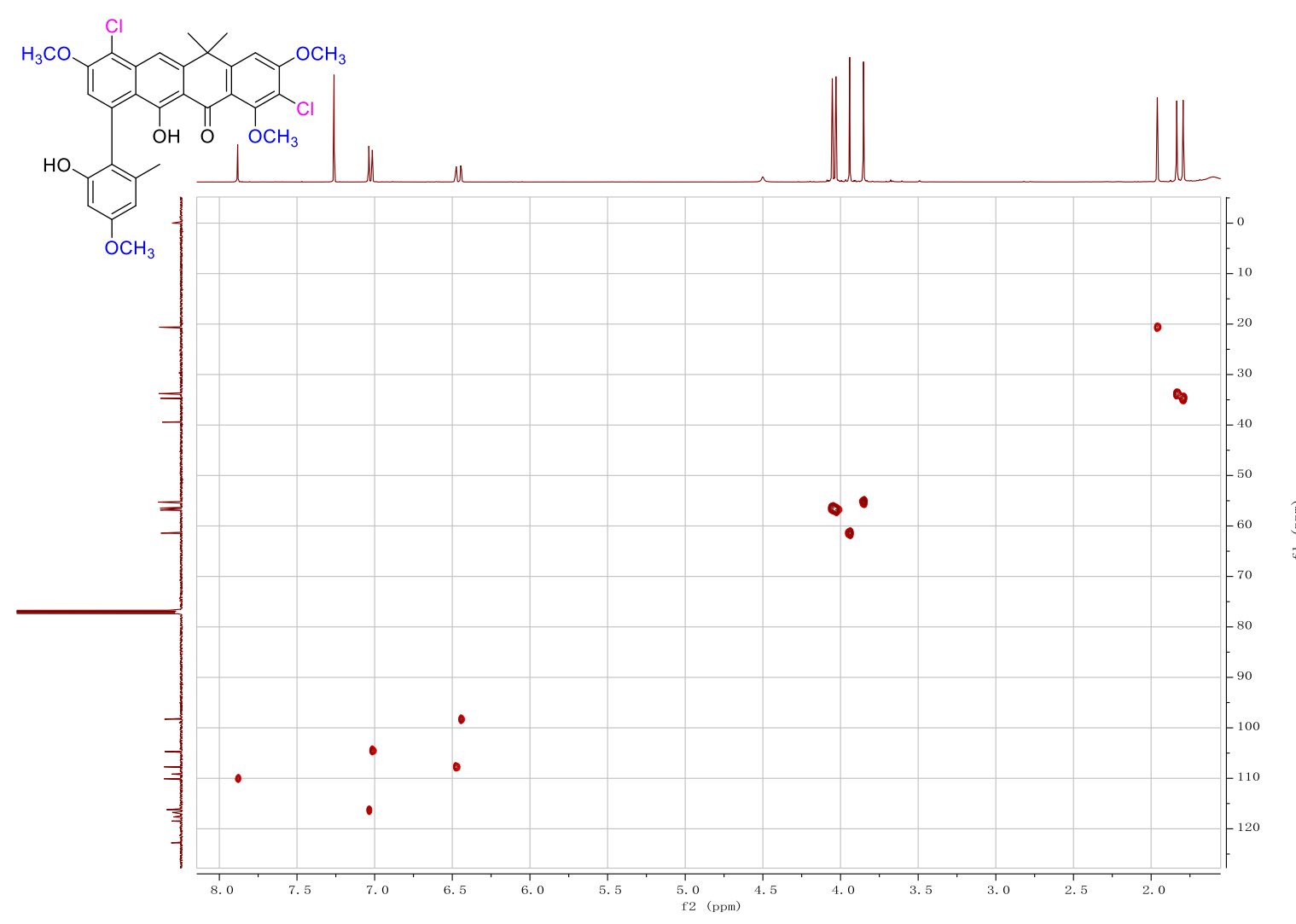

Figure S49. HSQC spectrum of 7 in $\mathrm{CDCl}_{3}$

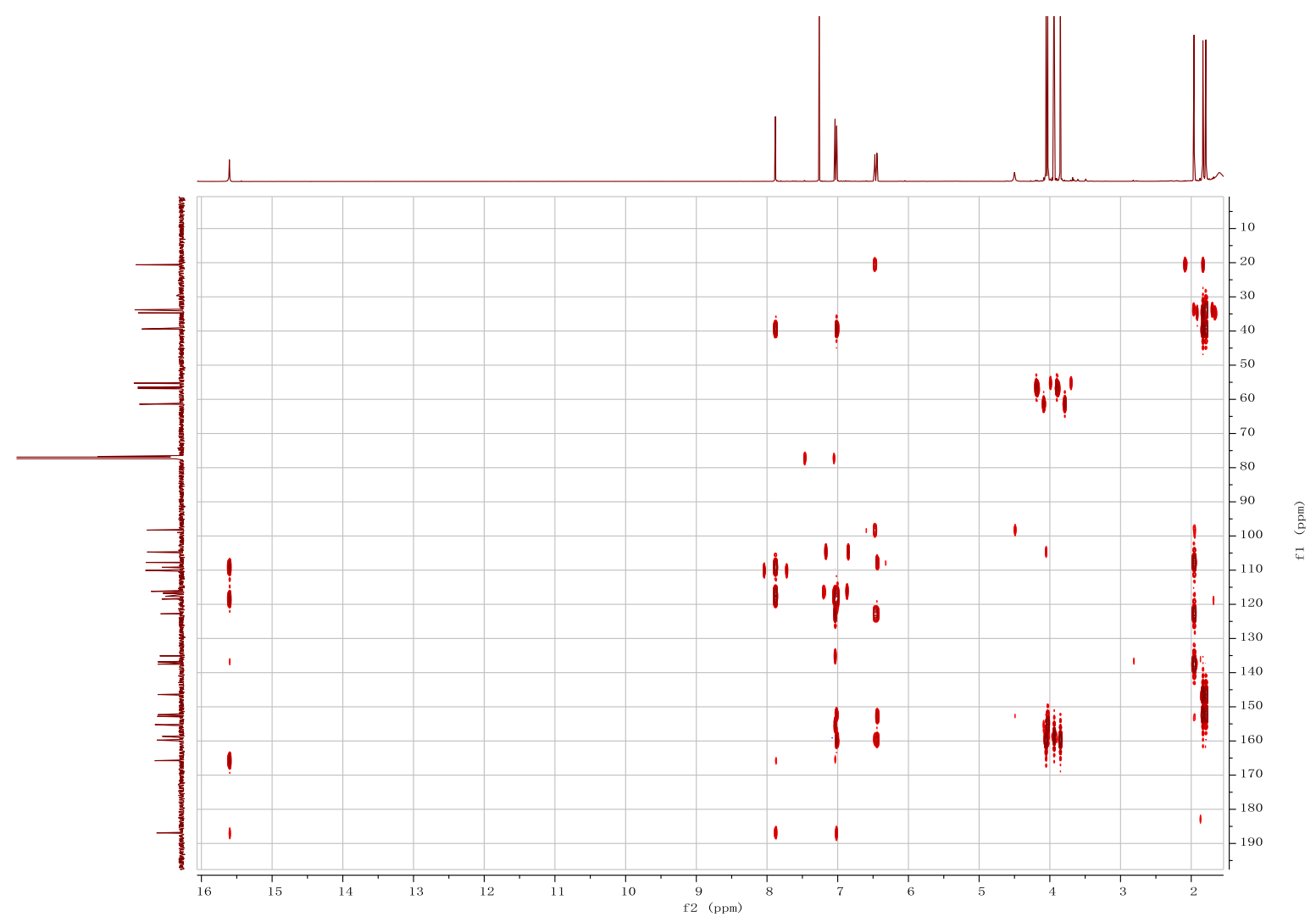

Figure S50. $\mathrm{HMBC}$ spectrum of 7 in $\mathrm{CDCl}_{3}$ 


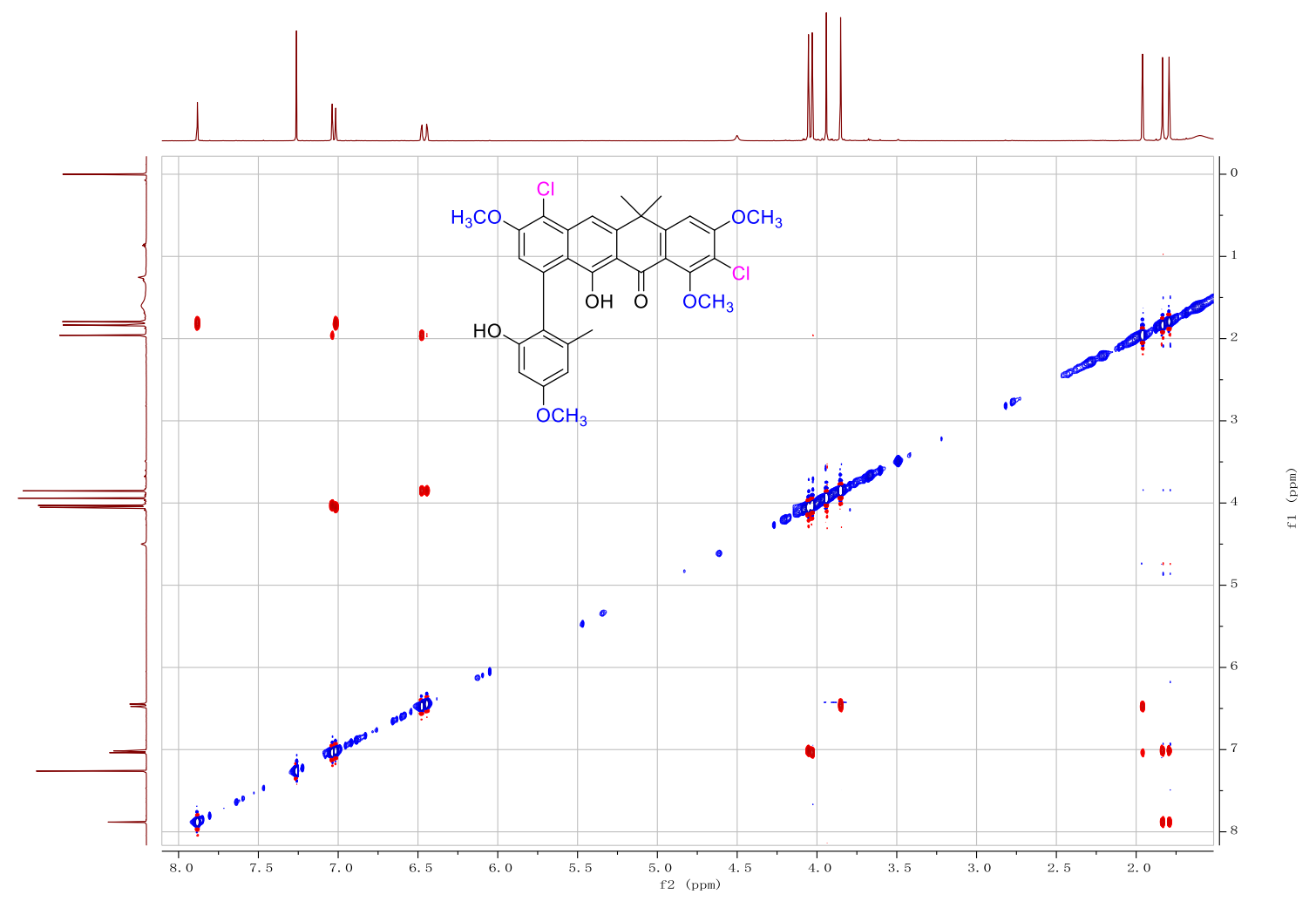

Figure S51. NOESY spectrum of 7 in $\mathrm{CDCl}_{3}$

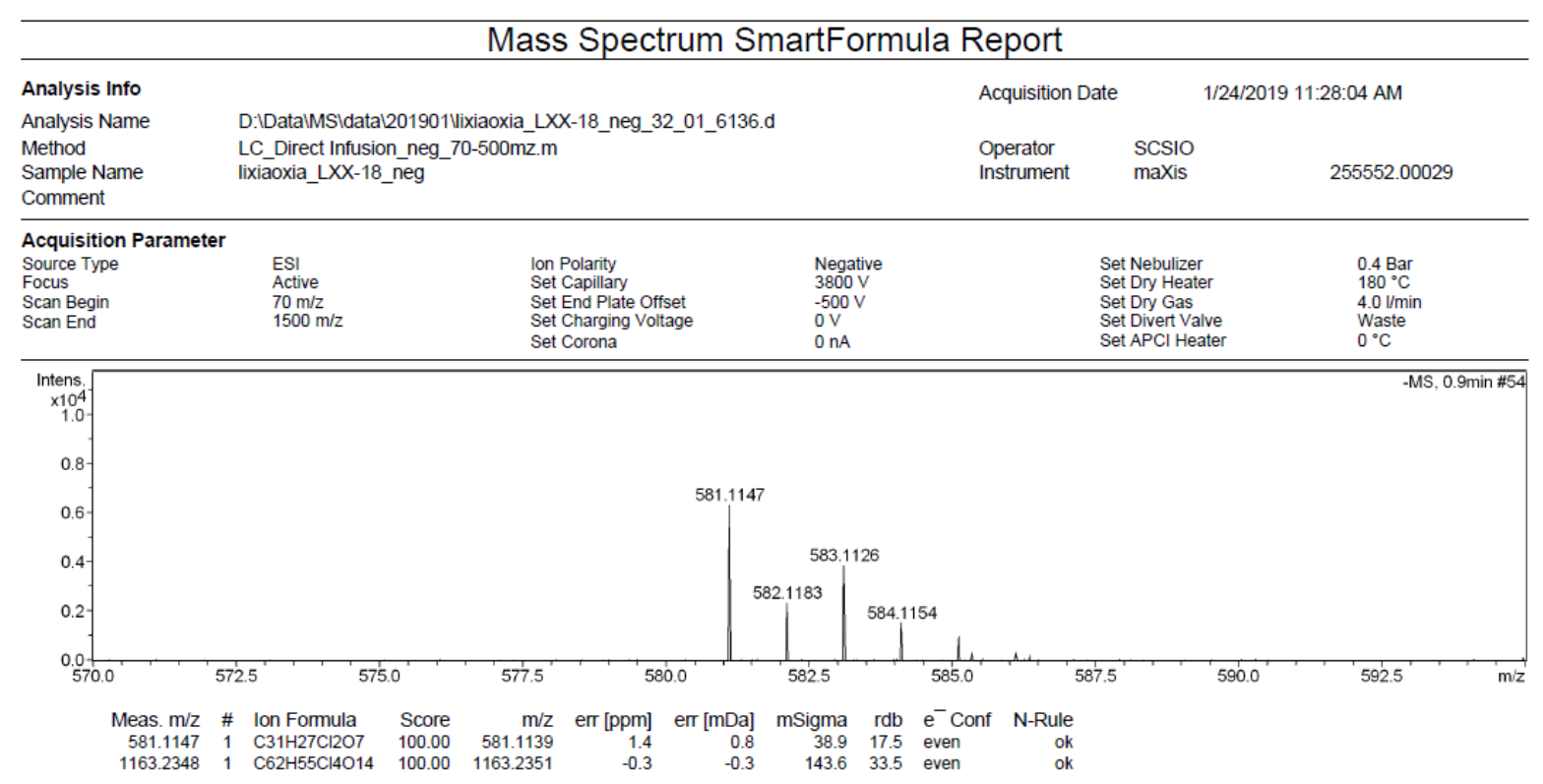

Figure S52. HR-ESI(-)MS of 7 


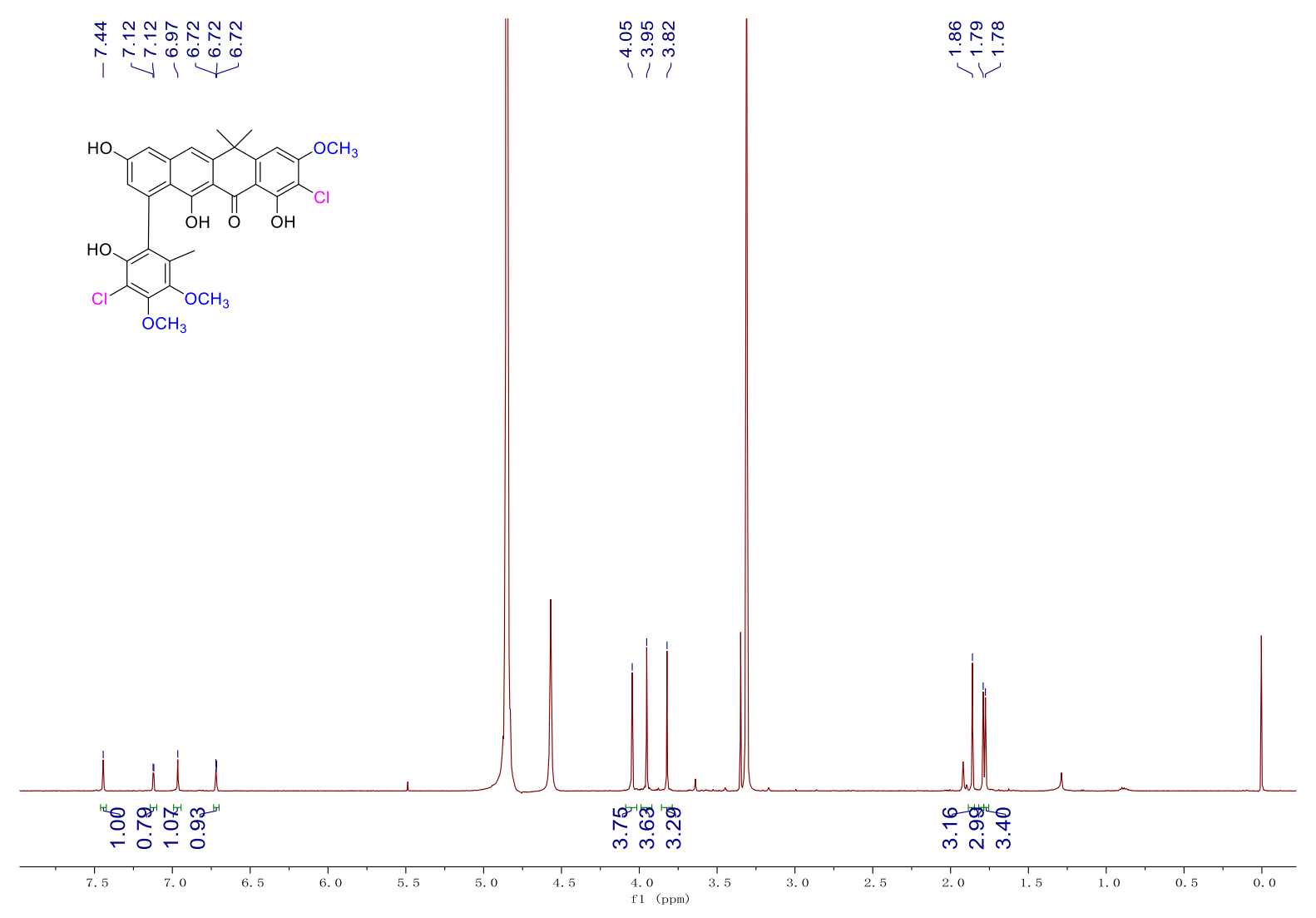

Figure S53. ${ }^{1} \mathrm{H}$ NMR $(500 \mathrm{MHz})$ spectrum of 8 in $\mathrm{CD}_{3} \mathrm{OD}$
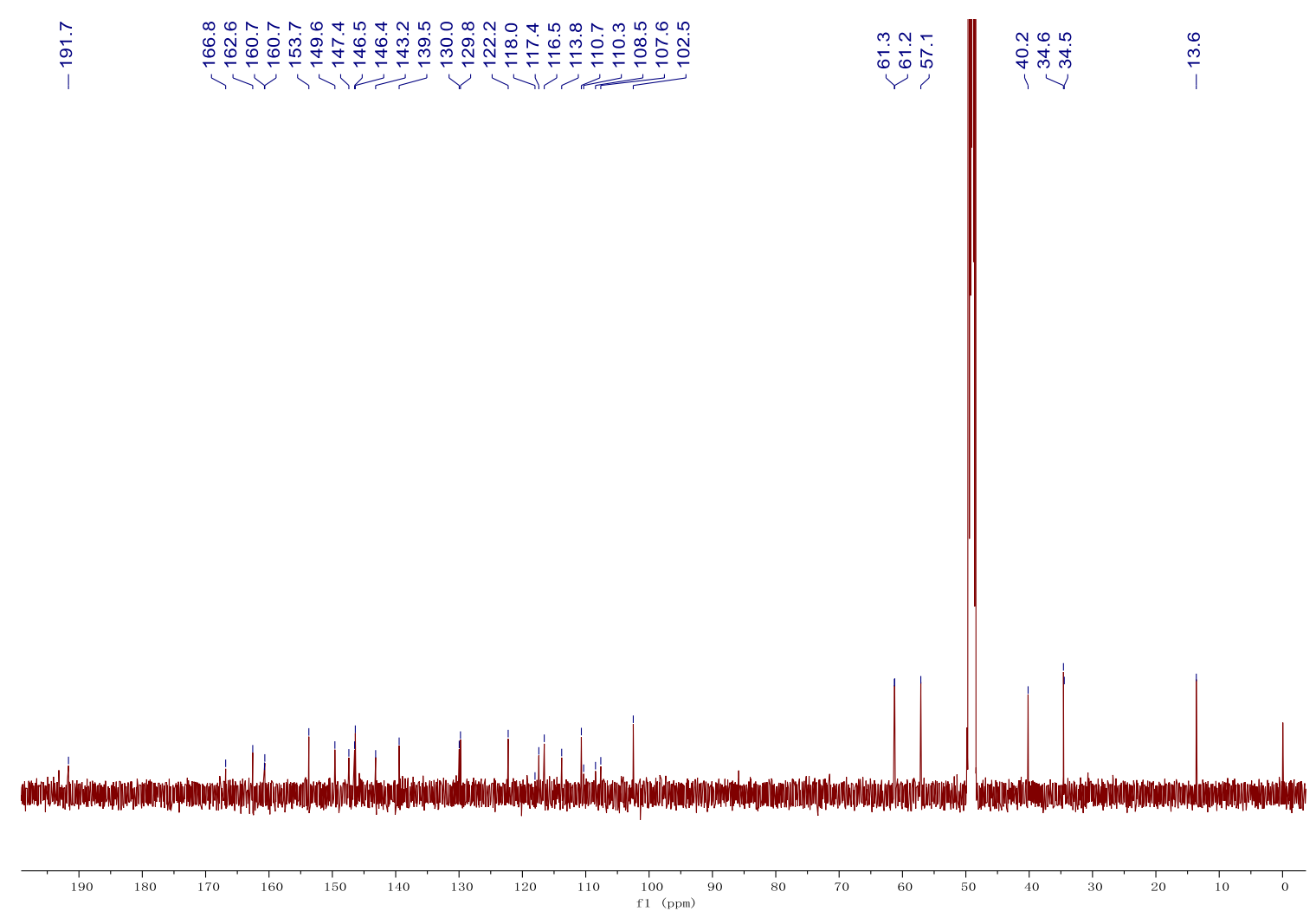

Figure S54. ${ }^{13} \mathrm{C}$ NMR (125 MHz) spectrum of 8 in $\mathrm{CD}_{3} \mathrm{OD}$ 


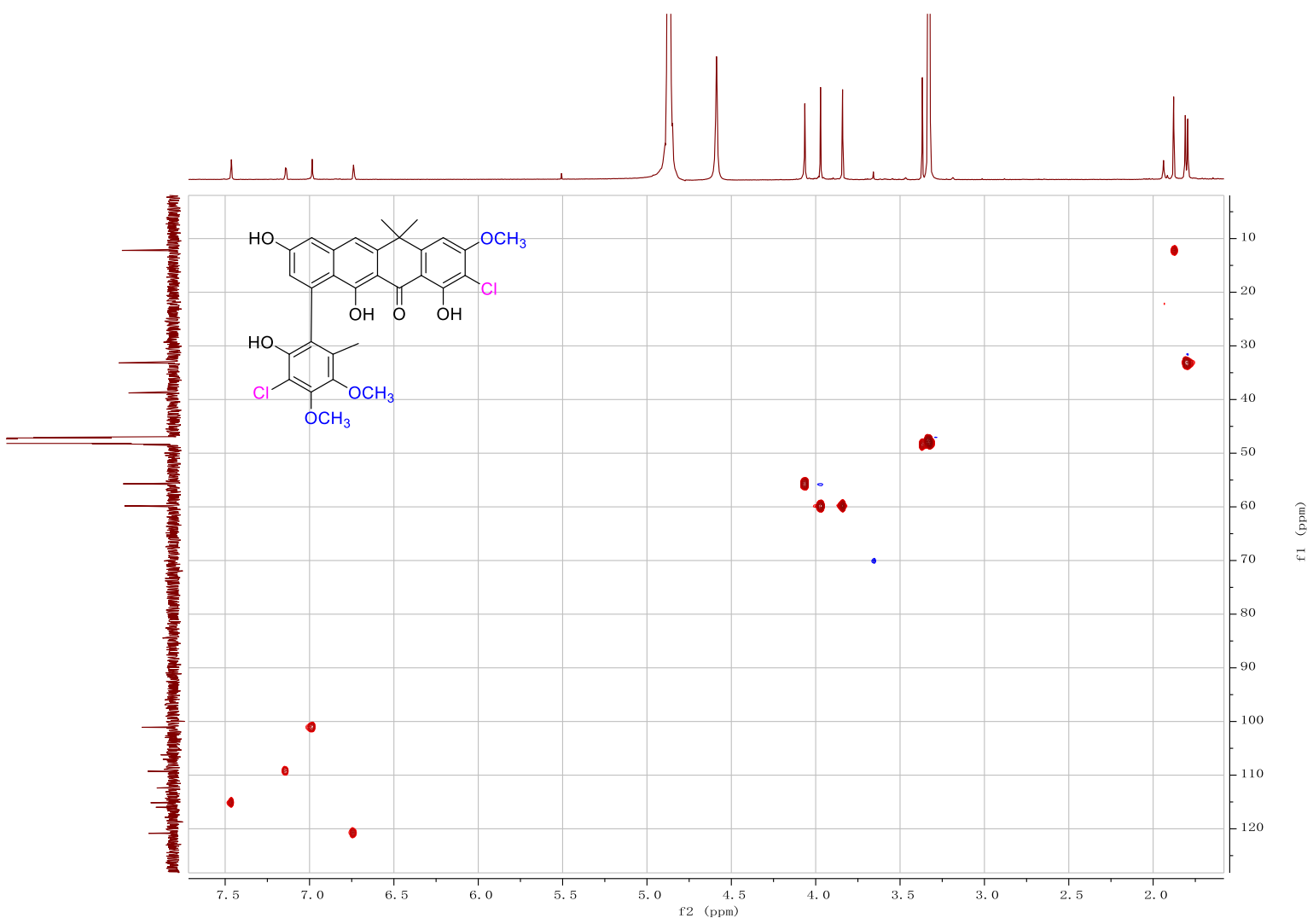

Figure S55. HSQC spectrum of $\mathbf{8}$ in $\mathrm{CD}_{3} \mathrm{OD}$

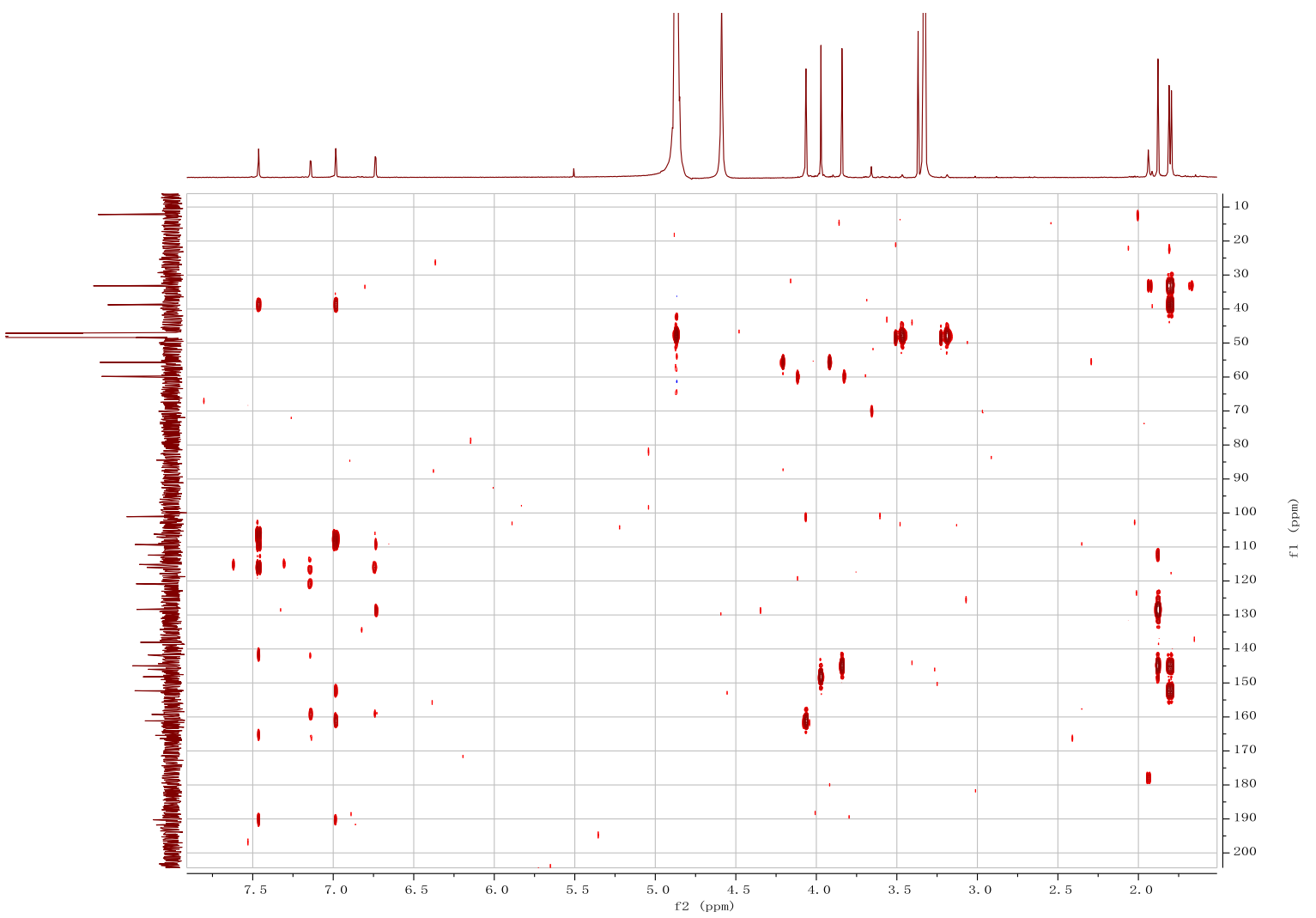

Figure S56. $\mathrm{HMBC}$ spectrum of $\mathbf{8}$ in $\mathrm{CD}_{3} \mathrm{OD}$

31 


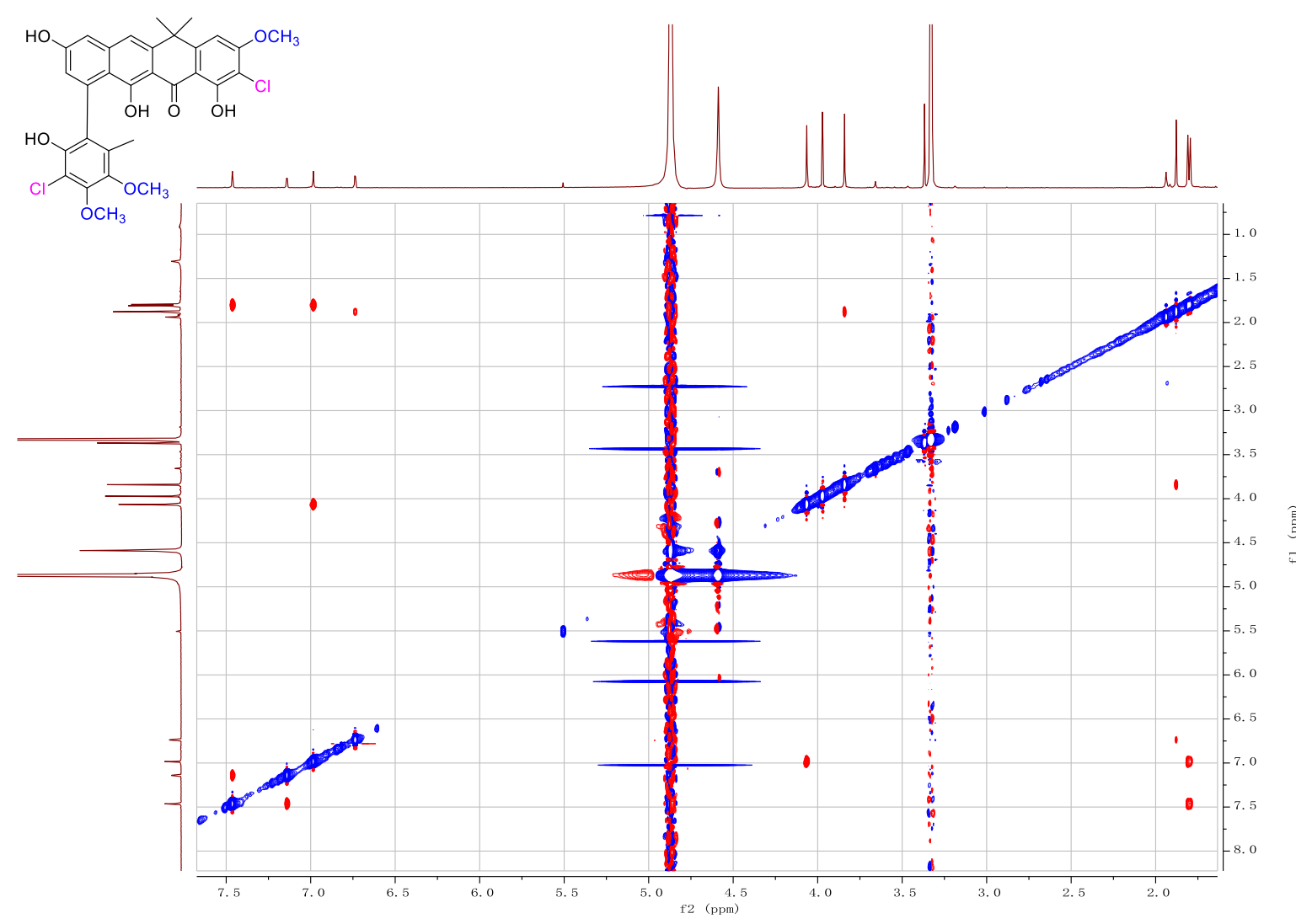

Figure S57. NOESY spectrum of $\mathbf{8}$ in $\mathrm{CD}_{3} \mathrm{OD}$

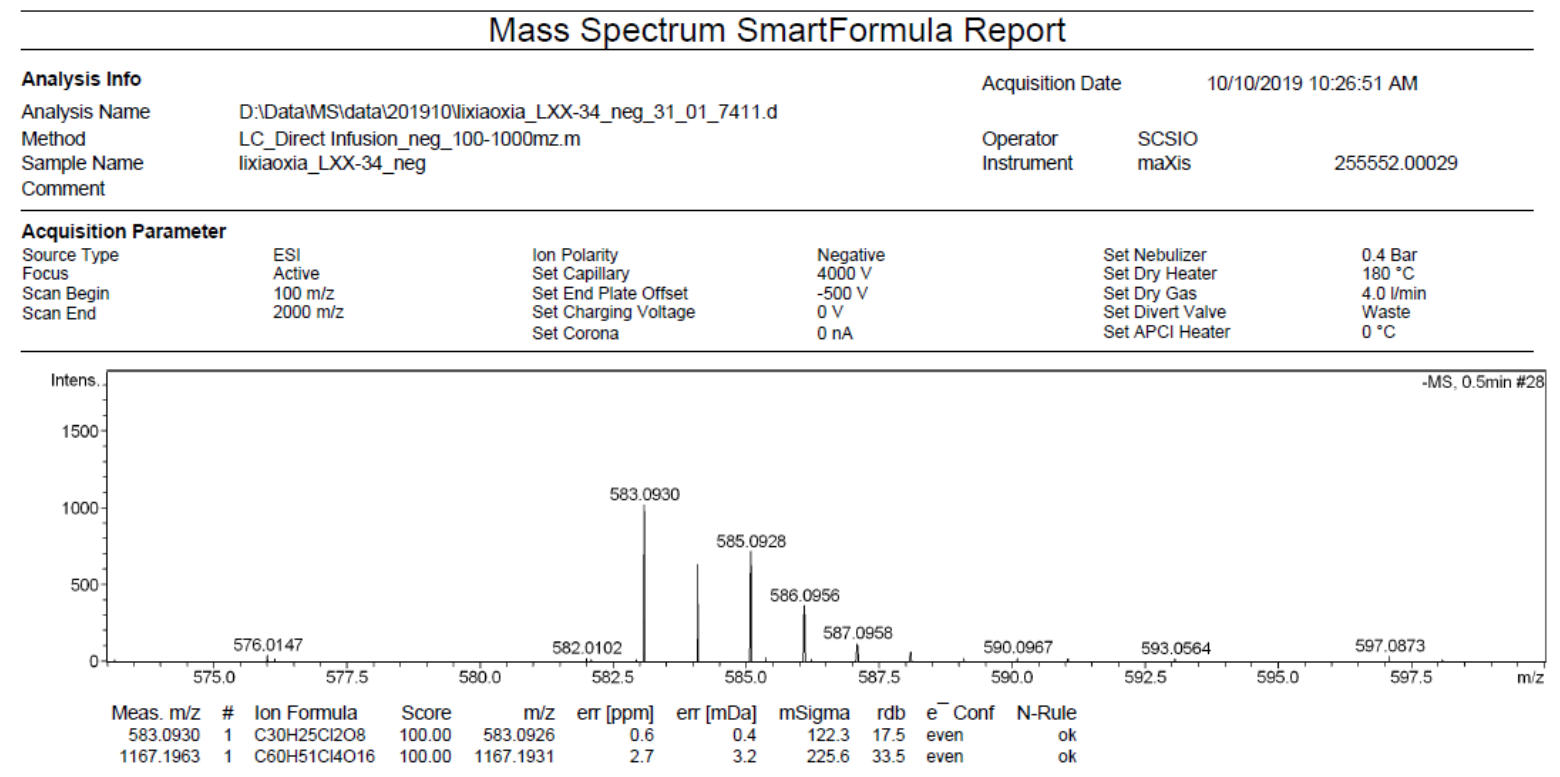

Figure S58. HR-ESI(-)MS of 8 


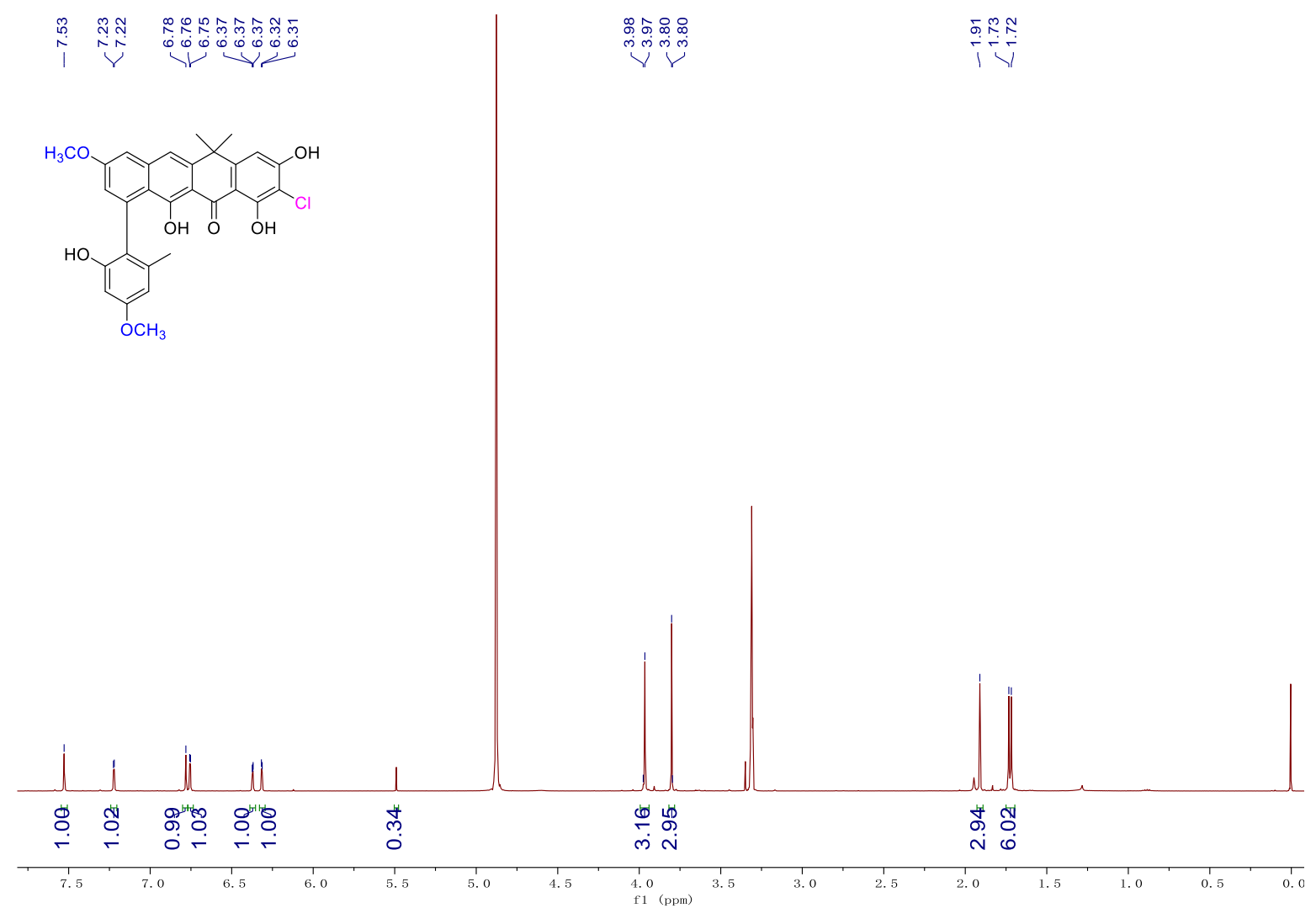

Figure S59. ${ }^{1} \mathrm{H}$ NMR $(500 \mathrm{MHz})$ spectrum of 9 in $\mathrm{CD}_{3} \mathrm{OD}$
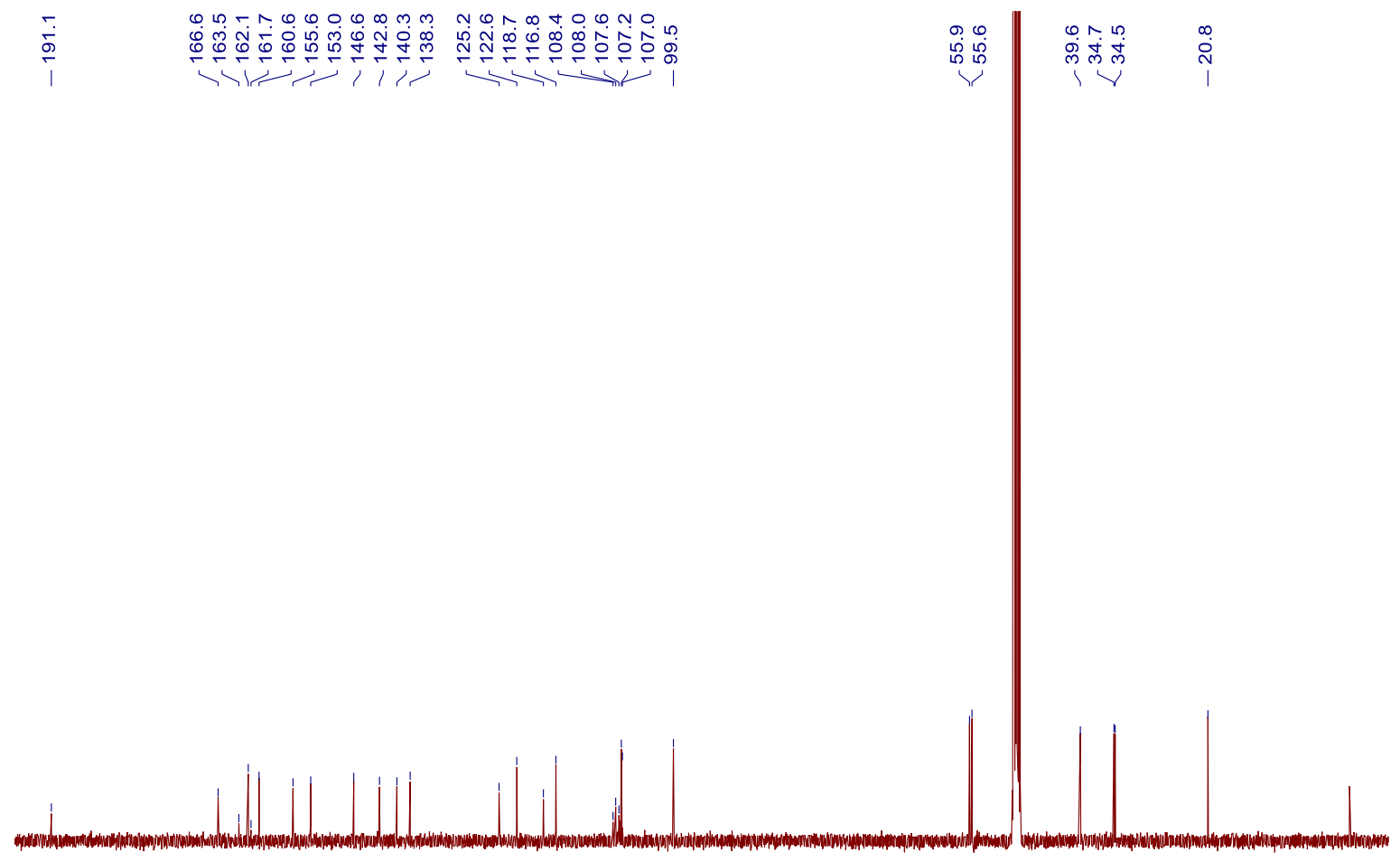

$\begin{array}{llllllllll}190 & 180 & 170 & 160 & 150 & 140 & 130 & 120 & 110 & 100 \\ \mathrm{f} 1(\mathrm{ppm}) & 90\end{array}$

Figure S60. ${ }^{13} \mathrm{C}$ NMR (125 MHz) spectrum of 9 in $\mathrm{CD}_{3} \mathrm{OD}$ 


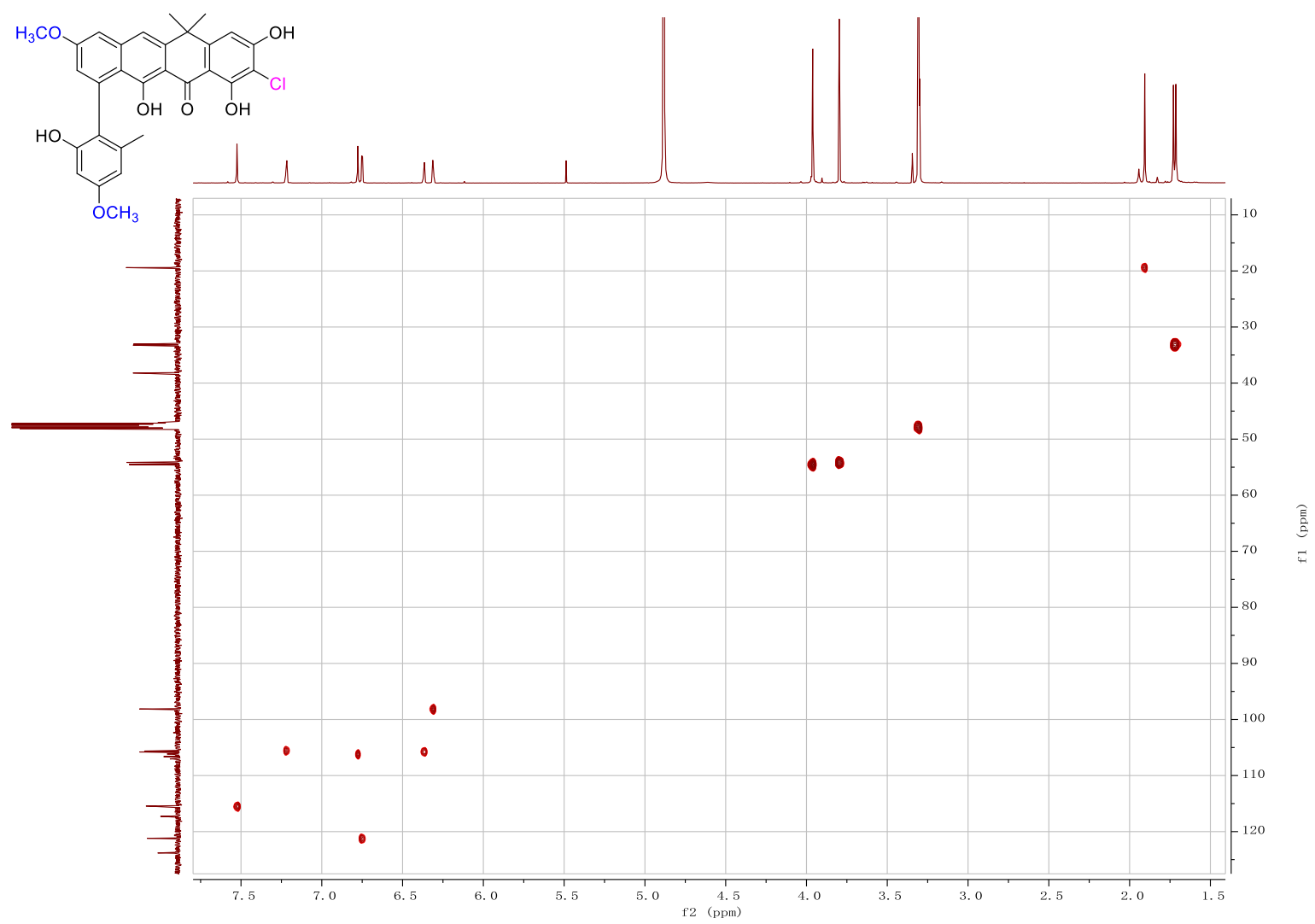

Figure S61. HSQC spectrum of 9 in $\mathrm{CD}_{3} \mathrm{OD}$

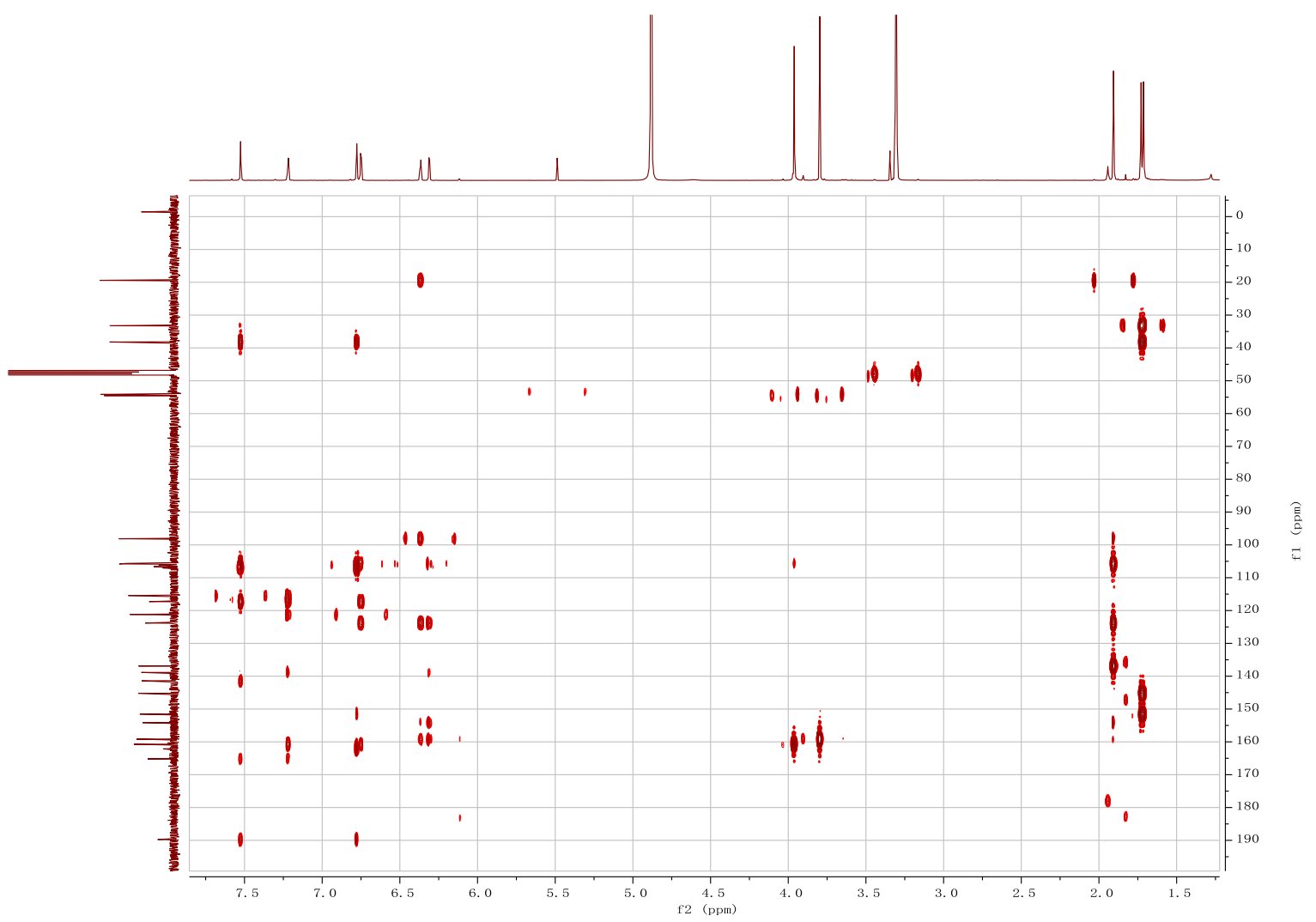

Figure S62. $\mathrm{HMBC}$ spectrum of 9 in $\mathrm{CD}_{3} \mathrm{OD}$

34 


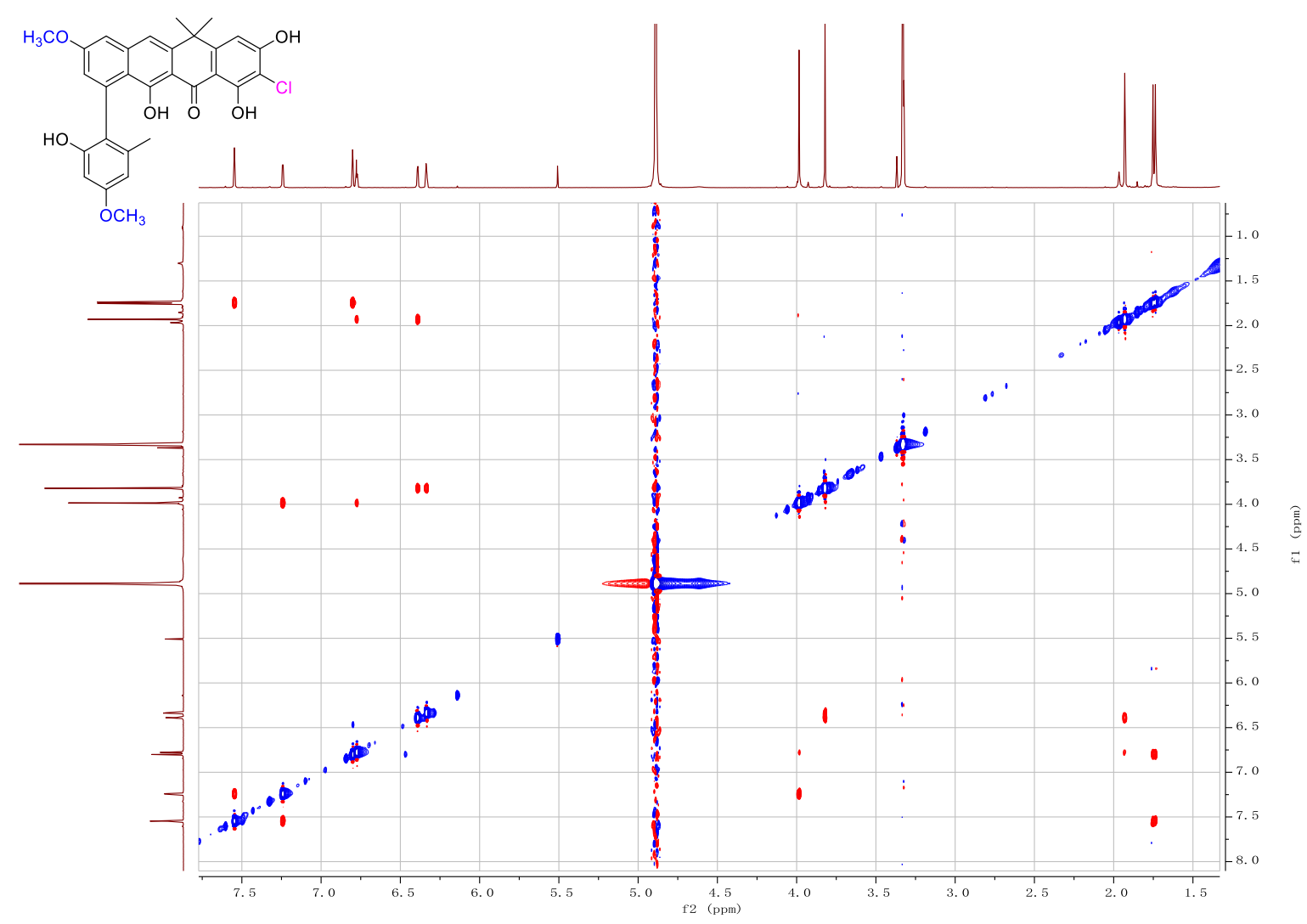

Figure S63. NOESY spectrum of 9 in $\mathrm{CD}_{3} \mathrm{OD}$

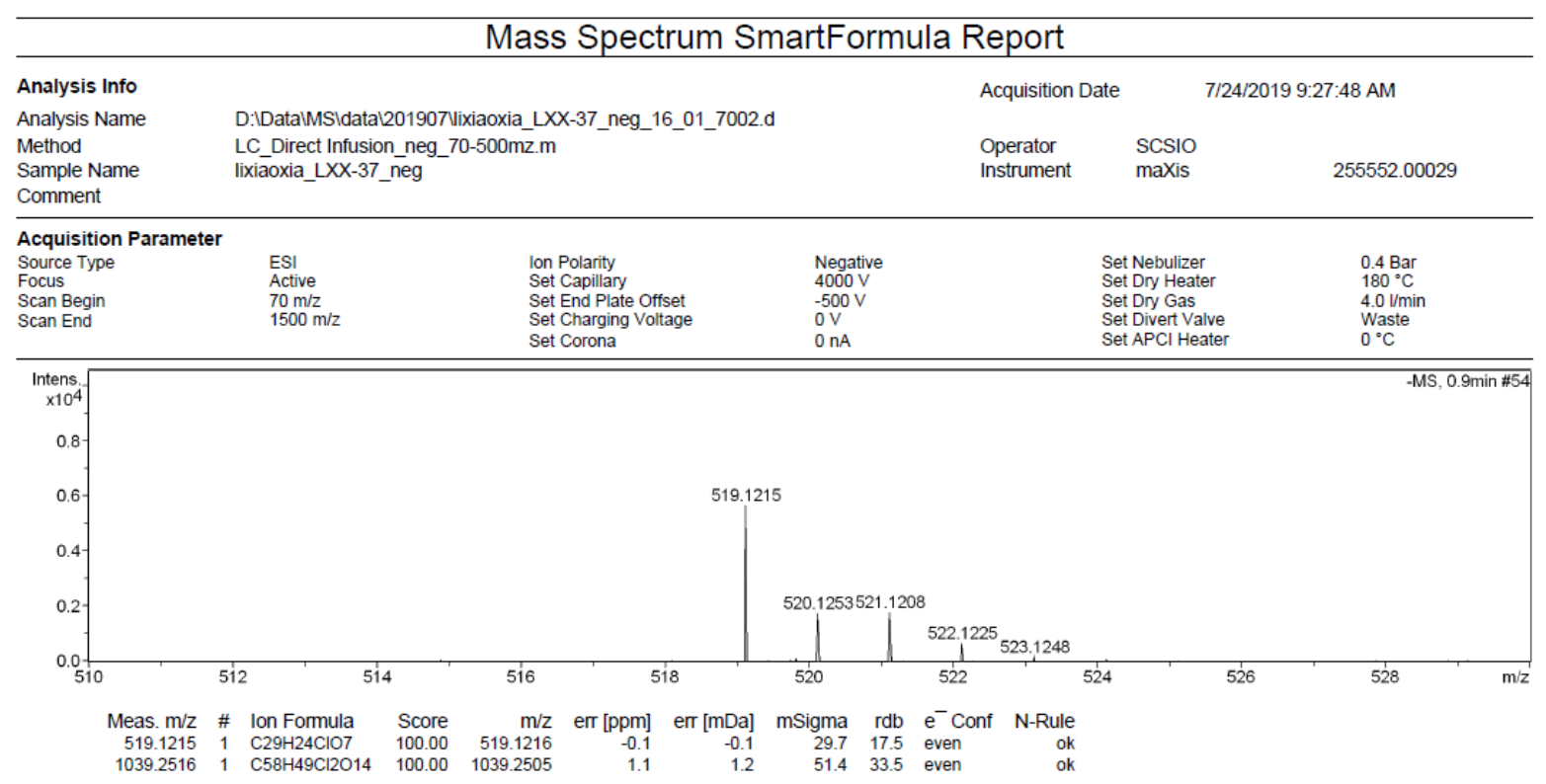

Figure S64. HR-ESI(-)MS of 9 


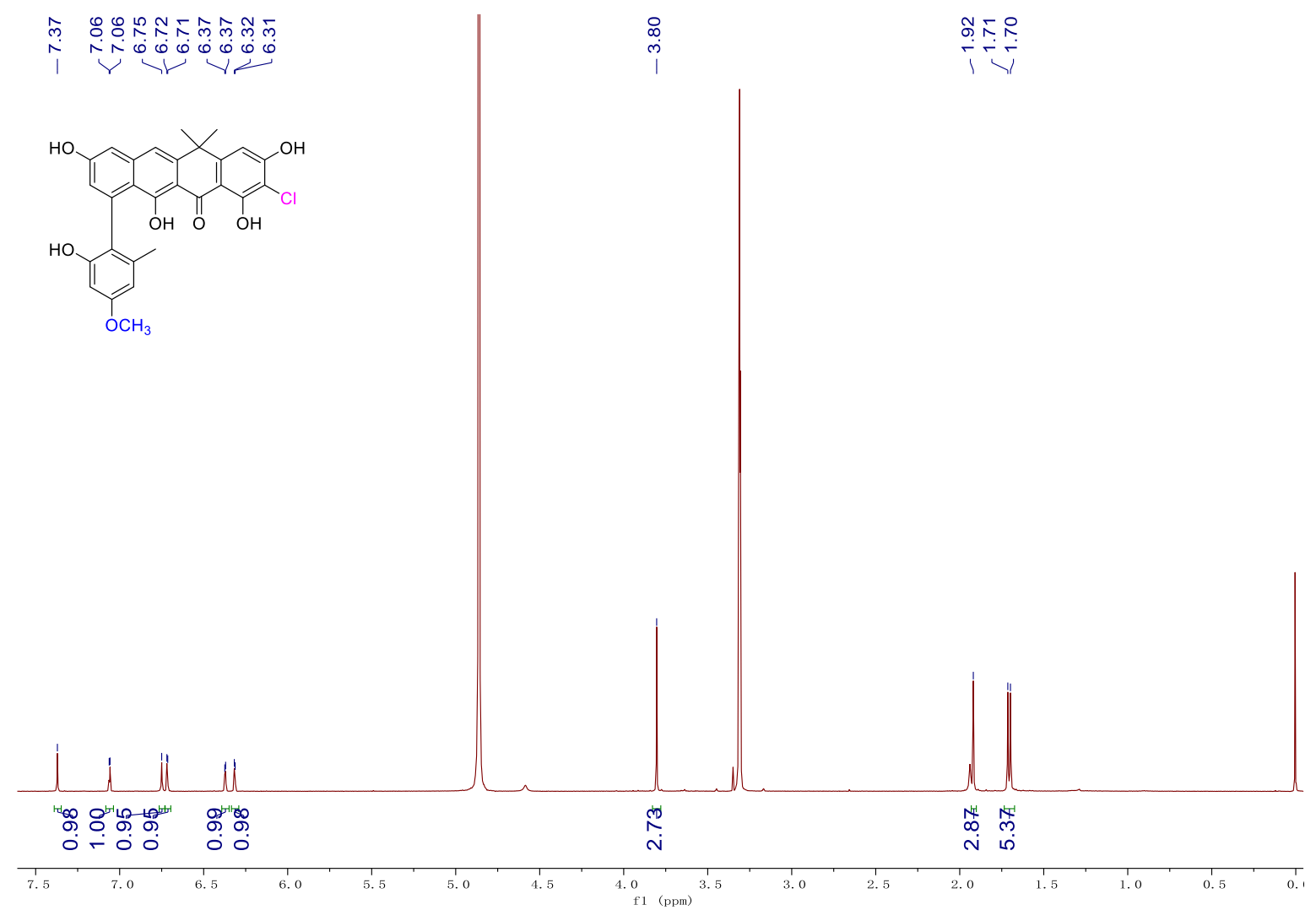

Figure S65. ${ }^{1} \mathrm{H}$ NMR $(500 \mathrm{MHz})$ spectrum of $\mathbf{1 0}$ in $\mathrm{CD}_{3} \mathrm{OD}$

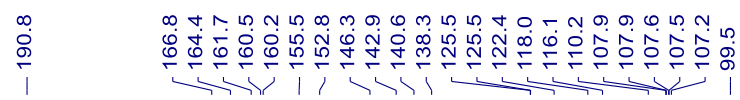
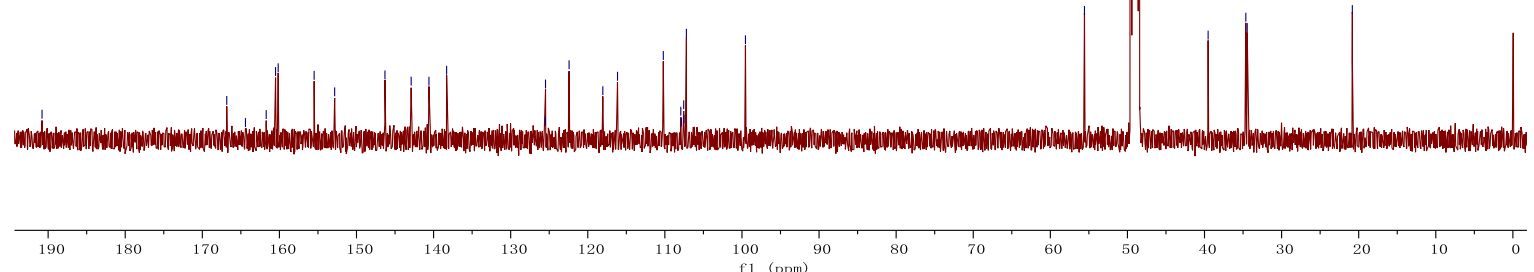

Figure S66. ${ }^{13} \mathrm{C}$ NMR (125 MHz) spectrum of $\mathbf{1 0}$ in $\mathrm{CD}_{3} \mathrm{OD}$ 


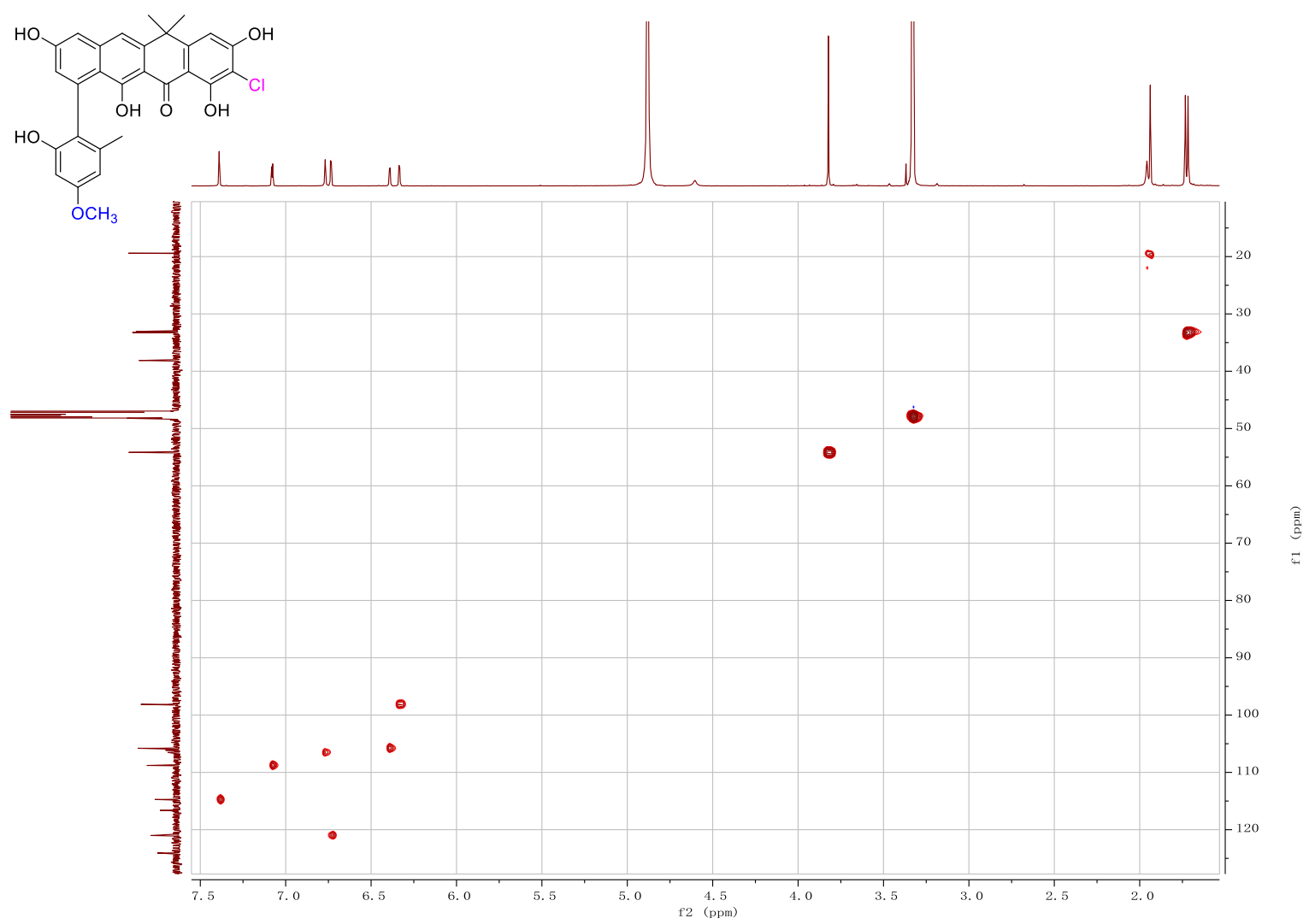

Figure S67. HSQC spectrum of $\mathbf{1 0}$ in $\mathrm{CD}_{3} \mathrm{OD}$

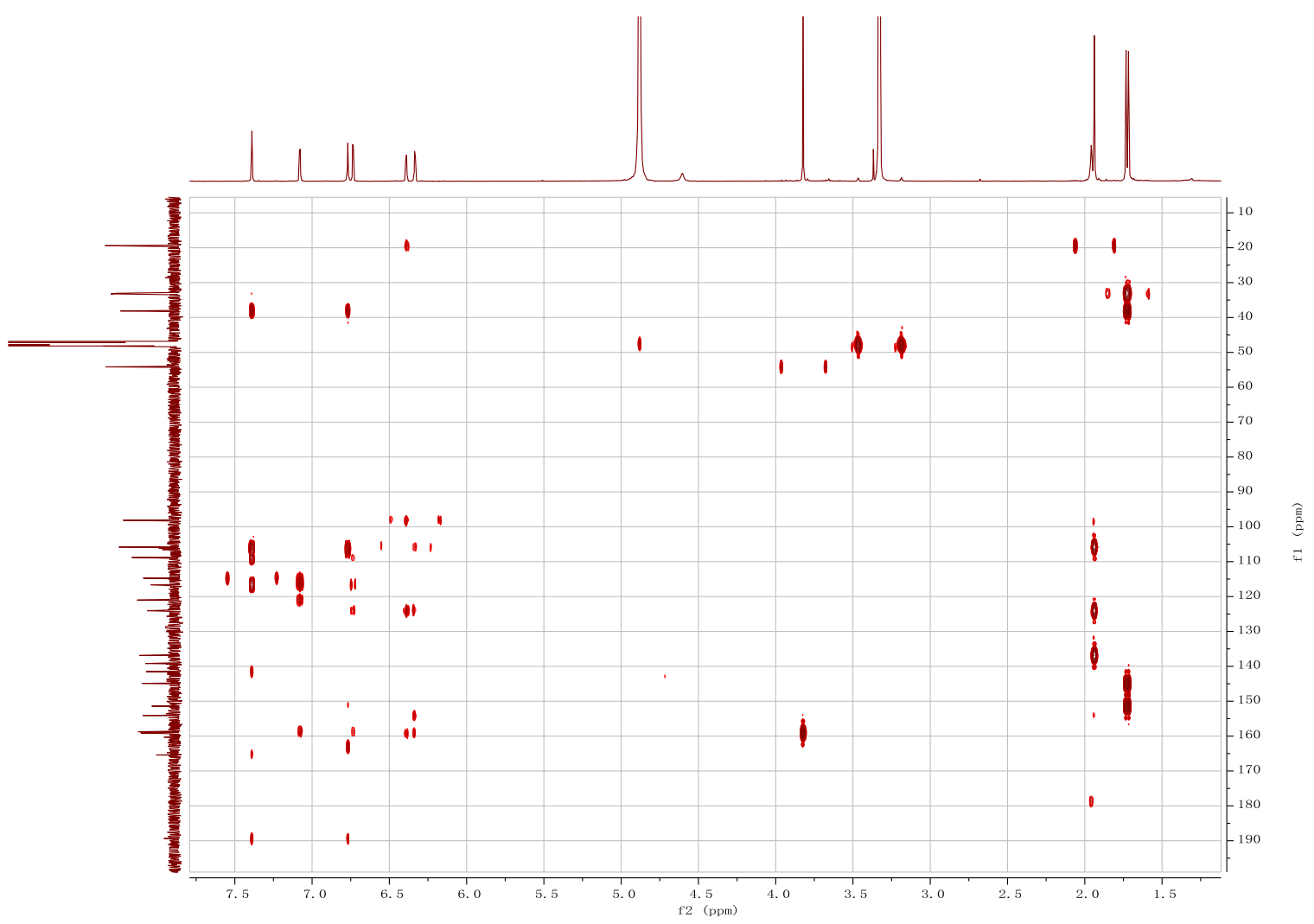

Figure S68. $\mathrm{HMBC}$ spectrum of $\mathbf{1 0}$ in $\mathrm{CD}_{3} \mathrm{OD}$

37 


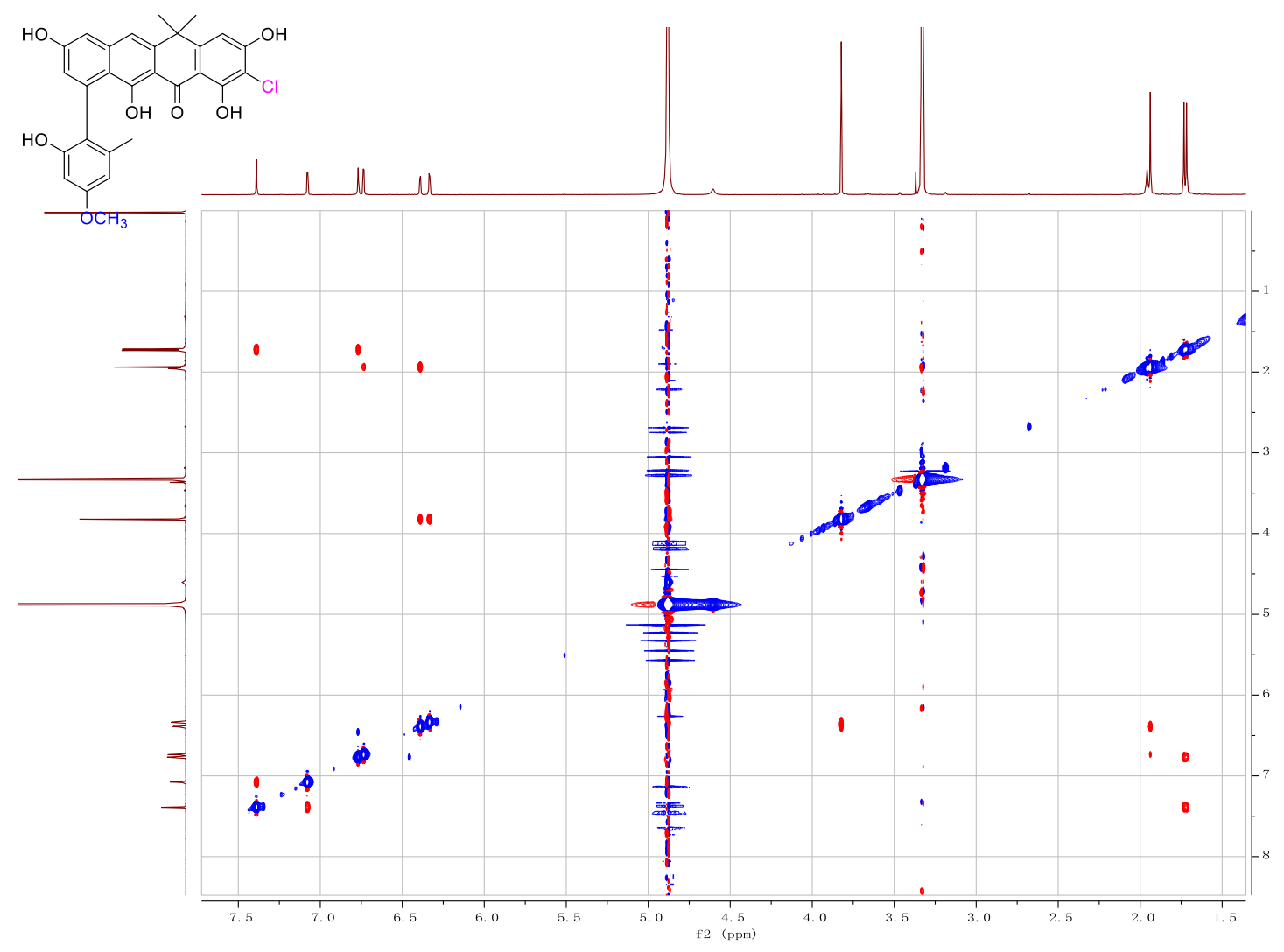

Figure S69. NOESY spectrum of $\mathbf{1 0}$ in $\mathrm{CD}_{3} \mathrm{OD}$

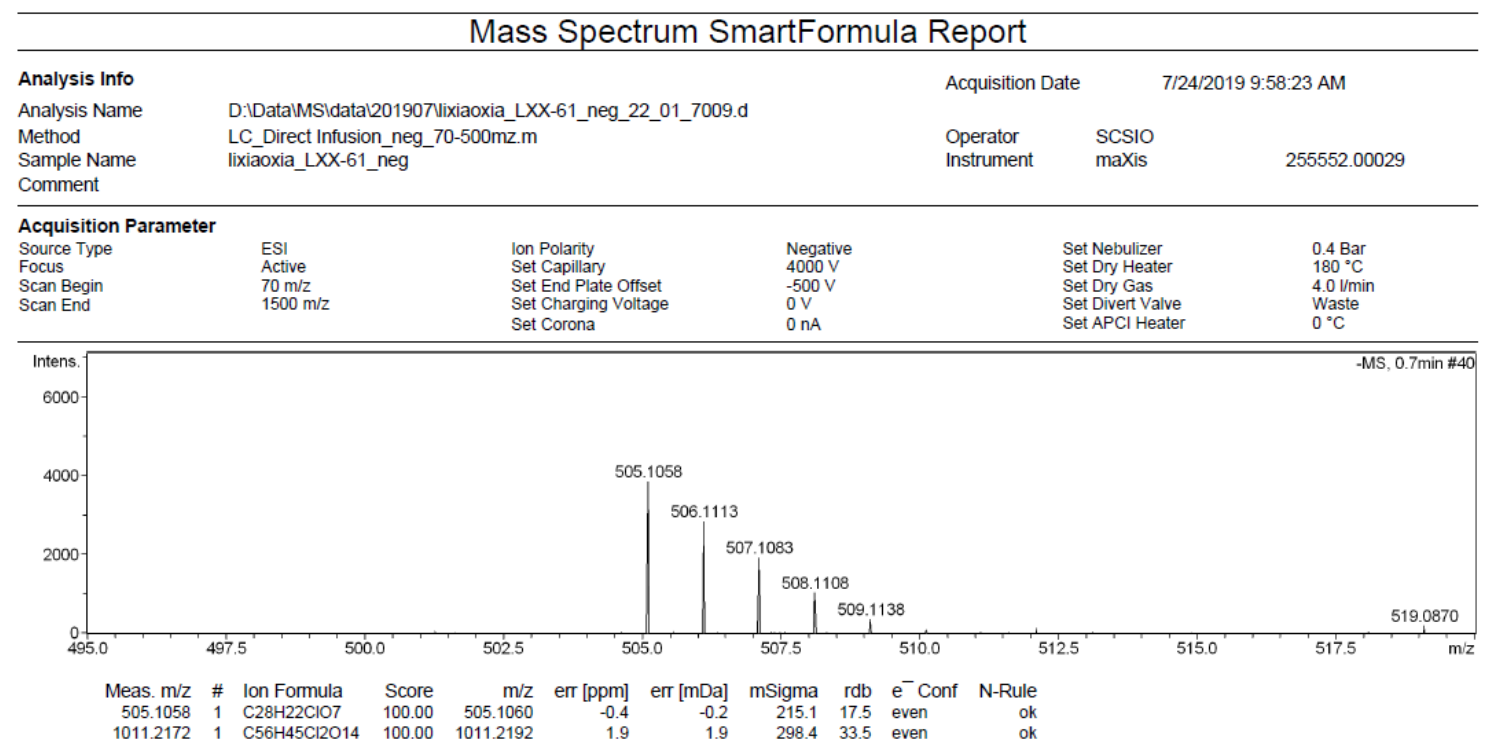

Figure S70. HR-ESI(-)MS of $\mathbf{1 0}$ 


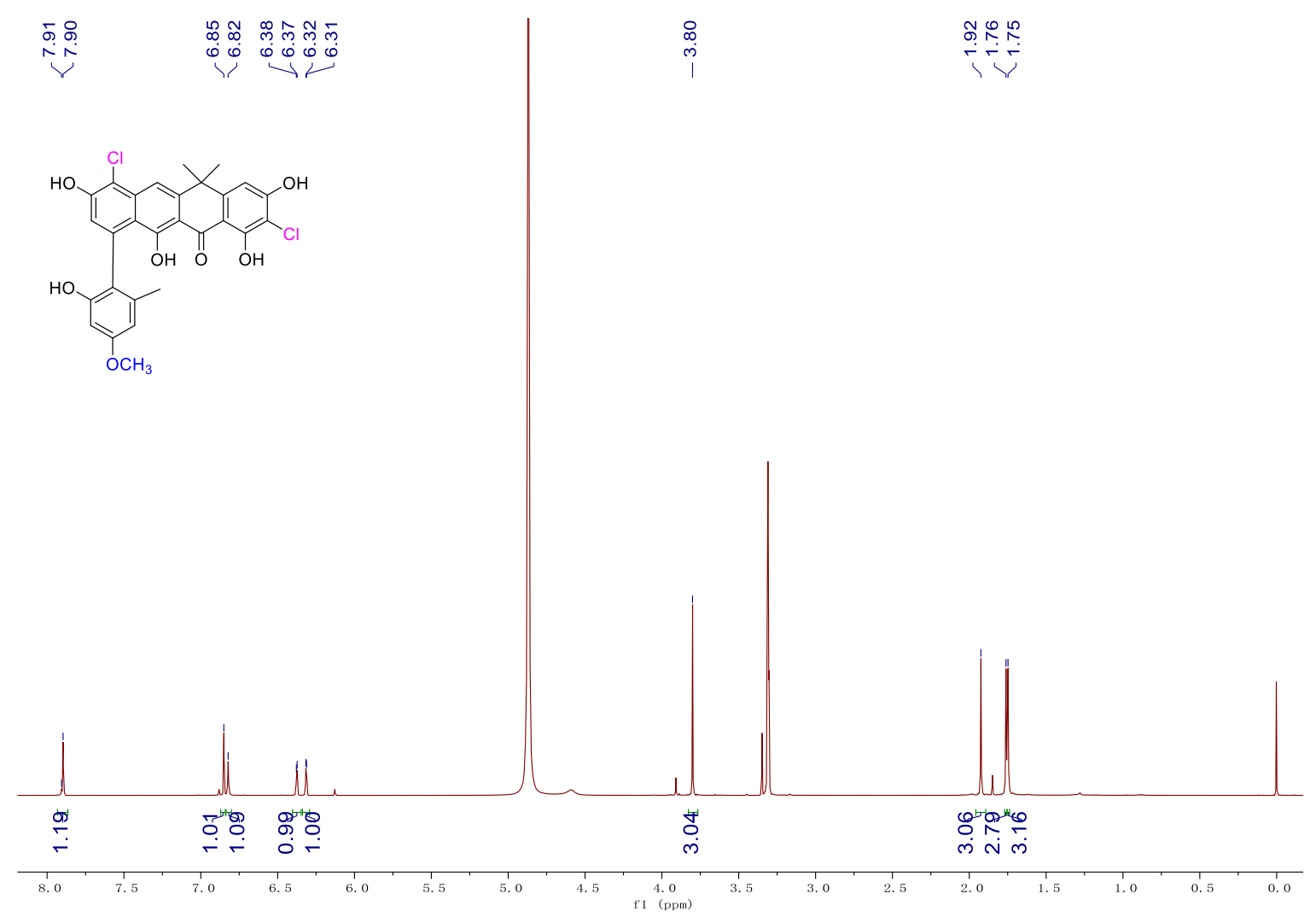

Figure S71. ${ }^{1} \mathrm{H}$ NMR $(500 \mathrm{MHz})$ spectrum of 11 in $\mathrm{CD}_{3} \mathrm{OD}$
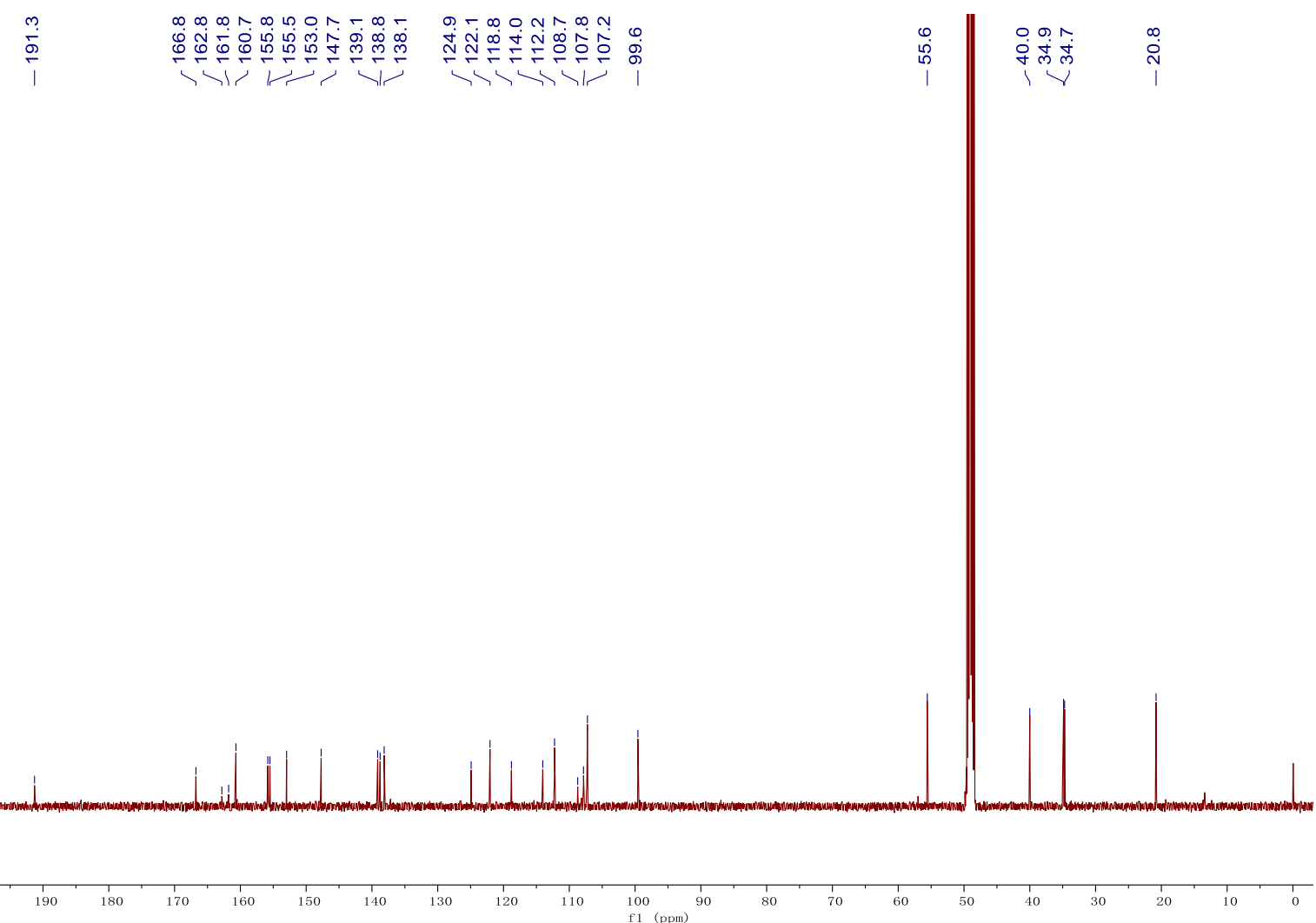

Figure S72. ${ }^{13} \mathrm{C}$ NMR (125 MHz) spectrum of 11 in $\mathrm{CD}_{3} \mathrm{OD}$ 


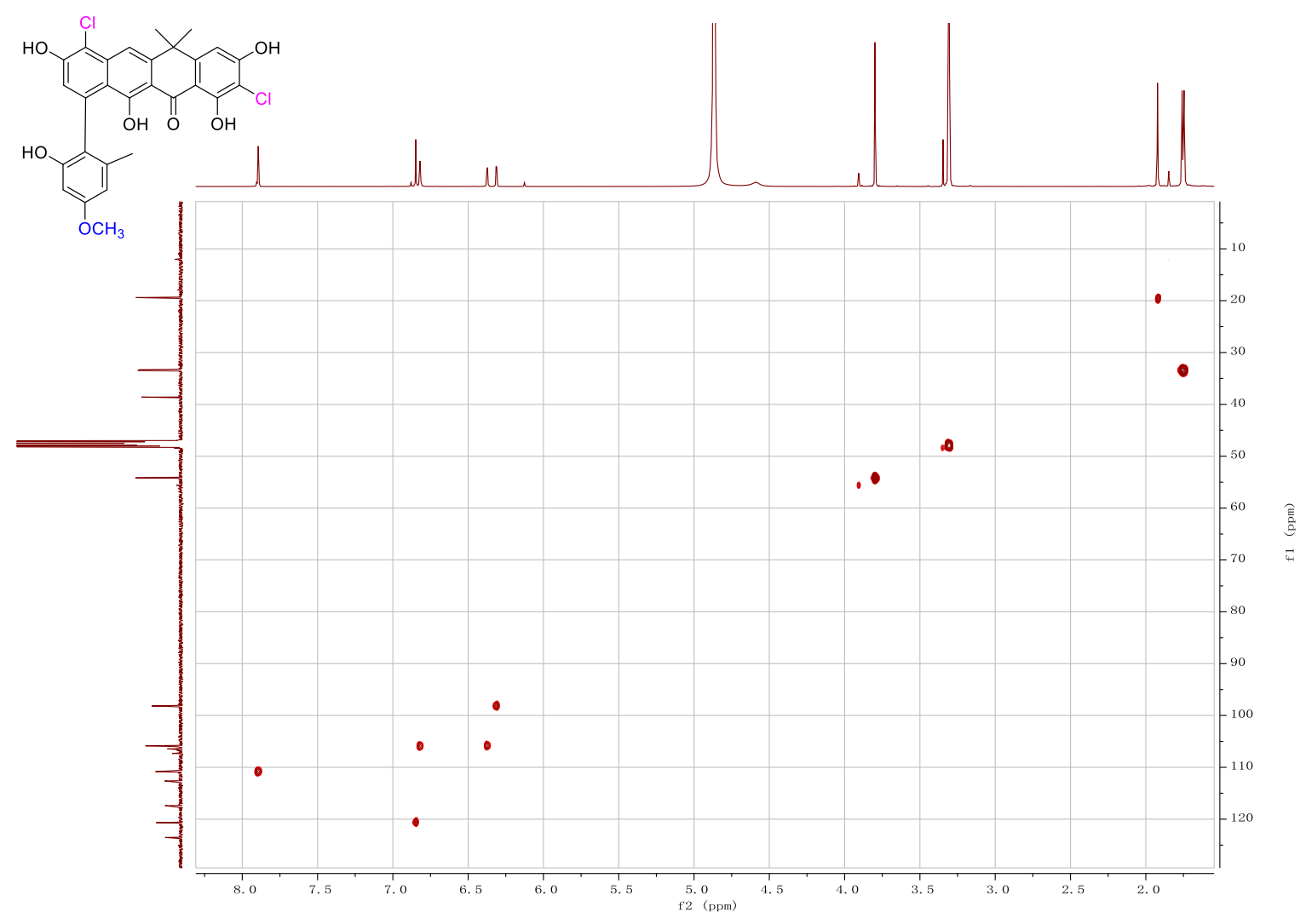

Figure S73. HSQC spectrum of $\mathbf{1 1}$ in $\mathrm{CD}_{3} \mathrm{OD}$

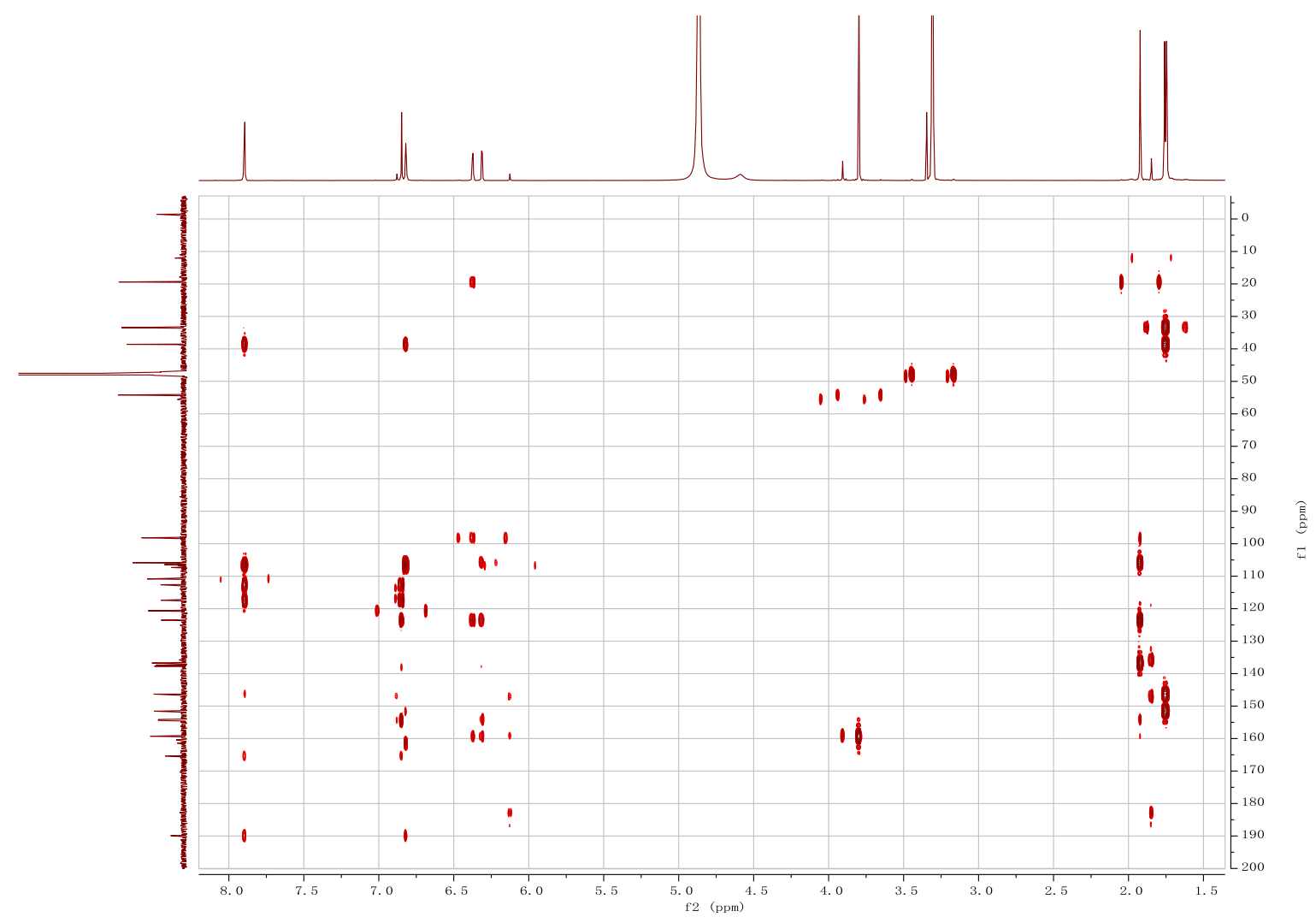

Figure S74. $\mathrm{HMBC}$ spectrum of 11 in $\mathrm{CD}_{3} \mathrm{OD}$ 


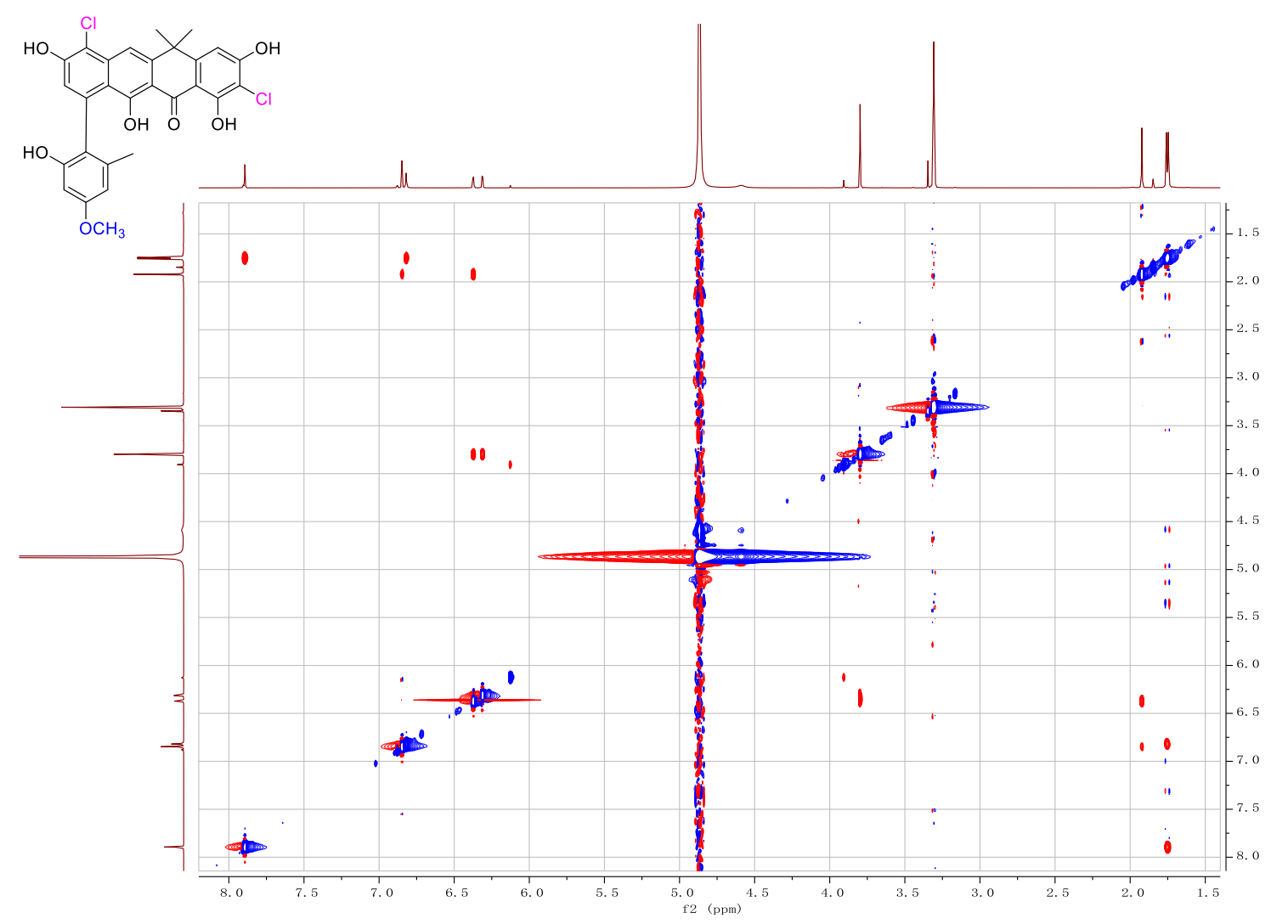

Figure S75. NOESY spectrum of 11 in $\mathrm{CD}_{3} \mathrm{OD}$

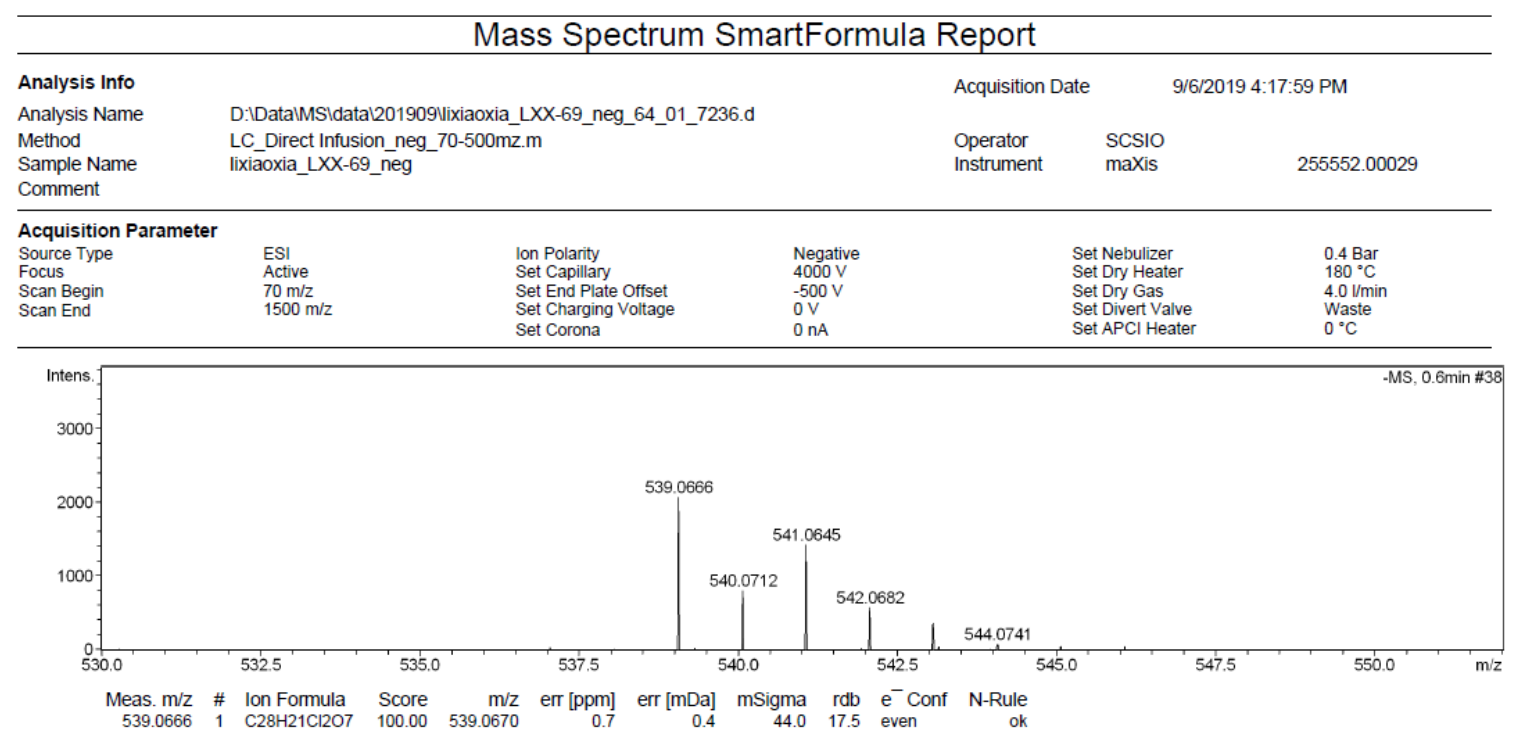

Figure S76. HR-ESI(-)MS of $\mathbf{1 1}$ 


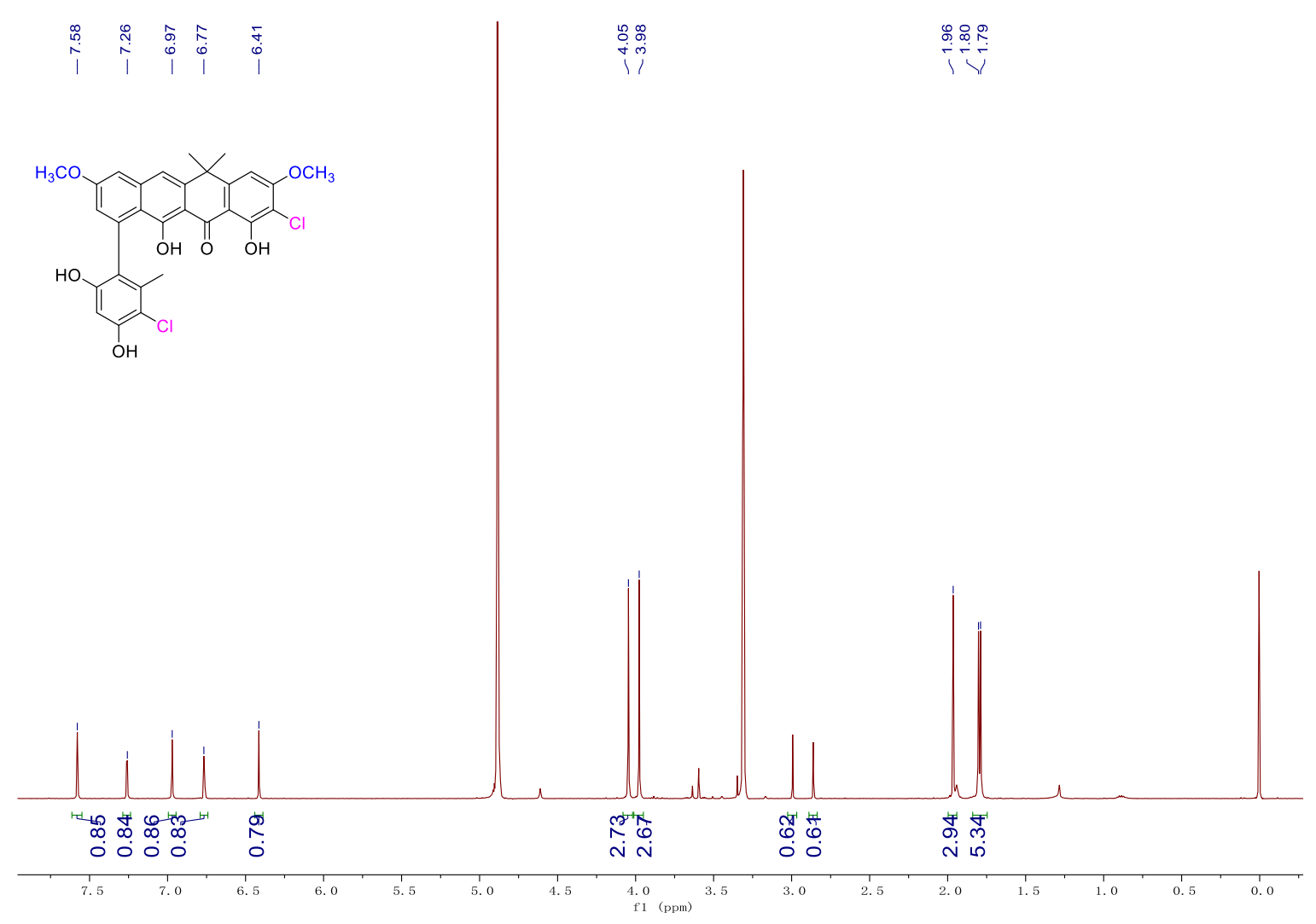

Figure S77. ${ }^{1} \mathrm{H}$ NMR $(500 \mathrm{MHz})$ spectrum of 12 in $\mathrm{CD}_{3} \mathrm{OD}$
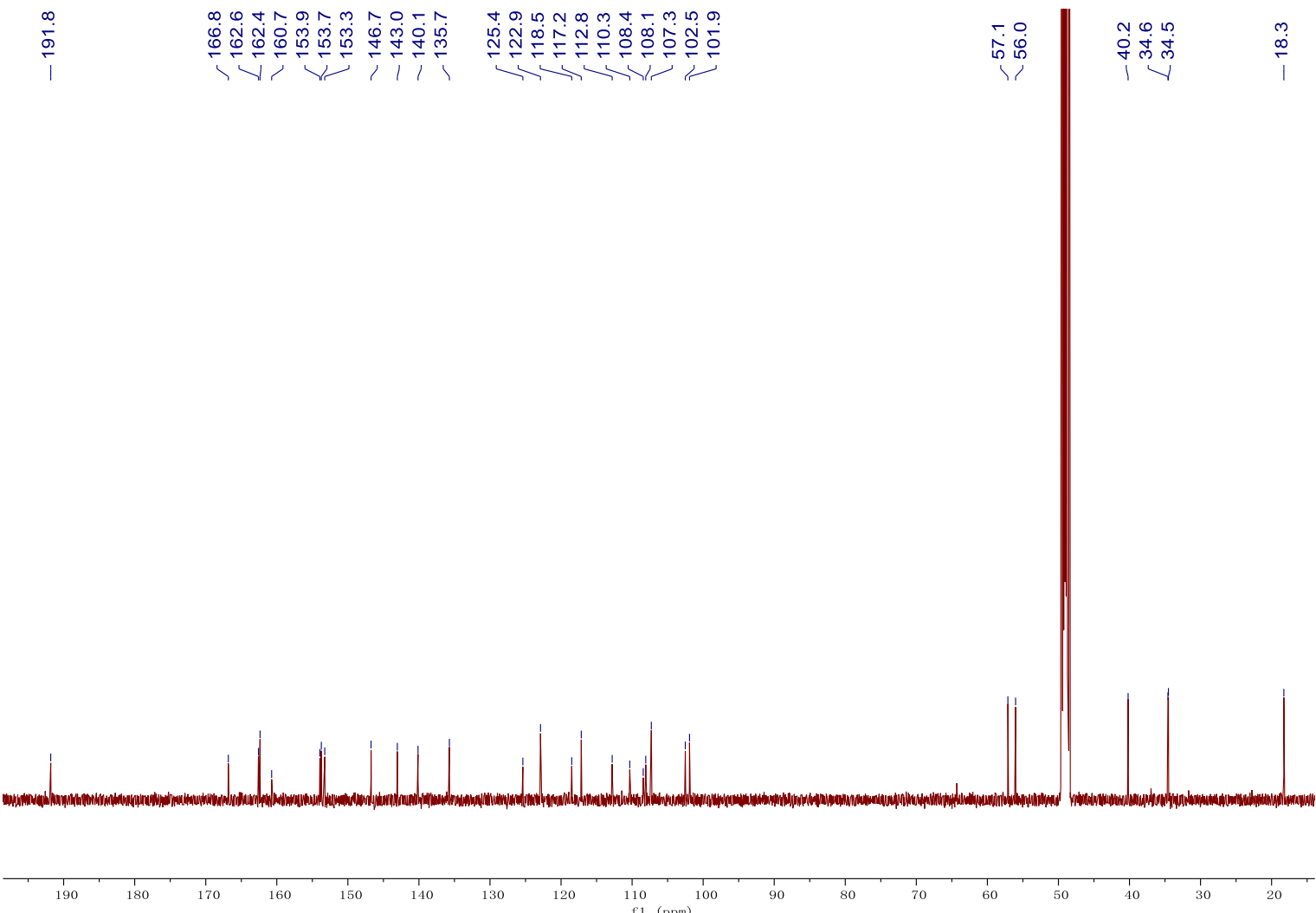

Figure S78. ${ }^{13} \mathrm{C}$ NMR (125 MHz) spectrum of 12 in $\mathrm{CD}_{3} \mathrm{OD}$ 


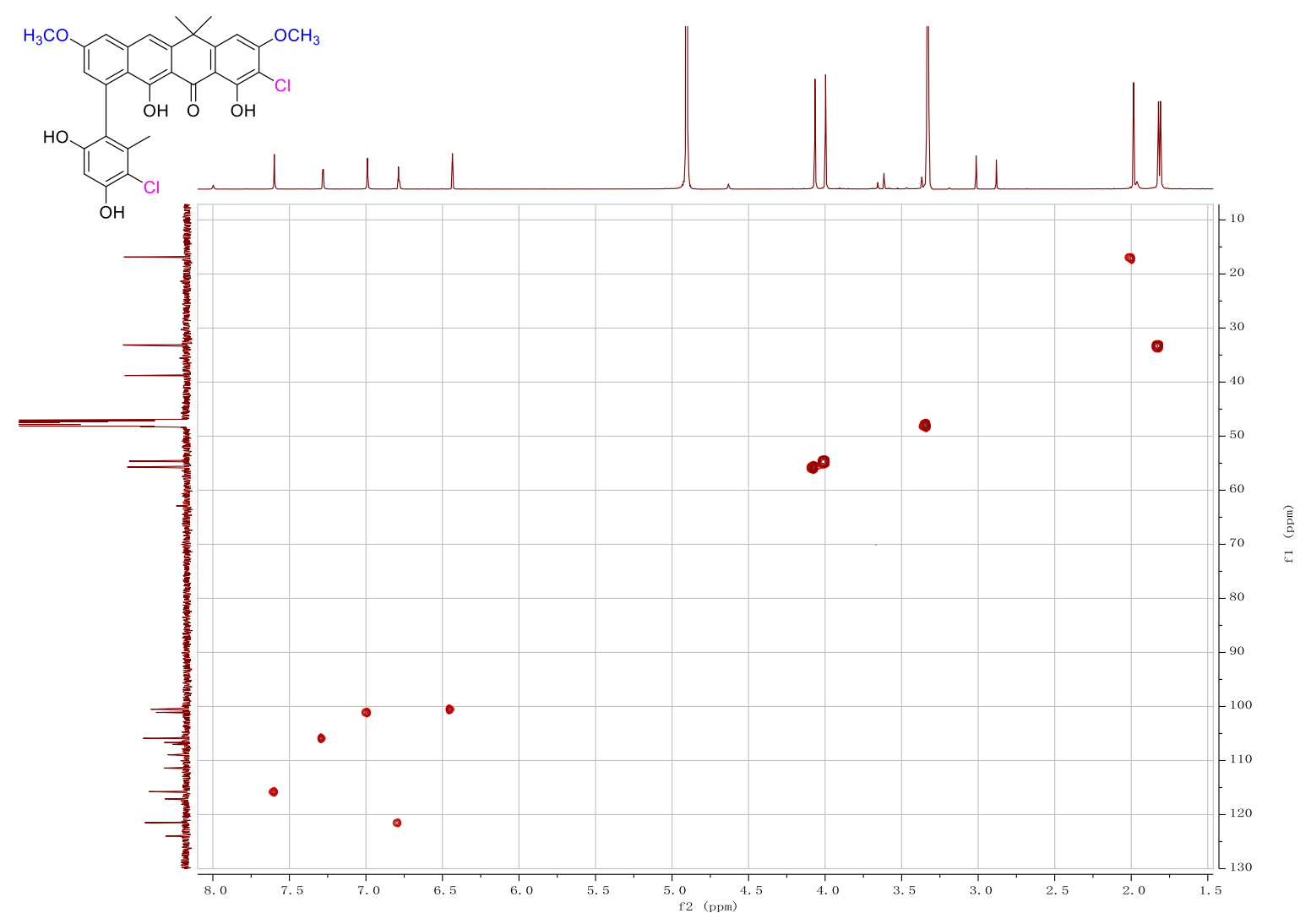

Figure S79. HSQC spectrum of $\mathbf{1 2}$ in $\mathrm{CD}_{3} \mathrm{OD}$

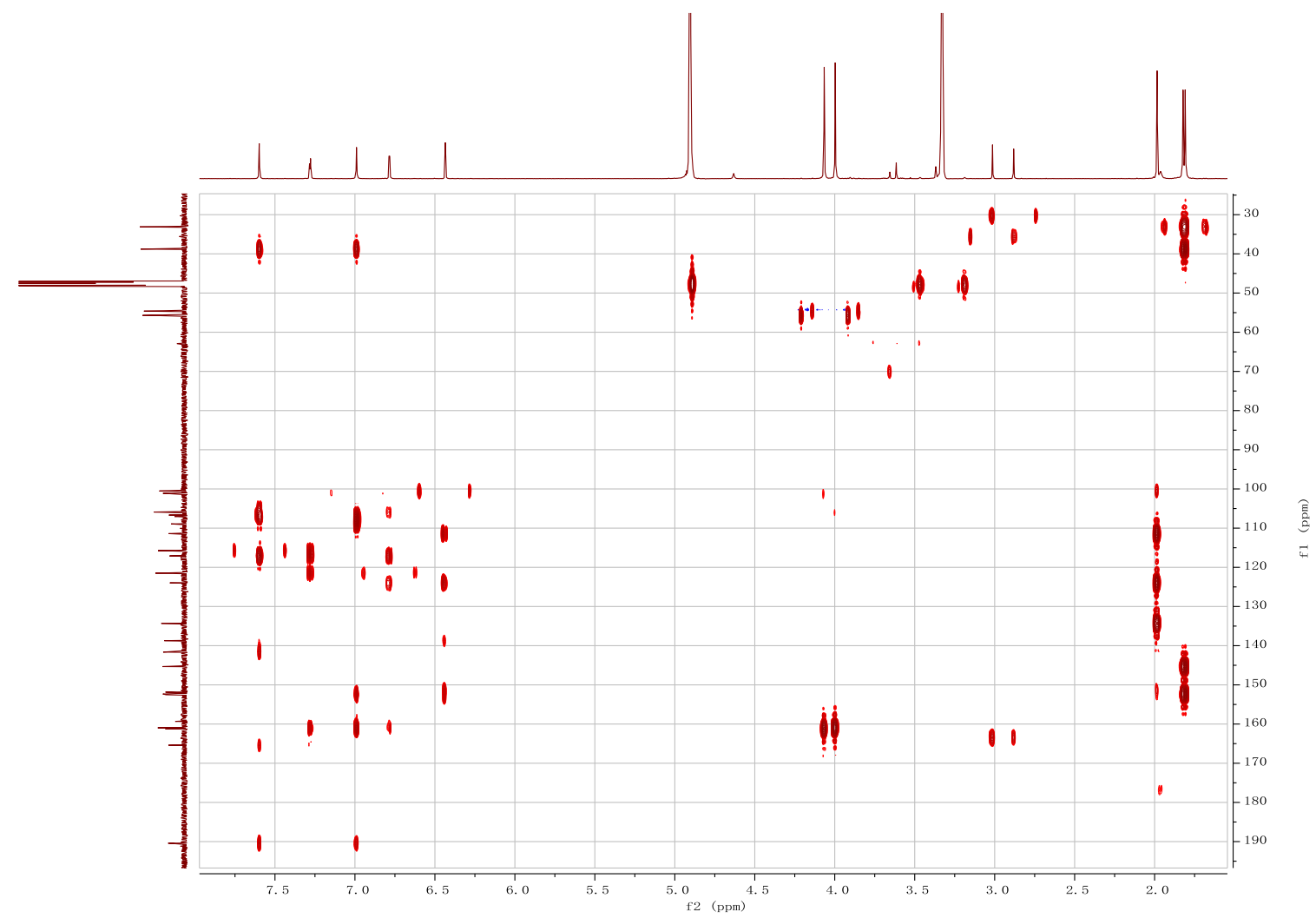

Figure S80. $\mathrm{HMBC}$ spectrum of $\mathbf{1 2}$ in $\mathrm{CD}_{3} \mathrm{OD}$ 


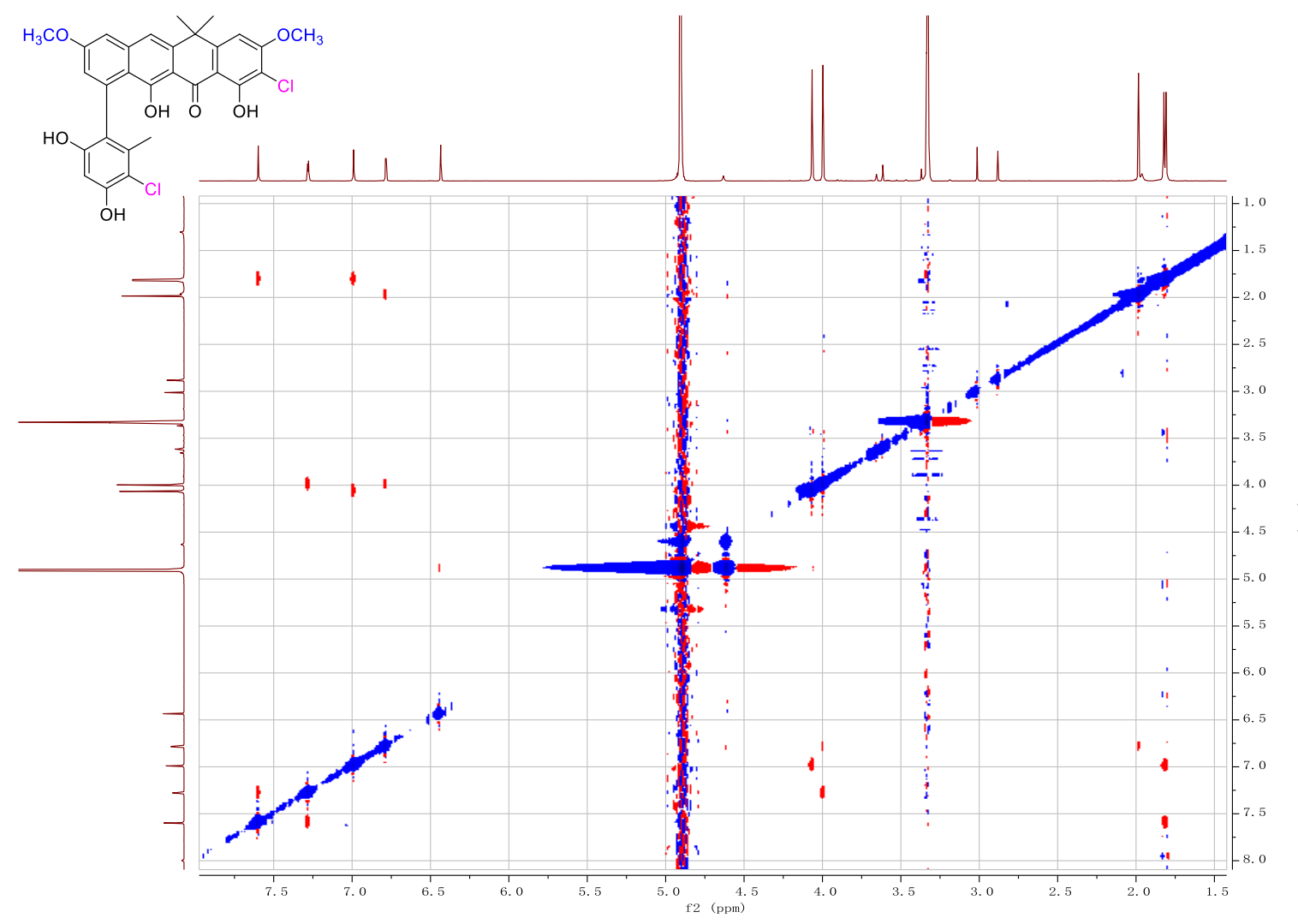

Figure S81. NOESY spectrum of 12 in $\mathrm{CD}_{3} \mathrm{OD}$

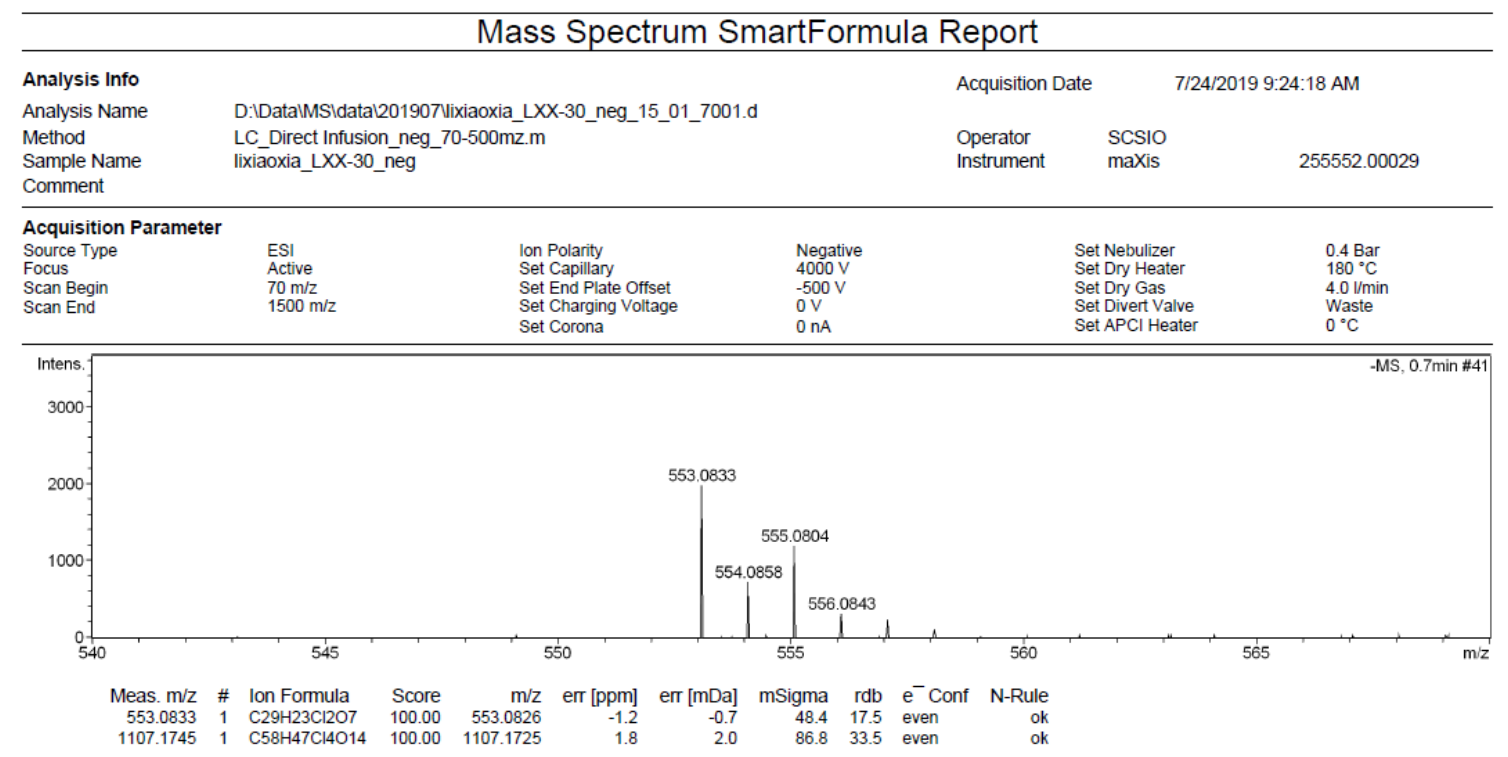

Figure S82. HR-ESI(-)MS of $\mathbf{1 2}$ 


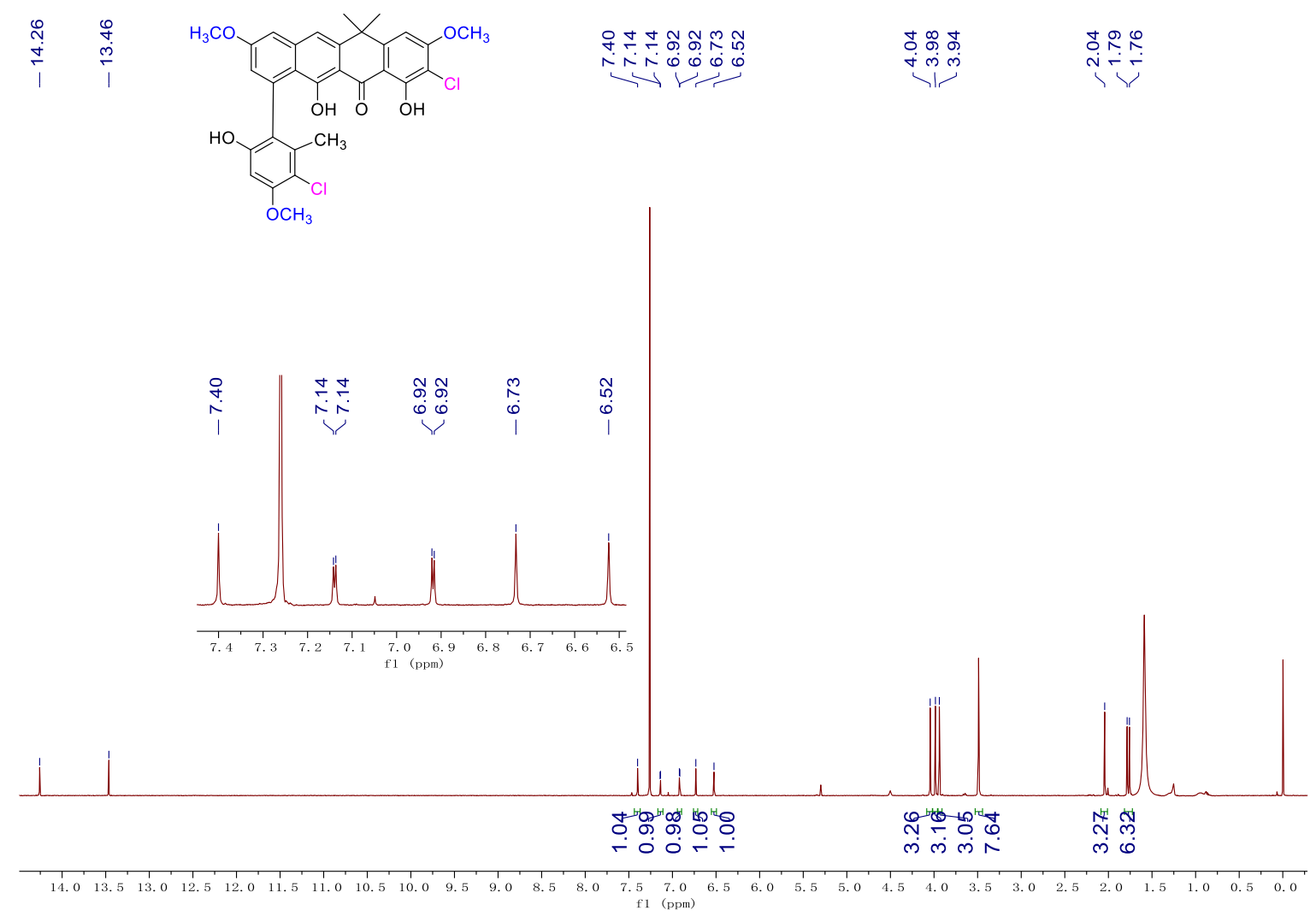

Figure S83. ${ }^{1} \mathrm{H}$ NMR $(500 \mathrm{MHz})$ spectrum of 13 in $\mathrm{CDCl}_{3}$

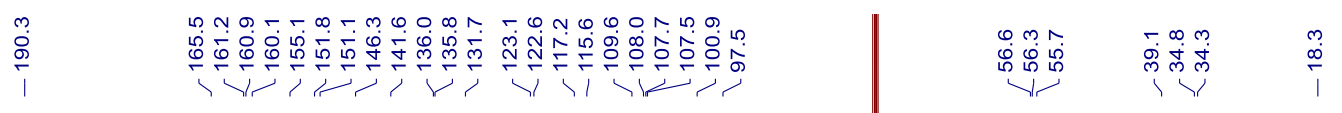

Figure S84. ${ }^{13} \mathrm{C}$ NMR (125 MHz) spectrum of 13 in $\mathrm{CDCl}_{3}$ 


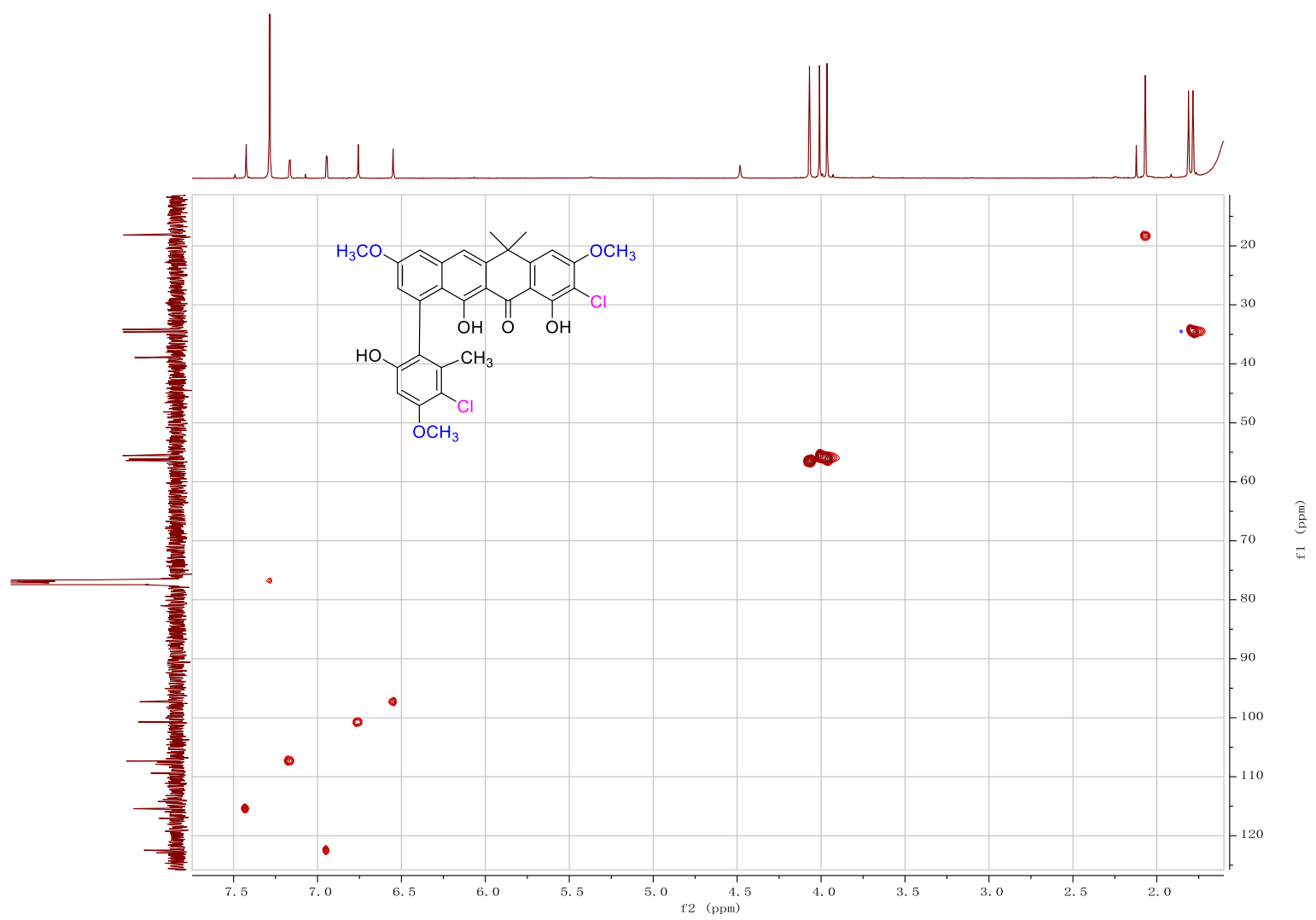

Figure S85. HSQC spectrum of $\mathbf{1 3}$ in $\mathrm{CDCl}_{3}$

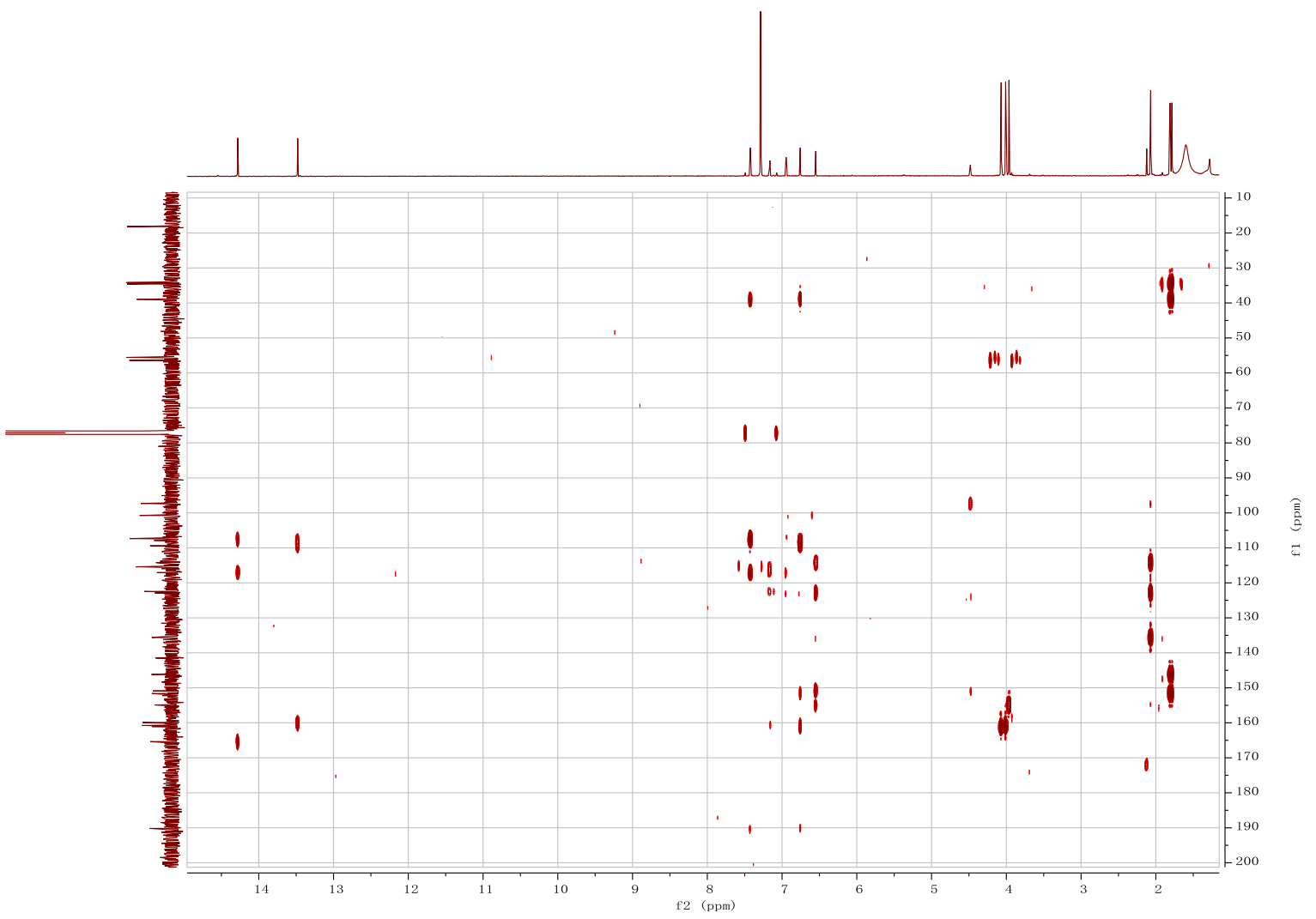

Figure S86. $\mathrm{HMBC}$ spectrum of $\mathbf{1 3}$ in $\mathrm{CDCl}_{3}$

46 


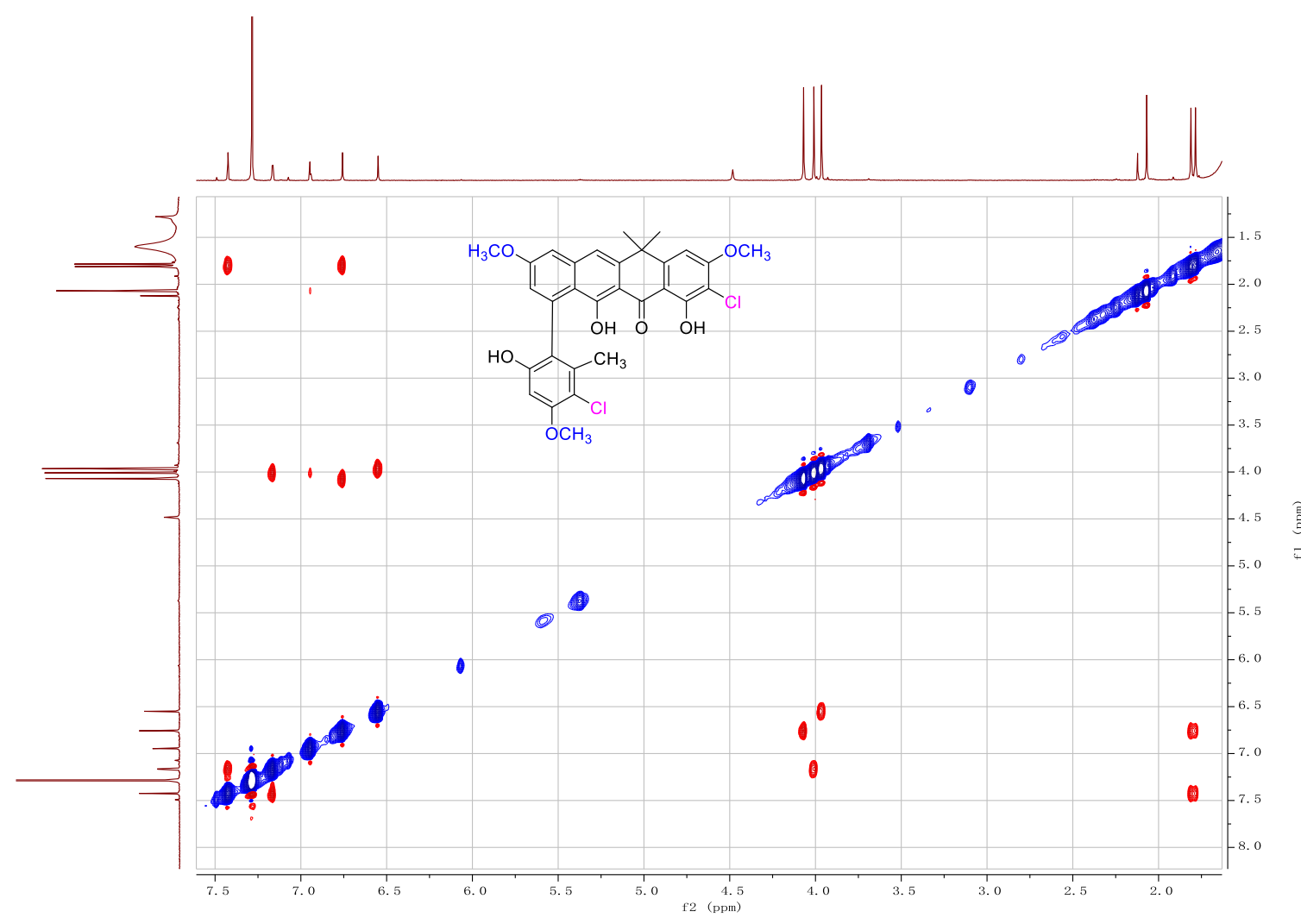

Figure S87. NOESY spectrum of 13 in $\mathrm{CDCl}_{3}$

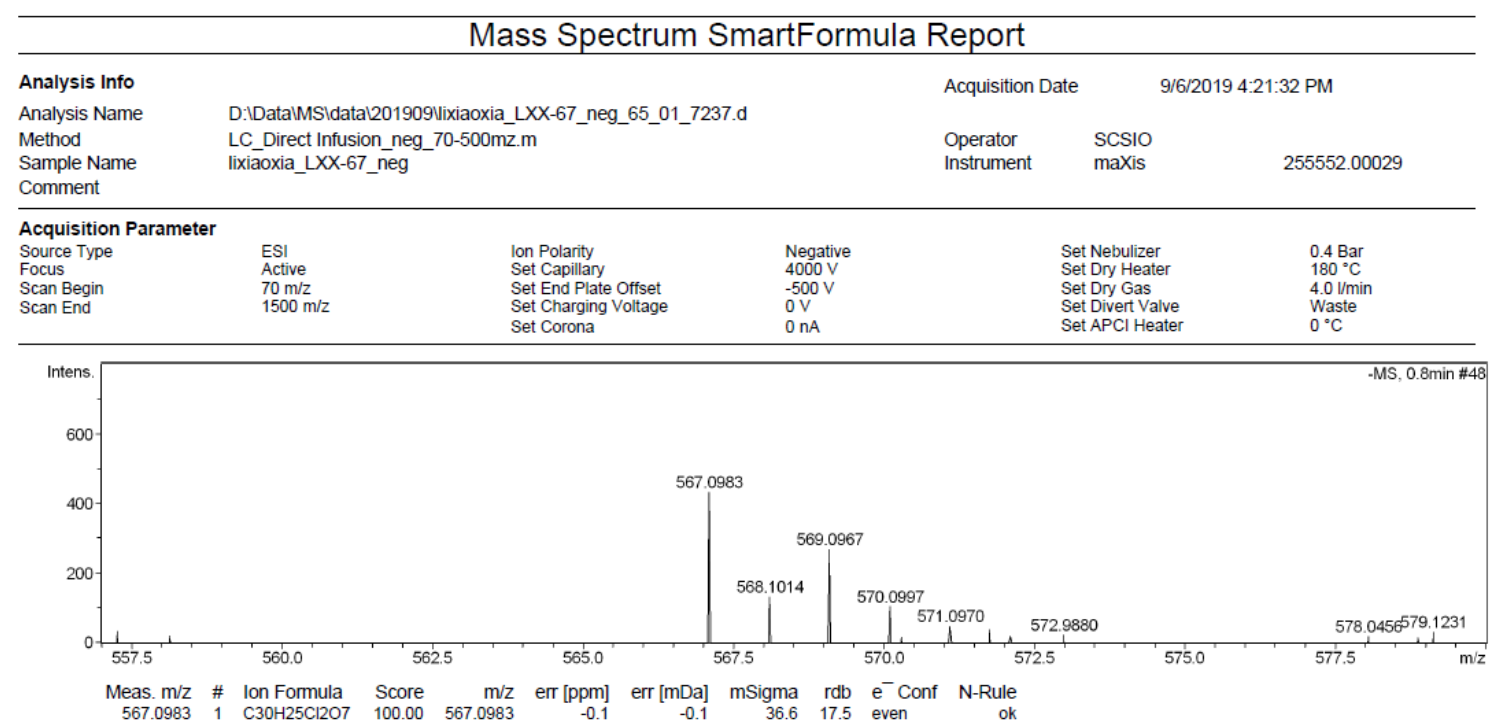

Figure S88. HR-ESI(-)MS of $\mathbf{1 3}$ 


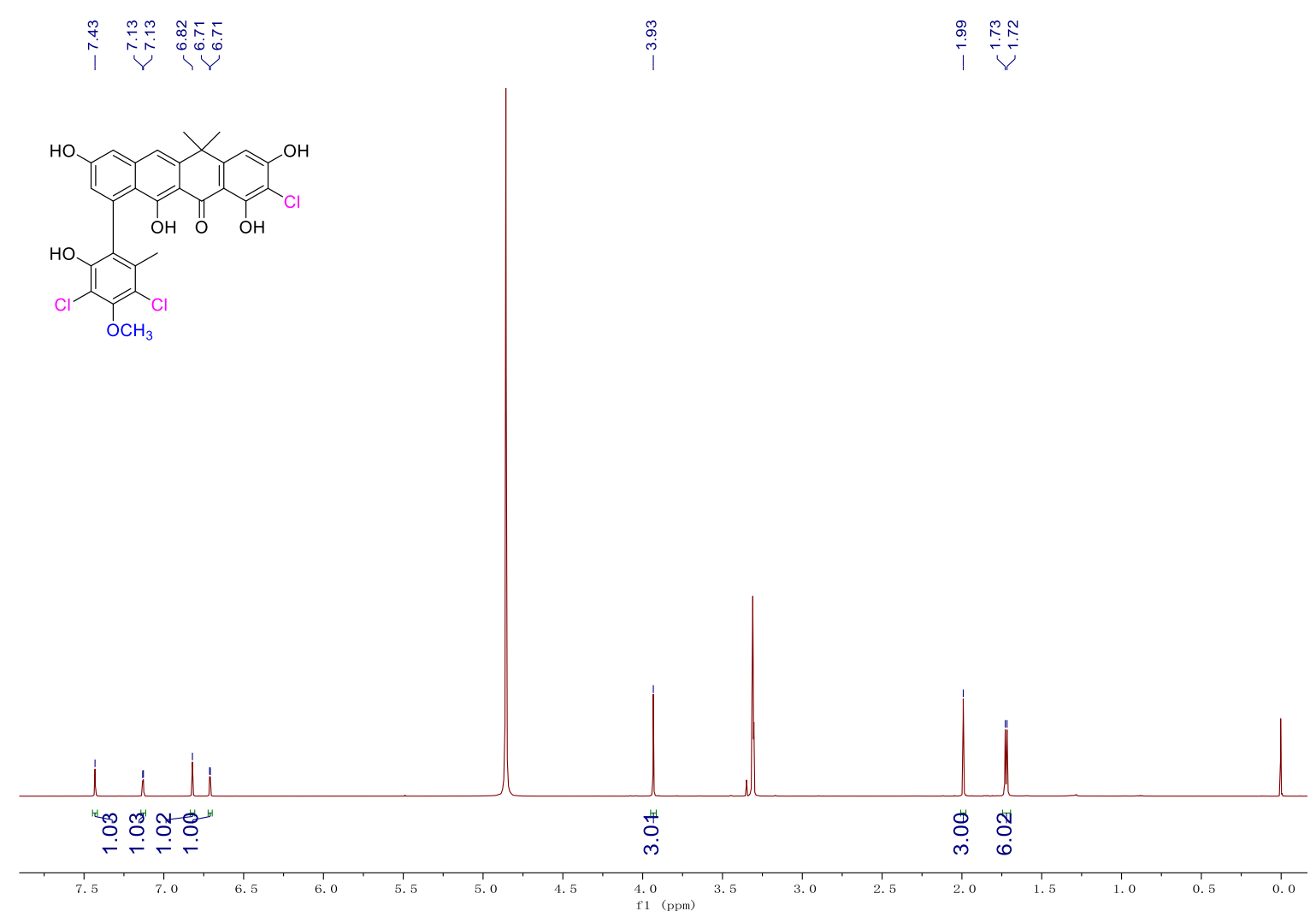

Figure S89. ${ }^{1} \mathrm{H}$ NMR $(500 \mathrm{MHz})$ spectrum of 14 in $\mathrm{CD}_{3} \mathrm{OD}$
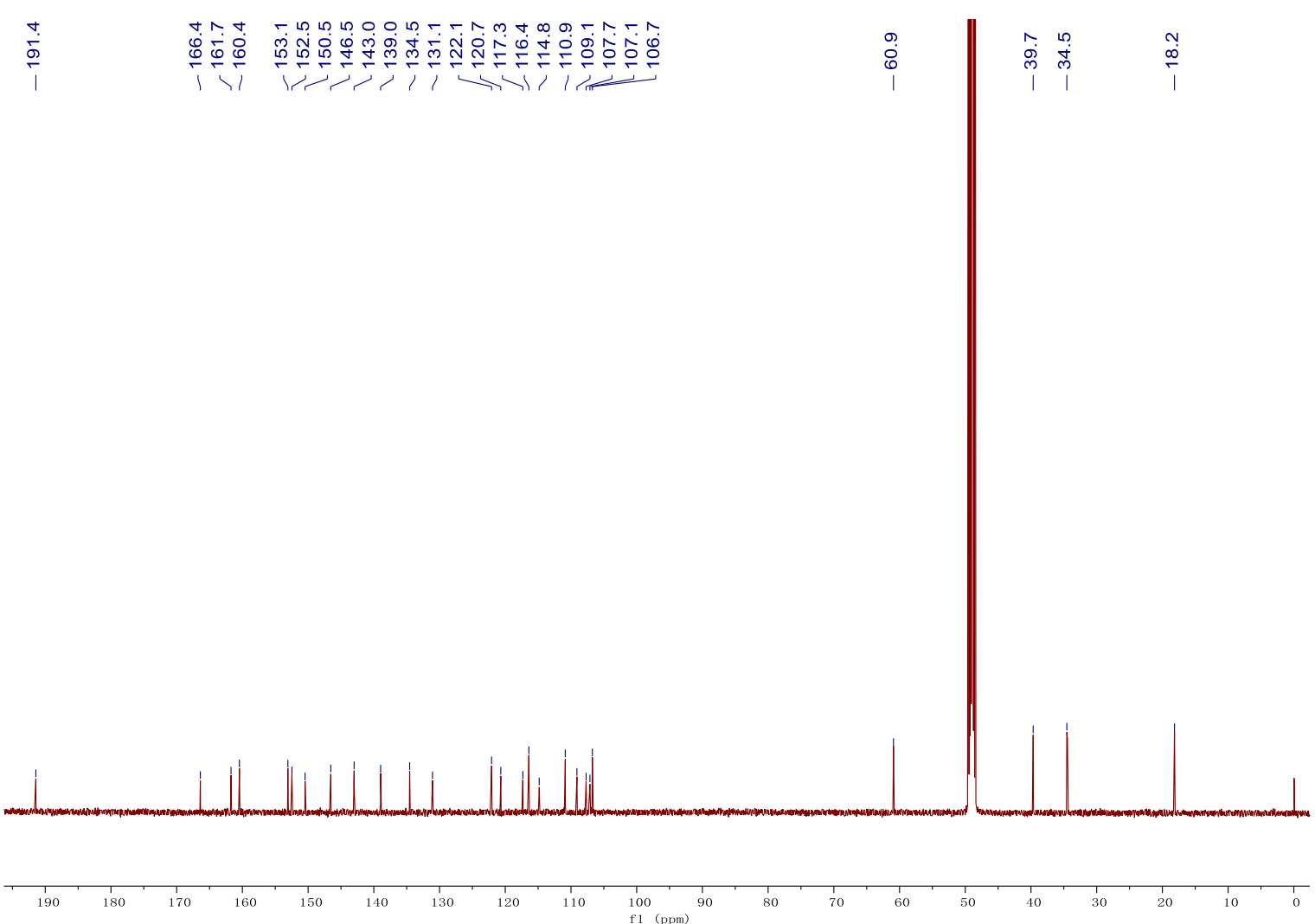

Figure S90. ${ }^{13} \mathrm{C}$ NMR (125 MHz) spectrum of $\mathbf{1 4}$ in $\mathrm{CD}_{3} \mathrm{OD}$ 


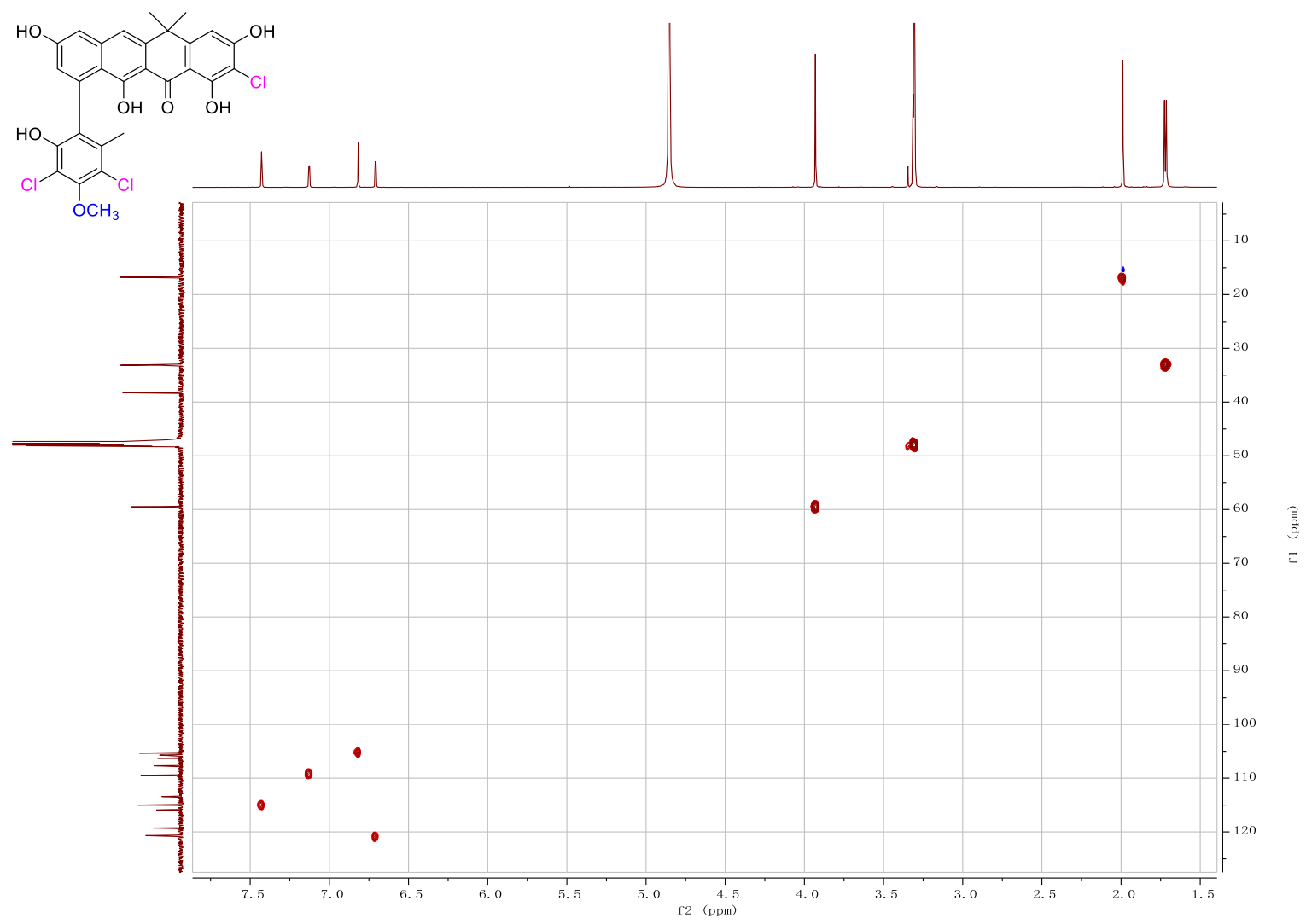

Figure S91. HSQC spectrum of $\mathbf{1 4}$ in $\mathrm{CD}_{3} \mathrm{OD}$

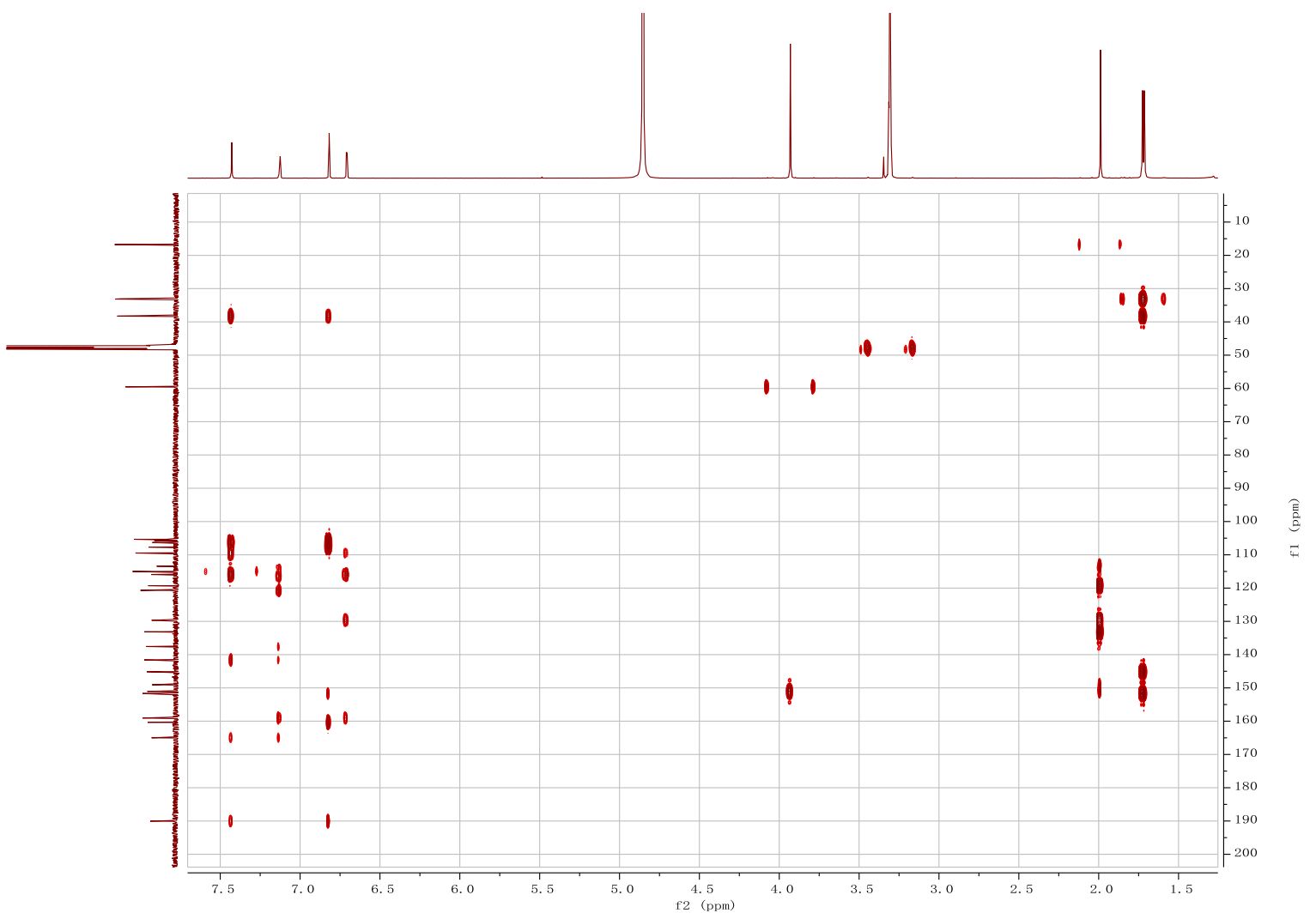

Figure S92. $\mathrm{HMBC}$ spectrum of $\mathbf{1 4}$ in $\mathrm{CD}_{3} \mathrm{OD}$

49 


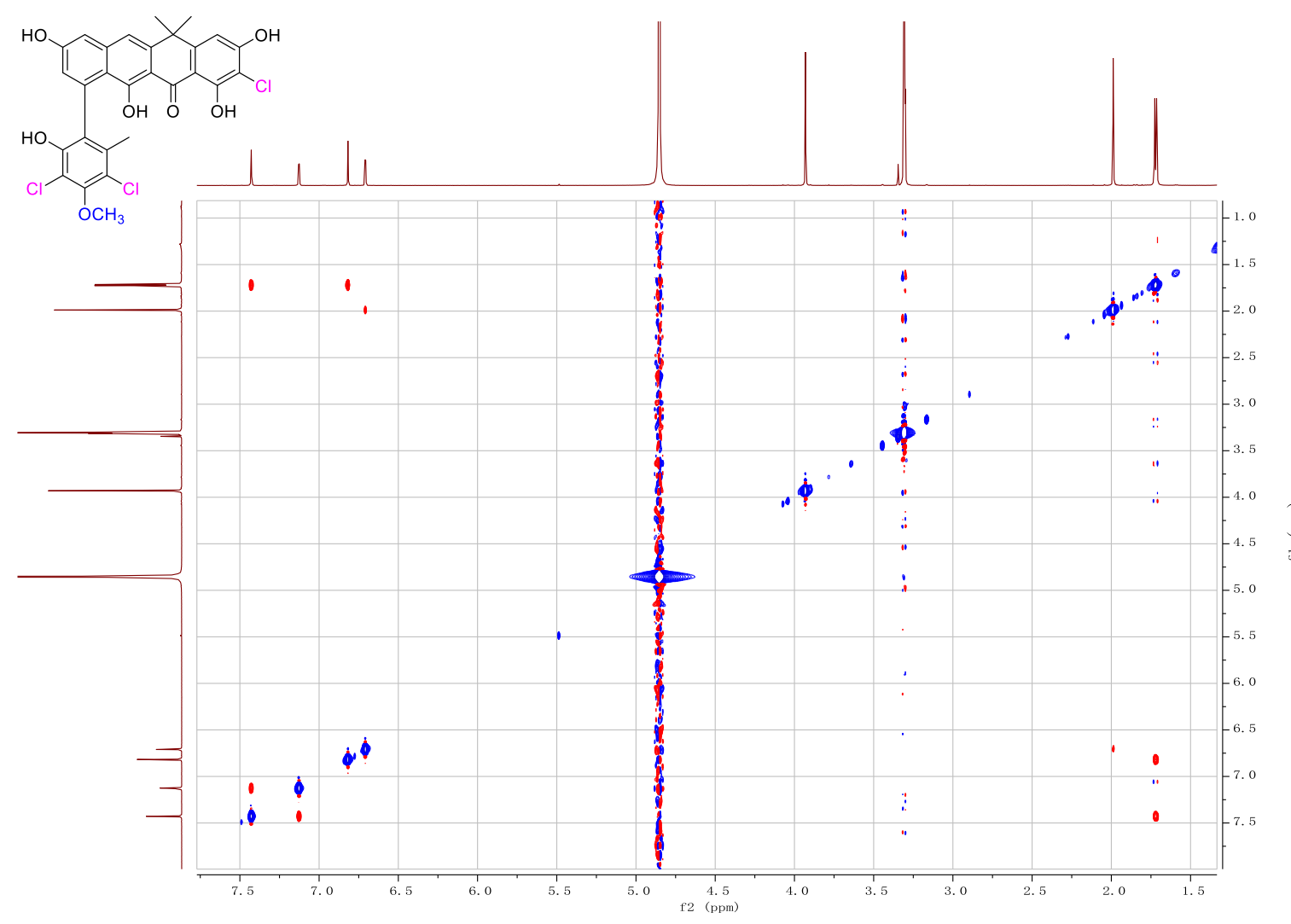

Figure S93. NOESY spectrum of 14 in $\mathrm{CD}_{3} \mathrm{OD}$

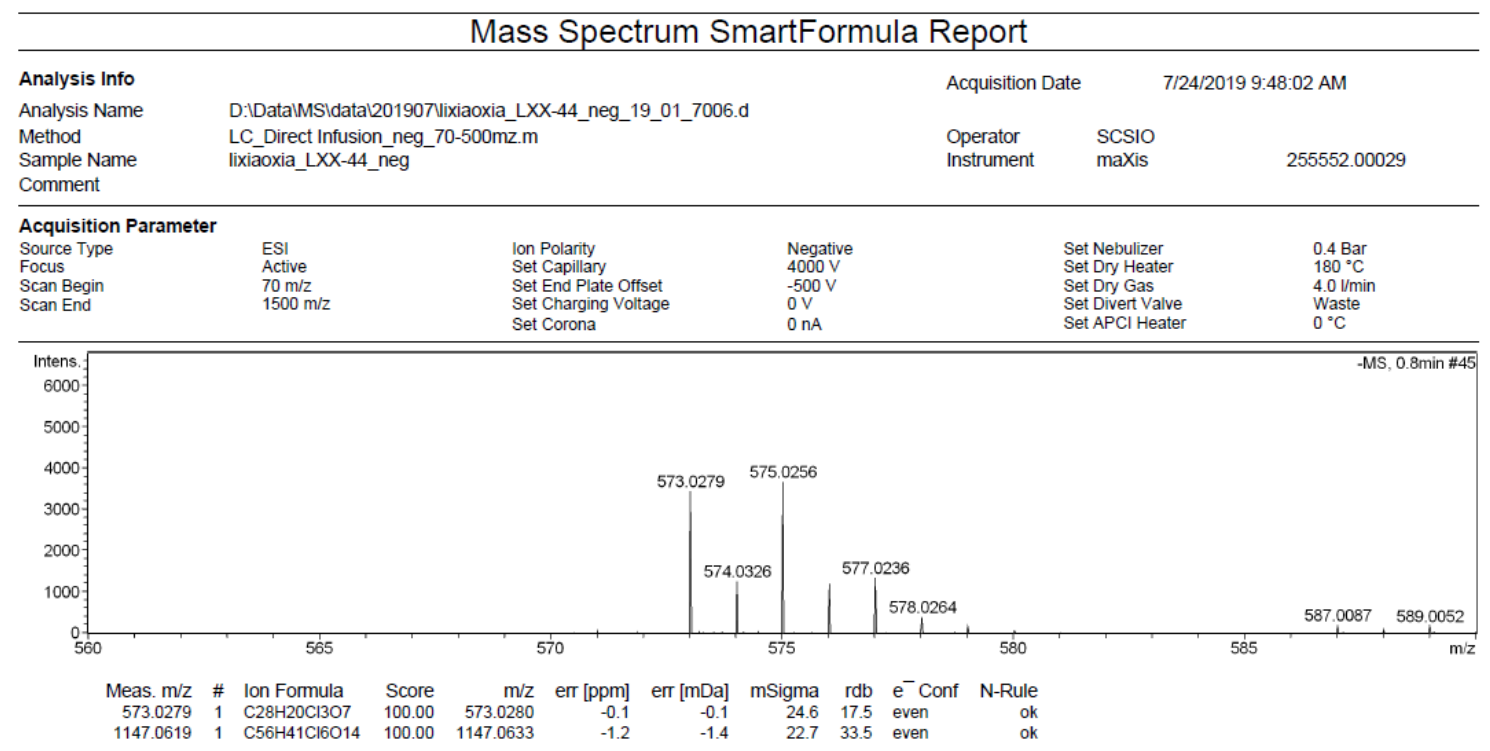

Figure S94. HR-ESI(-)MS of 14 


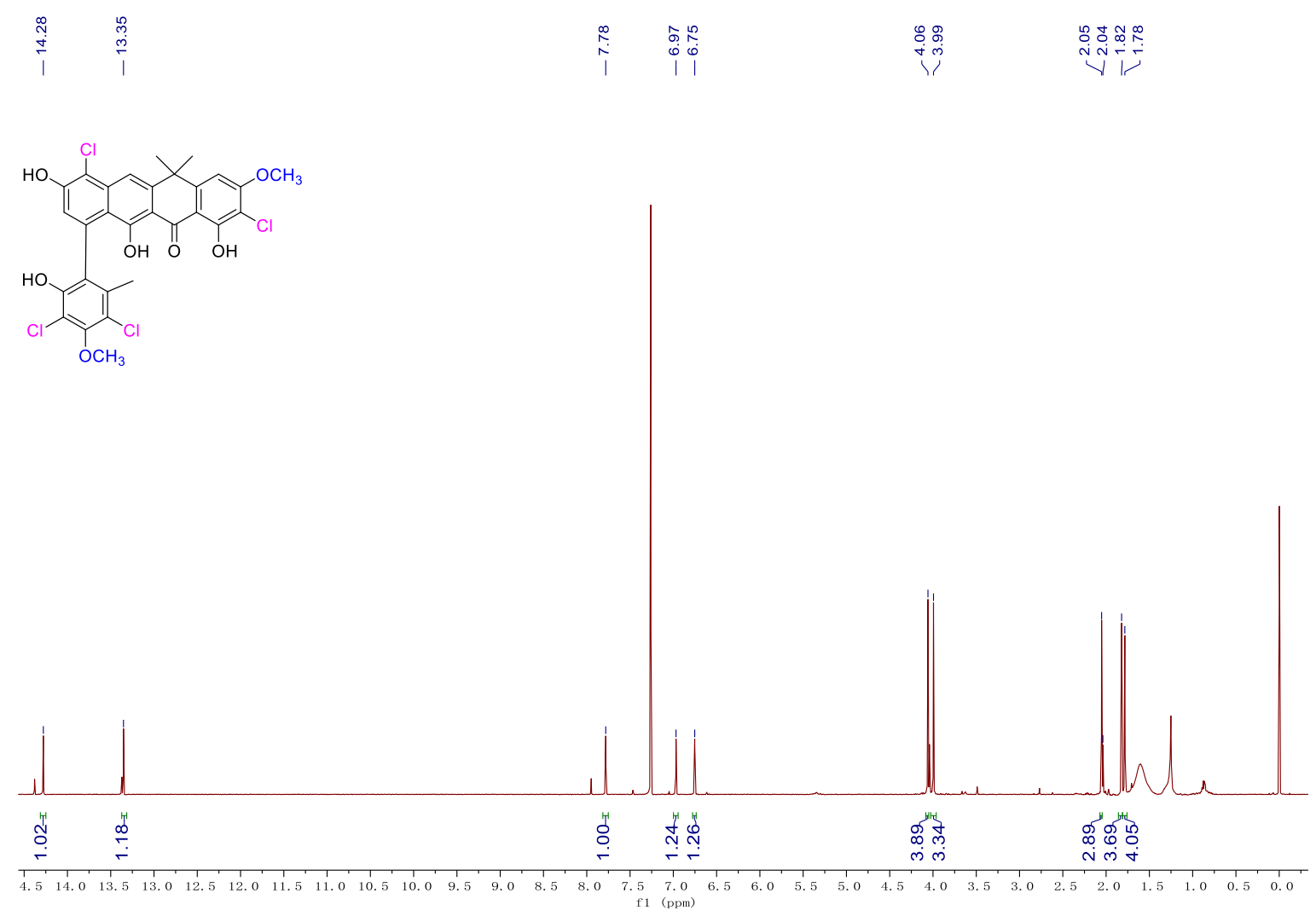

Figure S95. ${ }^{1} \mathrm{H}$ NMR $(500 \mathrm{MHz})$ spectrum of 15 in $\mathrm{CDCl}_{3}$

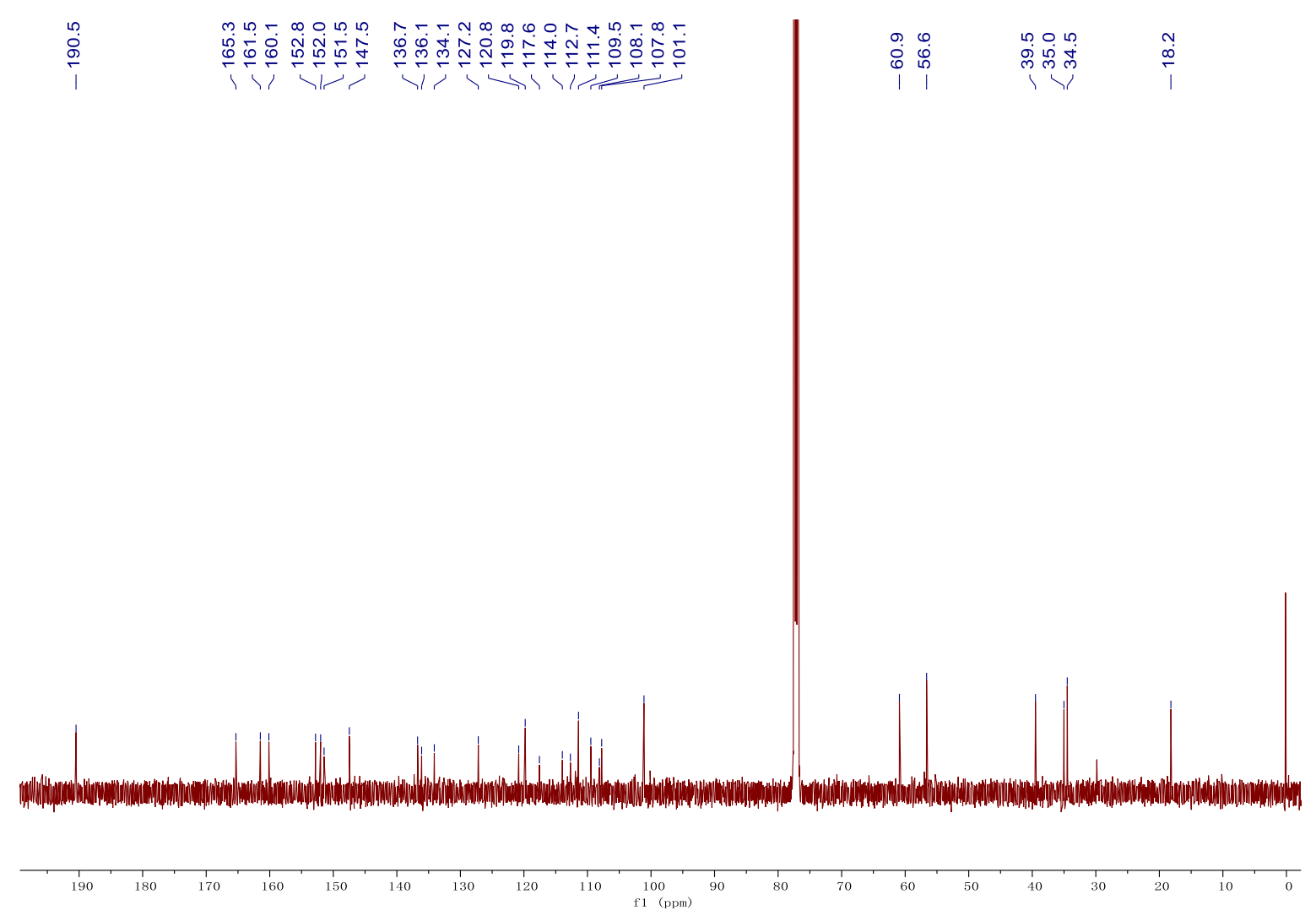

Figure S96. ${ }^{13} \mathrm{C} \mathrm{NMR}(125 \mathrm{MHz})$ spectrum of $\mathbf{1 5}$ in $\mathrm{CDCl}_{3}$ 


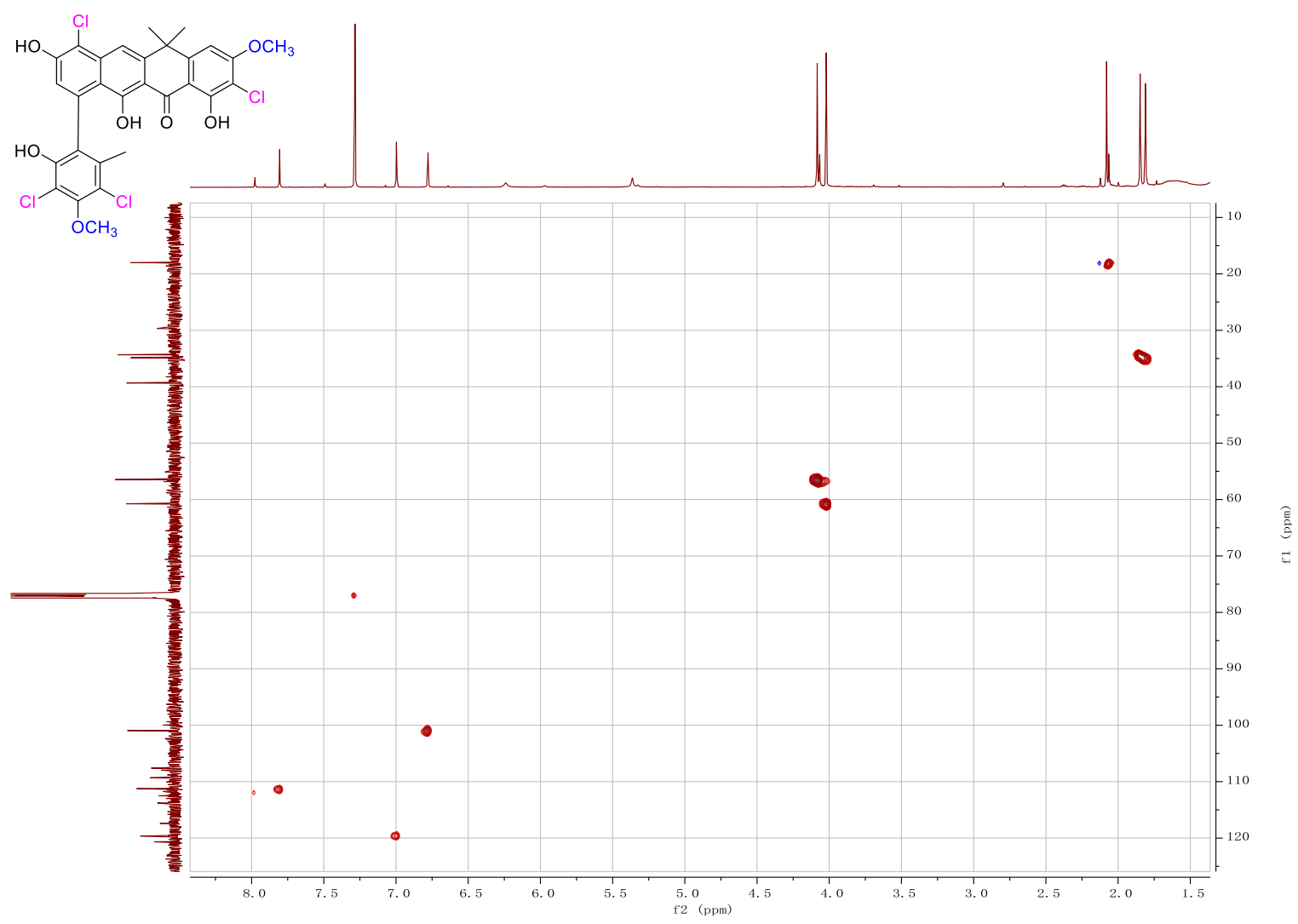

Figure S97. HSQC spectrum of 15 in $\mathrm{CDCl}_{3}$

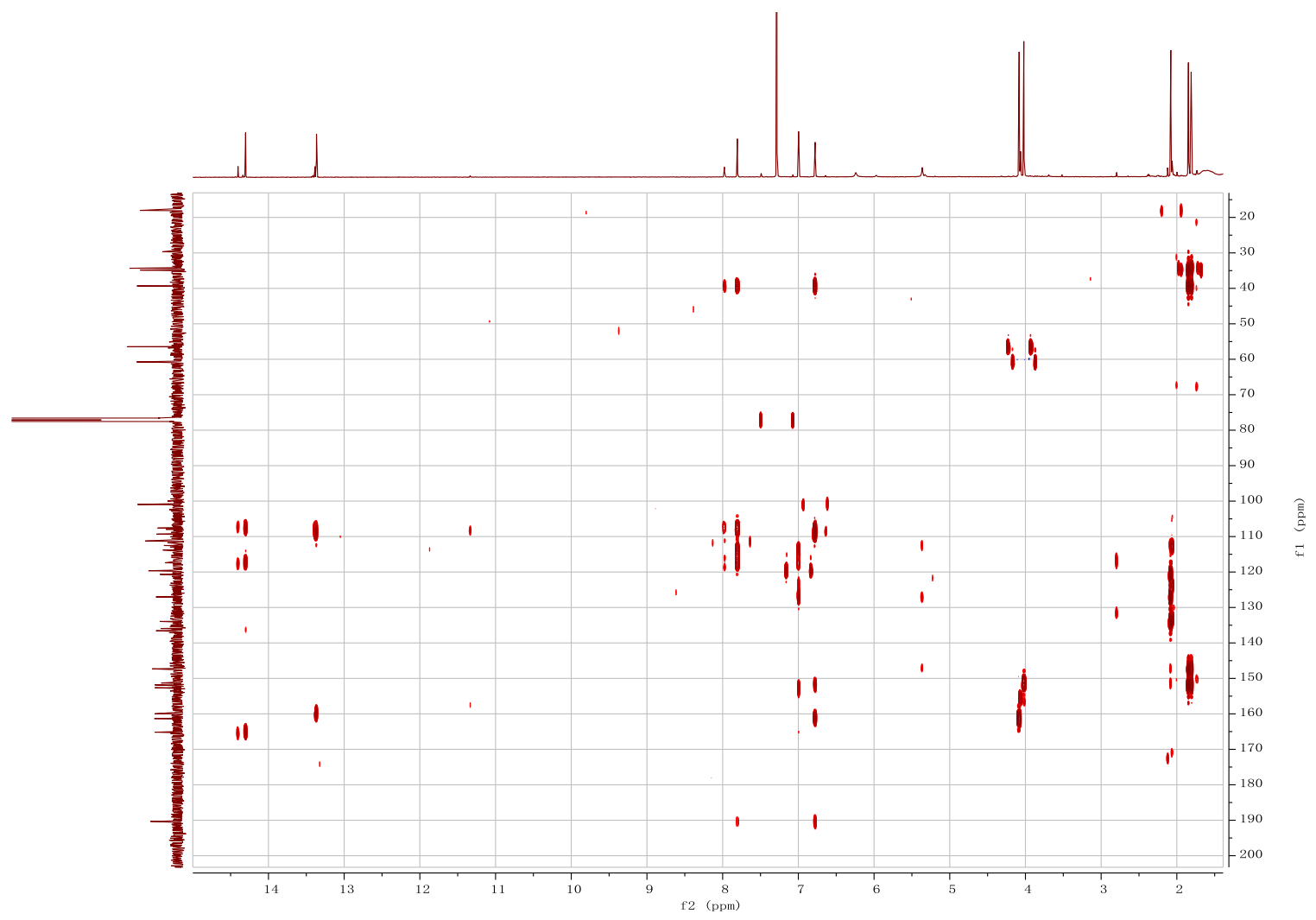

Figure S98. $\mathrm{HMBC}$ spectrum of 15 in $\mathrm{CDCl}_{3}$

52 


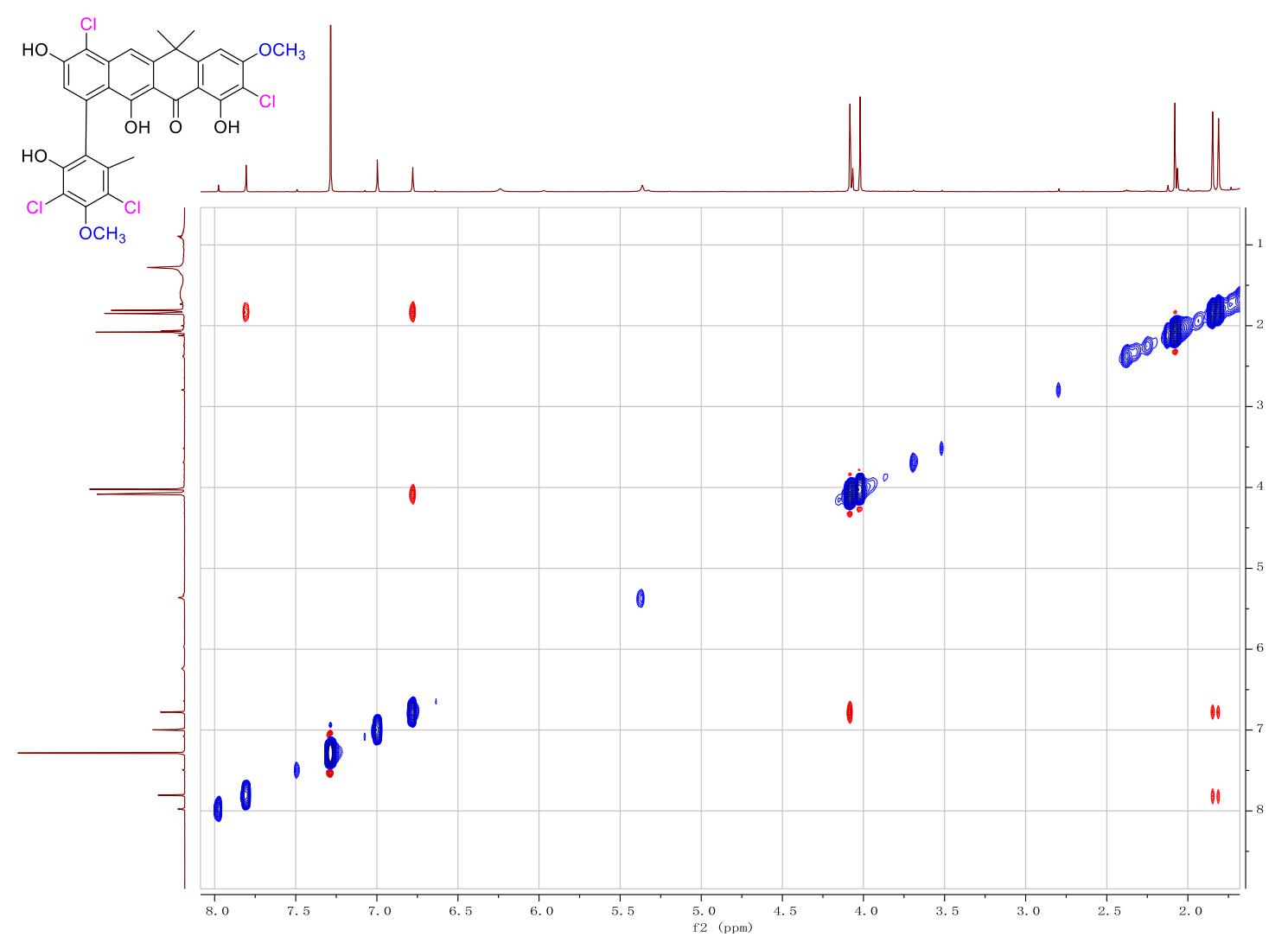

Figure S99. NOESY spectrum of 15 in $\mathrm{CDCl}_{3}$

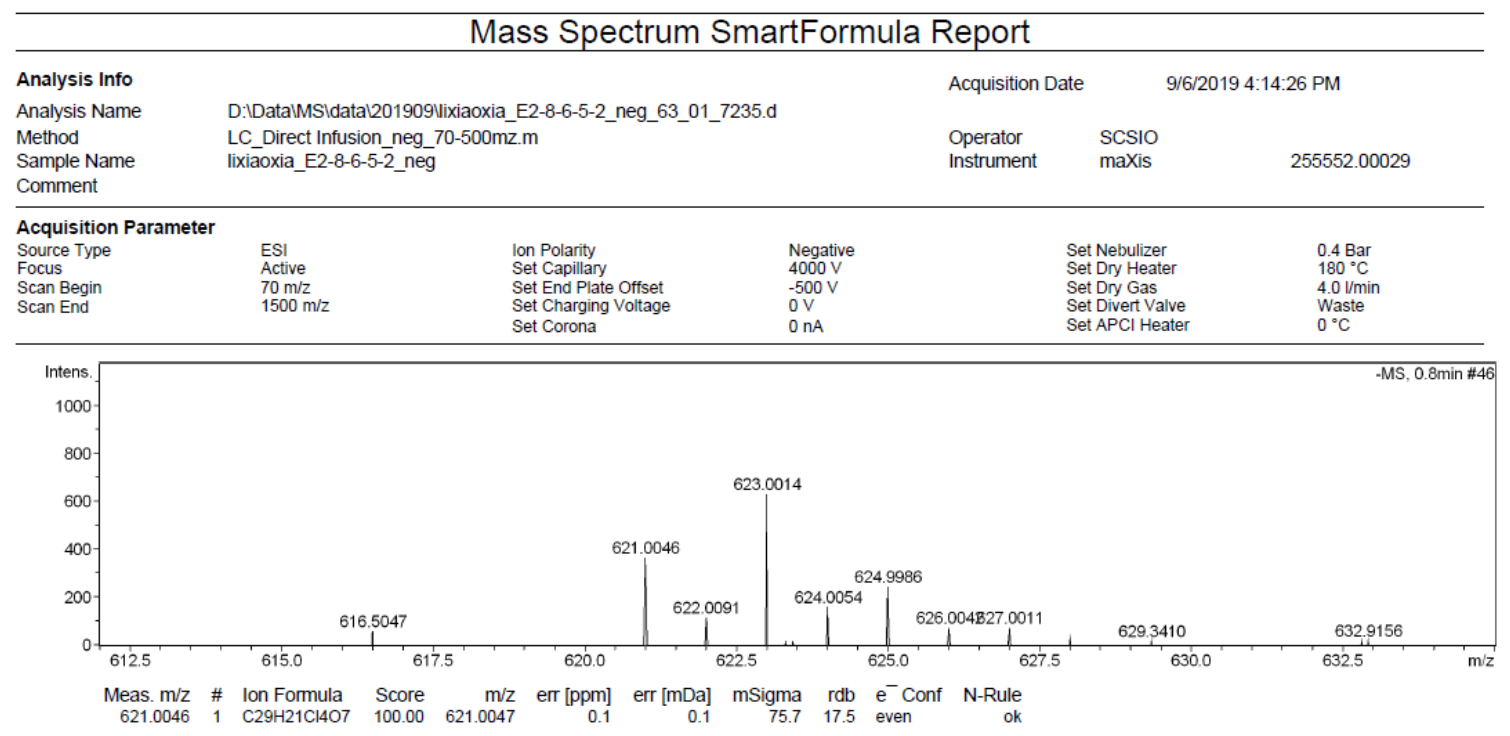

Figure S100. HR-ESI(-)MS of $\mathbf{1 5}$ 